US Army Corps of Engineers ${ }_{\circledast}$

Engineer Research and

Development Center

Navigation Systems Research Program

\title{
Freight Fluidity for the Port of Baltimore: Vessel Approach and Maritime Mobility Metrics
}

C. James Kruse, Dong Hun Kang, Kenneth N. Mitchell,

Patricia K. DiJoseph, and Marin M. Kress

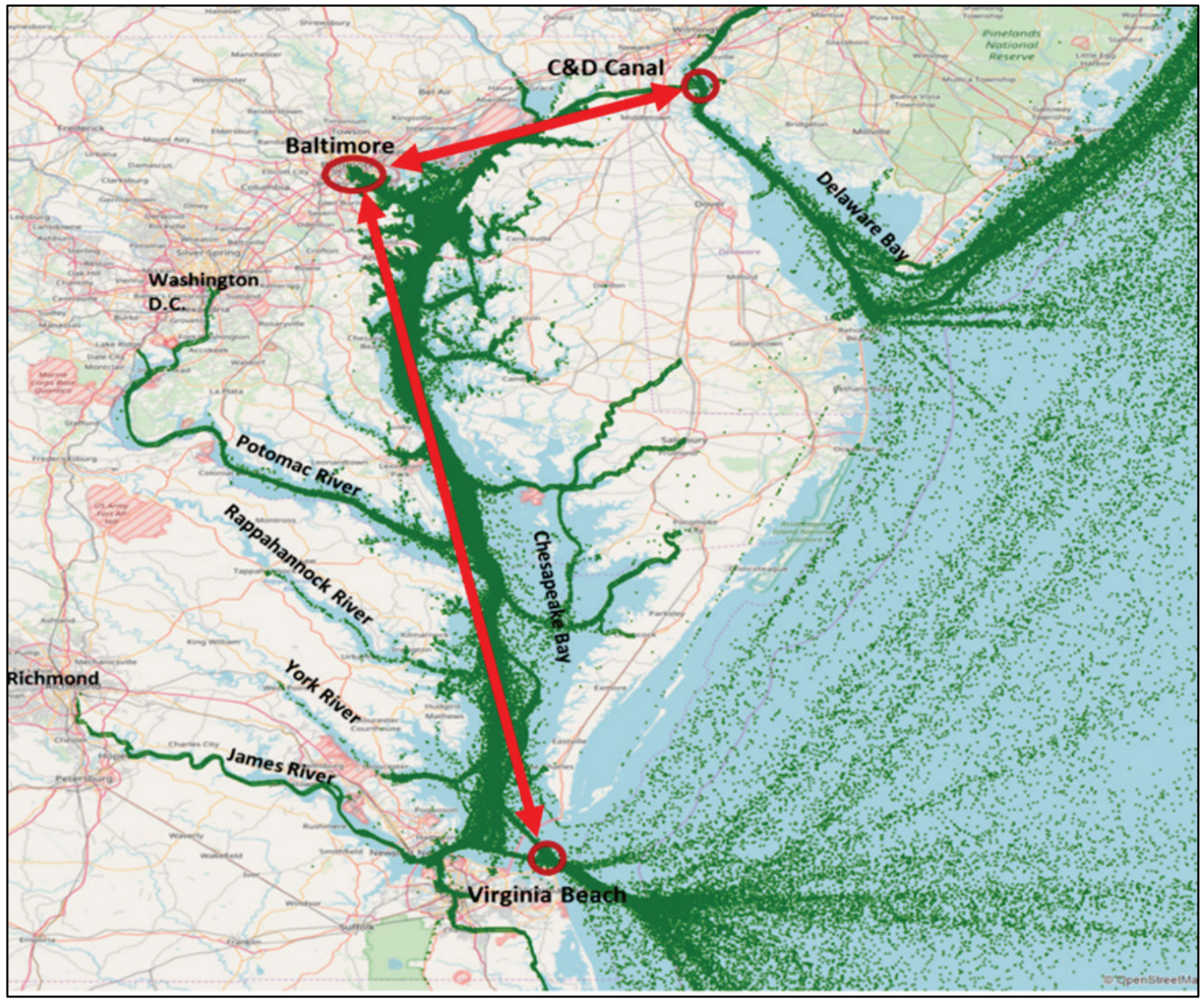


The US Army Engineer Research and Development Center (ERDC) solves the nation's toughest engineering and environmental challenges. ERDC develops innovative solutions in civil and military engineering, geospatial sciences, water resources, and environmental sciences for the Army, the Department of Defense, civilian agencies, and our nation's public good. Find out more at www.erdc.usace.army.mil.

To search for other technical reports published by ERDC, visit the ERDC online library at https://erdclibrary.on.worldcat.org/discovery. 


\title{
Freight Fluidity for the Port of Baltimore: Vessel Approach and Maritime Mobility Metrics
}

\author{
C. James Kruse and Dong Hun Kang \\ Texas A\&M Transportation Institute \\ 701 N. Post Oak, Suite 430 \\ Houston, TX 77024 \\ Kenneth N. Mitchell, Patricia K. DiJoseph, and Marin M. Kress \\ Coastal and Hydraulics Laboratory \\ US Army Engineer Research and Development Center \\ 3909 Halls Ferry Rd \\ Vicksburg, MS 39180-6199
}

Final report

Approved for public release; distribution is unlimited.

\footnotetext{
Prepared for Headquarters, US Army Corps of Engineers

Washington, DC

Under Funding Account Code W912HZ-16-BAA-01
} 


\section{Abstract}

The United States Army Corps of Engineers is tasked with maintaining waterborne transportation system elements. Understanding channel utilization by vessels informs decisions regarding operations, maintenance, and investments in those elements. Historically, investment decisions have been informed by safety, environmental considerations, and projected economic benefits of alleviating channel restrictions or shipping delays (usually derived from models). However, quantifying causes and impacts of shipping delays based on actual historical vessel location data and then identifying which causes could be ameliorated through investment has been out of reach until recently. In this study, Automatic Identification System vessel position reports were used to develop quantitative measures of transit and dwell-time reliabilities for commercial vessels calling at the Port of Baltimore, Maryland. This port has two deep-water approaches: Chesapeake Bay and the Chesapeake and Delaware Canal. Descriptive metrics were determined for each approach, including port cycle time, harbor stay hours, travel time inbound, and travel time outbound. Then, additional performance measures were calculated: baseline travel time, travel time index, and planning time index. The key finding of this study is that the majority of variability in port cycle time is due to the variability in harbor stay hours, not from channel conditions or channel restrictions.

DISCLAIMER: The contents of this report are not to be used for advertising, publication, or promotional purposes. Citation of trade names does not constitute an official endorsement or approval of the use of such commercial products. All product names and trademarks cited are the property of their respective owners. The findings of this report are not to be construed as an official Department of the Army position unless so designated by other authorized documents.

DESTROY THIS REPORT WHEN NO LONGER NEEDED. DO NOT RETURN IT TO THE ORIGINATOR. 


\section{Contents}

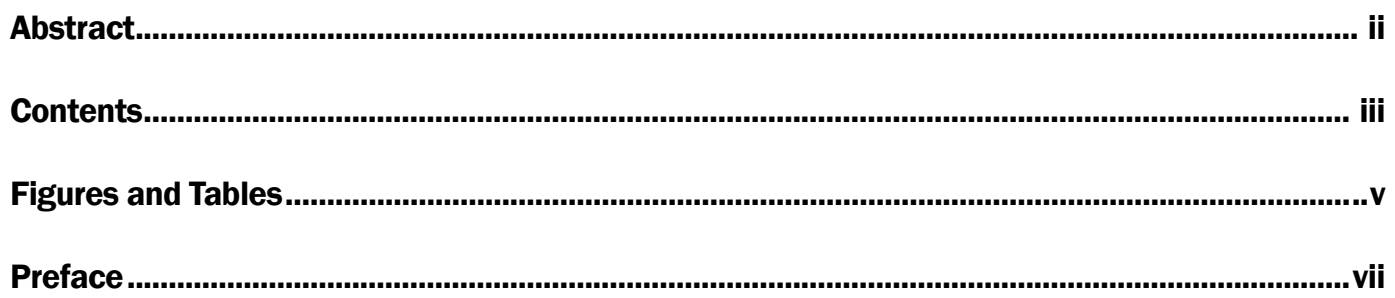

1 Introduction........................................................................................................................ 1

1.1 Background: Port area performance measurement.............................................. 1

1.2 Objective: Quantifying navigation channel utilization ............................................. 3

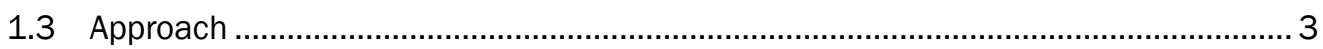

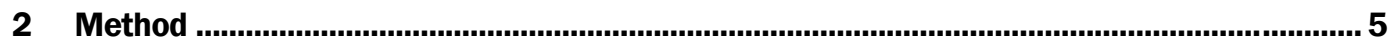

2.1 Automatic Identification System (AIS) data ......................................................... 5

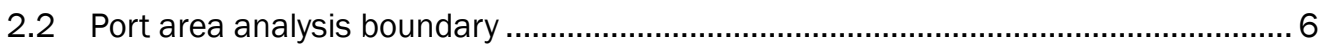

2.3 AIS data preparation ................................................................................... 8

2.4 Input metric definition .................................................................................. 10

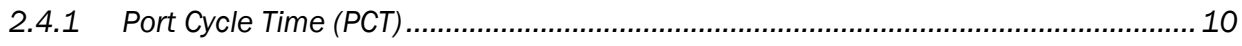

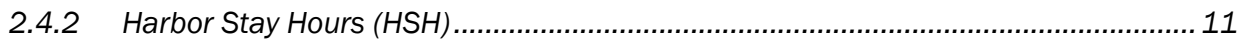

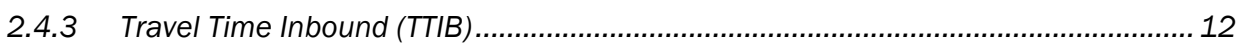

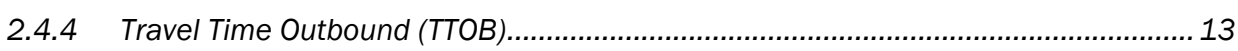

3 Results ..................................................................................................................................15

3.1 Overall sample count analysis .................................................................. 15

3.1.1 Trip sample count by route................................................................................ 15

3.1.2 Daily patterns of vessel arrival time.................................................................. 15

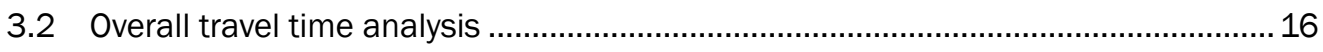

3.3 Overall performance measure results .......................................................... 18

3.3.1 Performance measures developed ...................................................................... 18

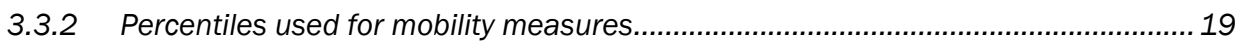

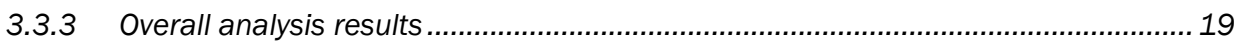

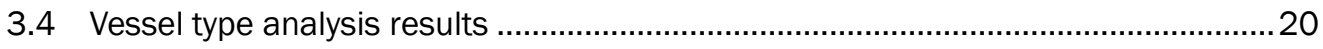

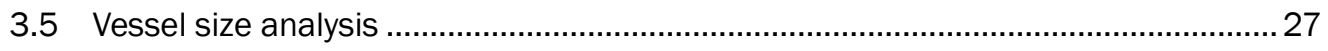

3.6 C\&D canal analysis - effect of pilot restrictions ......................................................30

3.6.1 Case 1: Some outbound trips are blocked by wide inbound vessels ........................ 31

3.6.2 Case 2: Canal is freed when inbound vessel exits the canal.................................... 33

3.6.3 Case 3: Inbound trips are blocked by wide outbound vessels. ................................. 34

3.6.4 Case 4: Canal is freed when outbound vessel exits the canal. ...................................36

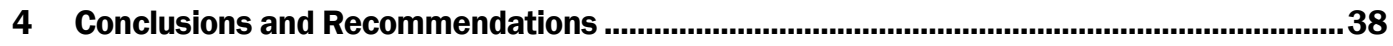

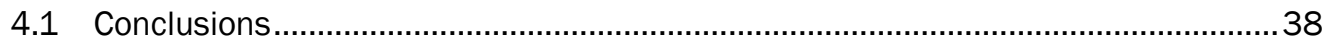

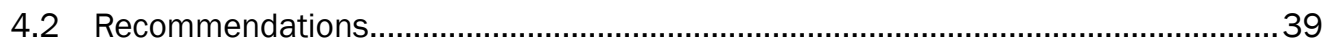

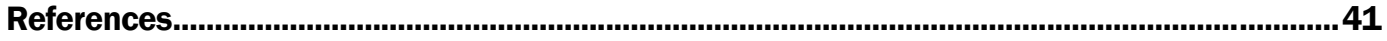


Appendix A: Arrival Count Plot by Hour by Day of Week.............................................................45

Appendix B: Complete Calculations Results for Output Measures .............................................46

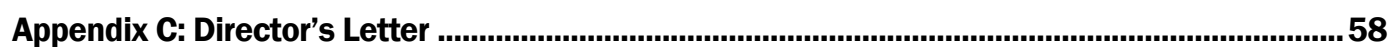

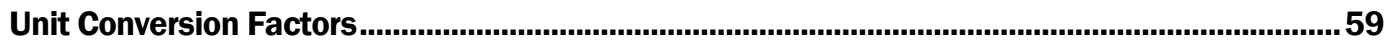

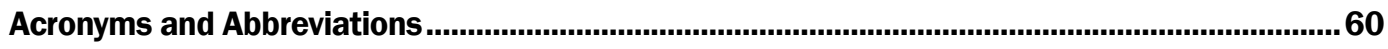

Report Documentation Page 


\section{Figures and Tables}

\section{Figures}

Figure 1. Map of two major routes for the Port of Baltimore analysis.

Figure 2. Trip points (TP) used in analysis............................................................................... 7

Figure 3. TIIB for C\&D Canal inbound (CD-In) route, January - April 2016.................................... 9

Figure 4. TIIB for Virginia Beach inbound (VB-In) route, January - April 2016 .................................. 9

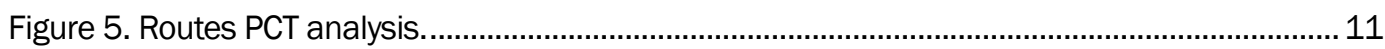

Figure 6. Map of HSH route......................................................................................................... 12

Figure 7. Paths for inbound transit time analysis....................................................................... 13

Figure 8. Paths for outbound transit time analysis.................................................................... 14

Figure 9. Arrival count by hour of day. ..................................................................................... 16

Figure 10. Plots of arrival count by day of week (A) and by month (B).......................................... 16

Figure 11. Cargo traffic at Port of Baltimore by ship-type group, 2016 ........................................... 21

Figure 12. Inbound cargo traffic grouped by ship type, 2016.......................................................2

Figure 13. Outbound cargo traffic grouped by ship type, 2016.......................................................23

Figure 14. PCT plots by ship-type group.................................................................................... 24

Figure 15. Cargo traffic by ship-size group. .................................................................................. 27

Figure 16. PCT plots by ship-size group.........................................................................................2

Figure 17. Illustration of Case 1: Outbound trips are blocked by wide inbound vessels....................32

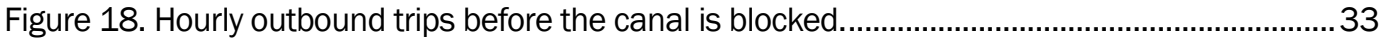

Figure 19. Illustration of Case 2: Canal is freed when inbound vessel exits the canal.....................33

Figure 20. Count of outbound trips after the canal is freed. .............................................................34

Figure 21. Illustration of Case 3: Inbound trips are blocked by wide outbound vessels...................35

Figure 22. Count of inbound (IB) trips before the canal is blocked................................................35

Figure 23. Illustration of Case 4: Canal is freed when outbound vessel exits the canal. ..................36

Figure 24. Count of IB trips after the canal is freed.......................................................................... 37

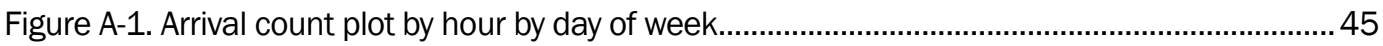

Figure B-1. Monthly average HSH by ship-type group, 2016 ..................................................... 57

Figure B-2. Monthly arrival count by ship-type group, 2016. ......................................................... 57

Figure C-1. Director's letter included with technical memorandum delivery....................................58

\section{Tables}

Table 1. Four types of port cycles with PCT equation. ………....................................................... 11

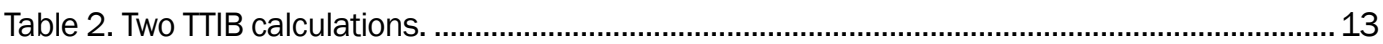

Table 3. Two types of travel time outbound (TTOB) and calculations............................................ 14

Table 4. Trip sample count for 2016 .............................................................................................. 15

Table 5. Overall summary statistics for PCT, HSH, TTIB, TTOB................................................... 17

Table 6. Overall performance measures, 2016 …………................................................................... 20 


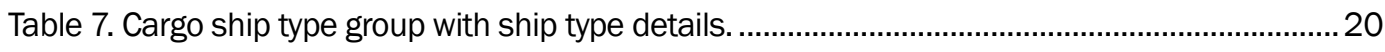

Table 8. Cargo traffic by ship-type group by inbound and outbound route, 2016 ...........................2

Table 9. TIIB hours by ship-type group by route, 2016 ..................................................................... 25

Table 10. TTOB hours by ship-type group by route, 2016 ……........................................................ 25

Table 11. PCT performance measures by route and vessel type. .....................................................26

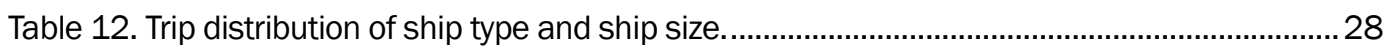

Table 13. Number of trips by vessel size by route.........................................................................2

Table 14. PCT performance measures by route and vessel size...................................................... 29

Table B-1. Overall performance measures by route, in hours........................................................ 47 


\section{Preface}

This study was conducted for Headquarters, US Army Corps of Engineers (USACE), by the Texas A\&M Transportation Institute located at Texas A\&M University, College Station, TX, under a Broad Agency Announcement contract (Funding Account Code W912HZ-16-BAA-01); and by the US Army Engineer Research and Development Center (ERDC), Vicksburg, MS. Funding for this study was provided by the USACE Navigation Systems Research Program.

At the time of publication of this ERDC Coastal and Hydraulics (CHL) technical report, Ms. Lauren M. Dunkin was chief, Coastal Engineering Branch; Mr. Benjamin Burnham was chief, Navigation Branch; Ms. Ashley Frey was chief, Navigation Division; Mr. Charles E. Wiggins, CHL Technical Programs Office, was the ERDC technical director for Navigation; and Ms. Morgan M. Johnston, Navigation Branch, was the USACE Navigation Systems program manager. The deputy director of ERDC CHL was Mr. Keith Flowers, and the director was Dr. Ty V. Wamsley.

COL Teresa A. Schlosser was the commander of ERDC, and the director of ERDC was Dr. David W. Pittman.

The author ORCiD numbers are as follows:

- Dr. Kenneth N. Mitchell: oooo-0001-6345-9159

- Dr. Patricia K. DiJoseph: 0000-0003-0857-428X

- Dr. Marin M. Kress: 0000-0002-5835-5686.

This technical report should be cited as follows:

Kruse, C. James, Dong Hun Kang, Kenneth N. Mitchell, Patricia K. DiJoseph, and Marin M. Kress. 2022. Freight Fluidity for the Port of Baltimore: Vessel Approach and Maritime Mobility Metrics. ERDC/CHL TR-22-1. Vicksburg, MS: US Army Engineer Research and Development Center. http://dx.doi.org/10.21079/11681/43000 


\section{Introduction}

\subsection{Background: Port area performance measurement}

The US Army Corps of Engineers (USACE) has an interest in the interrelated topics of freight fluidity and marine transportation system performance due to its Civil Works Navigation Mission, which gives it responsibility for maintaining tens of thousands of miles of navigation channels around the country (USACE 2020). Many of these maintained navigation channels serve as the entrance and approach channels to deepdraft coastal ports that serve a critical economic role, both regionally and nationally, by employing thousands and providing cost-effective access to global markets for freight. The reliability of the supply chains that move this freight is the result of public and private entities managing their own assets, whether channels and roads, or ships and vehicles. However, the overall goal is a reliable system where freight flows smoothly from origin to destination. This concept is described as freight fluidity, and while there is no single definition of freight fluidity for all modes, attempts to measure freight fluidity usually start with identifying and measuring normal conditions and then measuring variations from that normal (Turnbull 2014). In other words, freight fluidity is often evaluated by examining related metrics such as traffic congestion, unexpected delays, or the variation in dwell times when a vehicle is loading/offloading cargo.

Freight fluidity measures for roadways are well established, with popular products including reports ranking cities or regions based on their roadway traffic congestion; examples include the Urban Mobility Report from the Texas A\&M Transportation Institute (TAMTI) (Shrank et al. 2019) and the INRIX Global Traffic Scorecard (INRIX 2021). Other sources provide real-time estimates of roadway fluidity designed to alert travelers to disruption and delay. This may include live video footage such as state-owned traffic cameras (Caltrans 2021) or color-coded representations of road segment delay such as on the I-95 Live Traffic View (Eastern Transportation Coalition 2021). The availability of fluidityrelated data on roadways has been dramatically expanded by the widespread availability of mobile phones that draw data from travelers in real time to provide a source of remote measurement of vehicle speed in real time. Automatic Identification System (AIS) data now provide a similar opportunity for the marine world to develop standardized fluidity measures across waterways. There is also interest in combining fluidity 
measures from roadways and waterways to develop multimodal freight fluidity metrics.

Although the USACE navigation mission supports key elements of marine transportation, the performance of the overall marine transportation system is inextricably linked to land-side transportation modes such as road and rail. If a vessel crosses the ocean at optimum speed, but then must wait at anchorage for a berth to open, the efficiencies of the crossing did not serve to alter freight fluidity. Similarly, if a channel is deepened to allow for larger ships to arrive at port carrying more cargo on a single voyage but no corresponding capacity expansions are made to the landside freight transportation systems, then the speed of the overall supply chain may not be improved and a new bottleneck may have instead been created.

Rather than pursue continuous expansion of freight transportation systems, some freight operators have focused on improving the efficiency of existing systems through intense performance measurement, communication, and coordination among users. One example of this is the freight fluidity indicator work by Transport Canada, which started in 2007 and brought together data that had previously been held by private entities or different government agencies (Tardif 2014). Part of this work included partnering with the TAMTI to develop two fluidity indicators: (1) the Fluidity Index (reflecting average conditions) and (2) the Planning Time Index (reflecting daily variation in travel time) (Eisele et al. 2011). Transport Canada presents fluidity information through a "web-based, multimodal tool that measures the performance of individual segments of supply chains in near real-time, as well as the end-to-end transit time of freight flows. The focus is on bottlenecks and impediments along major trade corridors, with special attention to port infrastructure" (Tardif 2014). The collection of detailed transportation data from multiple modes has allowed Transport Canada to perform new kinds of analyses, including "measuring and analyzing the reliability and the variability in transit times for different commodities and supply chains, identifying bottlenecks and impediments in the transportation system, analyzing immediate and residual impacts of disruptions to the transportation network, estimating wait times at border crossings between Canada and the United States, and measuring the carbon footprint of freight supply chains" (Tardif 2014). The ownership structure of seaports differs between Canada, the United States, and other countries, but interest in understanding the factors affecting maritime transportation fluidity is widespread. 


\subsection{Objective: Quantifying navigation channel utilization}

Understanding and quantifying how mariners use navigation channels, how this use is limited by external factors such as weather, and how fluidity can be reliably measured is all critical to how and where USACE should direct future improvements in channel design and ongoing waterway maintenance decisions. Research and documentation in this area continue to grow. Previous work exploring freight fluidity and the marine transportation system in North America includes the following: research into the use of time-stamped vessel position reports as a source of performance data (Mitchell and Scully 2014; Scully and Mitchell 2015); national performance metrics across the marine transportation system (Kress et al. 2016); the development of a travel time atlas for vessels moving on inland waterways (DiJoseph et al. 2019); case studies for corridor-level fluidity (Mitchell et al. 2019); and modeling waterway closure impacts on vessel waiting times (Kaneria et al. 2019). AIS data have also been used to measure navigational channel performance on a shortterm scale (e.g., in the days or weeks around the time of a storm event) (Farhadi et al. 2016; Touzinsky et al. 2018) to quantify vessel behavior in a discrete area such as the Houston Ship Channel where pilotage is required (Roy and $\mathrm{Wu}$ 2019) or the Sabine-Neches Waterway (Wu et al. 2016; Wu, Rahman, and Zaloom 2018); and in studies focused on maritime metrics development (DiJoseph and Mitchell 2015; DiJoseph et al. 2019; Mitchell and Scully 2014). The use of AIS data as a source for vessel dwelltime information has been demonstrated in five consecutive years of annual reports published by the US Department of Transportation, Bureau of Transportation Statistics, Port Performance Freight Statistics Program, which focus on vessel dwelltimes at terminals within a select group of the busiest ports across the United States (USDOT 2017, 2018, 2019, 2020, 2021).

\subsection{Approach}

Previous work by Kruse et al. (2018) looked at the deep-draft port of Mobile, AL, over a $2 \mathrm{yr}^{*}$ time-period to evaluate navigation channel performance in terms of fluidity as well as to measure port cycle time and

\footnotetext{
${ }^{\star}$ For a full list of the spelled-out forms of the units of measure used in this document, please refer to US Government Publishing Office Style Manual, 31st ed. (Washington, DC: US Government Publishing Office 2016), 248-52, https://www.govinfo.gov/content/pkg/GPO-STYLEMANUAL-2016/pdf/GPO-

STYLEMANUAL-2016.pdf.
} 
other elements of maritime mobility. With a goal of understanding navigation channel utilization for the two deep-water approaches to the Port of Baltimore, Maryland, this project examined a year of nonpassenger commercial vessel traffic to and from the Port to develop associated quantitative metrics as described in the remainder of this report. Commercial passenger vessels such as cruise ships are not included in this analysis. A detailed description of the technical approach used in this study is presented in Section 2, Method. 


\section{Method}

\subsection{Automatic Identification System (AIS) data}

To support the analysis presented in this report, archived vessel position reports from calendar year 2016 were sampled from the US Coast Guard (USCG) Nationwide Automatic Identification System (NAIS) (USCG 2018). The NAIS is the official government archive of geo-referenced position reports generated and broadcasted by the on-board AIS transceivers carried by commercial vessels operating in US waters and subject to the carriage requirement issued by Congress. As of 2016, AIS carriage requirements set by the USCG had expanded to include most commercial self-propelled vessels on US navigable waters including any vessel over $65 \mathrm{ft}$ in length towing vessels over $26 \mathrm{ft}$ in length with a greater than $600 \mathrm{hp}$ engine, vessels certified to carry 150 or more passengers, dredges in or near a commercial channel, and vessels moving certain dangerous cargo (USCG 2018; US Code of Regulations 2019). Additional information about AIS technical standards and history is available from the main international groups involved in setting technical standards (IALA 2008; IEC 2001; ITUR 2014; PIANC 2019).

As the AIS broadcast mandate is applicable to nearly all commercial vessels, it is ideally suited to enable quantitative and statistically robust evaluations and monitoring of performance trends within the US marine transportation system. To support this study, archived vessel position reports from the USCG NAIS were provided to the USACE AIS Analysis Package (AISAP) web tool (USACE 2018) via a suite of web services called through batch scripting to compile a complete historical record of marine vessel traffic that called upon the Port of Baltimore in 2016. AIS vessel position reports are time stamped and georeferenced with multiple fields of vessel identifying information (e.g., Maritime Mobile Service Identity [MMSI] number, International Maritime Organization [IMO] number, call sign). Additional information in AIS messages includes vessel course, rate of turn, speed, and heading. Not all vessels have IMO numbers, so MMSI was used as a unique identifier of a vessel throughout this study. This study examined commercial cargo vessels only, not passenger vessels such as cruise ships or ferries. 


\subsection{Port area analysis boundary}

The AIS data used in this analysis cover the entire year of 2016 of nonpassenger commercial vessel trips to and from the Port of Baltimore. For geographical coverage of the analysis, two major routes were analyzed:

Virginia Beach (VB) Route to the Port of Baltimore: Starting at Virginia Beach, VA, near Cape Henry and moving northward through Chesapeake Bay. This route includes a $50 \mathrm{ft}$ channel that generally varies from $800 \mathrm{ft}$ wide in Maryland to 1,000 ft wide in Virginia (NAB 2021). Some sections of the Chesapeake Bay are naturally deeper and wider than the maintained channels.

Chesapeake and Delaware Canal (C\&D) Route to the Port of Baltimore: Starting from the Delaware River going westward through the C\&D Canal. Restrictions applied to all vessels going through the C\&D Canal in 2016 and are still in place: maximum permitted sailing draft in the canal is $33.5 \mathrm{ft}$; the combined beam of passing ships cannot exceed $165 \mathrm{ft}$ (Association of Maryland Pilots 2019).

Figure 1 shows the termini of the routes, and the green dots represent AIS data points in the region; not all AIS points shown in Figure 1 were included in this study.

Figure 1. Map of two major routes for the Port of Baltimore analysis.

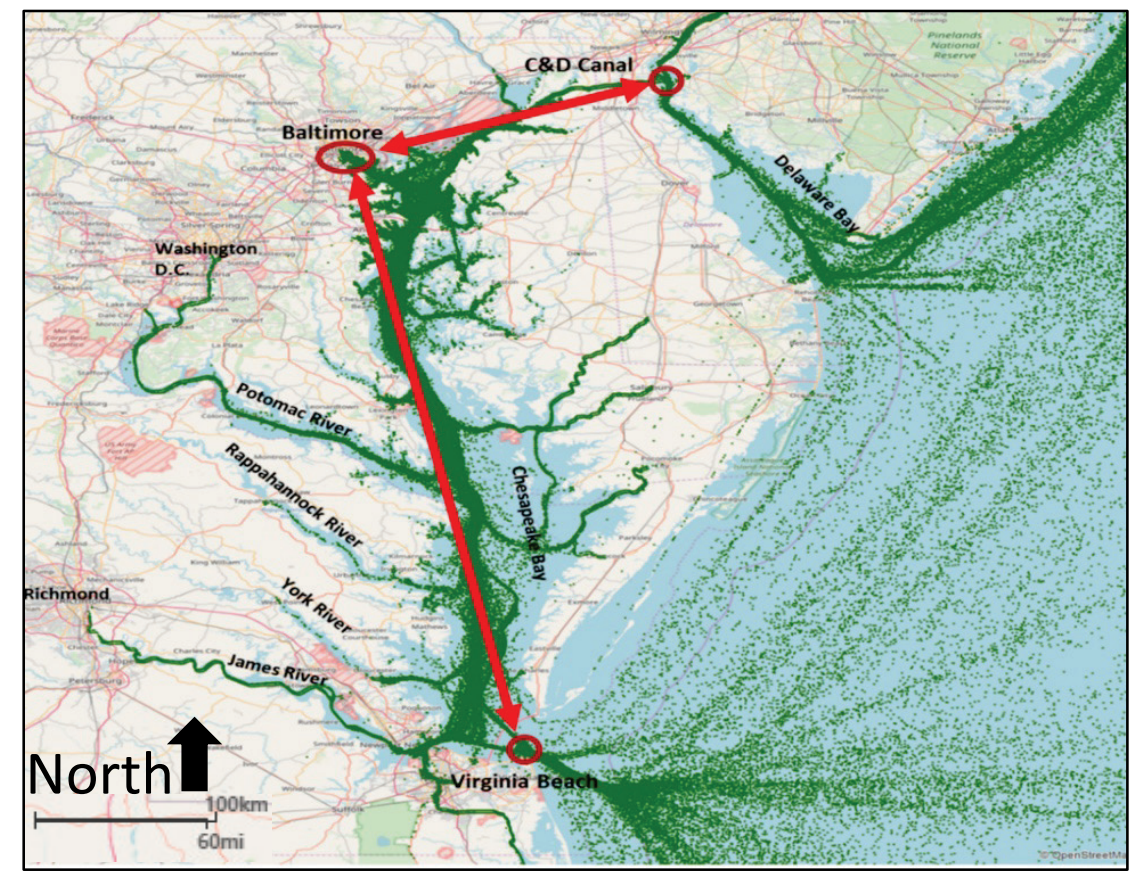


As shown in the Figure 1 map, the routes have multiple branching points for other origin/destinations besides the Port of Baltimore and to temporary anchorage areas in the middle of the routes. To calculate the travel time for the Port of Baltimore from the Virginia Beach origin and from the C\&D Canal origin, trip points (TPs) were assigned at strategic locations along the routes so that only direct trips from Virginia Beach and the C\&D Canal would be included in the analysis and travel time calculation. Any trips that diverged from the direct route were excluded from the analysis and travel time calculations. Figure 2 shows the TPs where the time stamps were collected for travel time calculations. The green dots inside the shaded boxes represent the AIS position reports that were used in this study.

Figure 2. Trip points (TP) used in analysis.

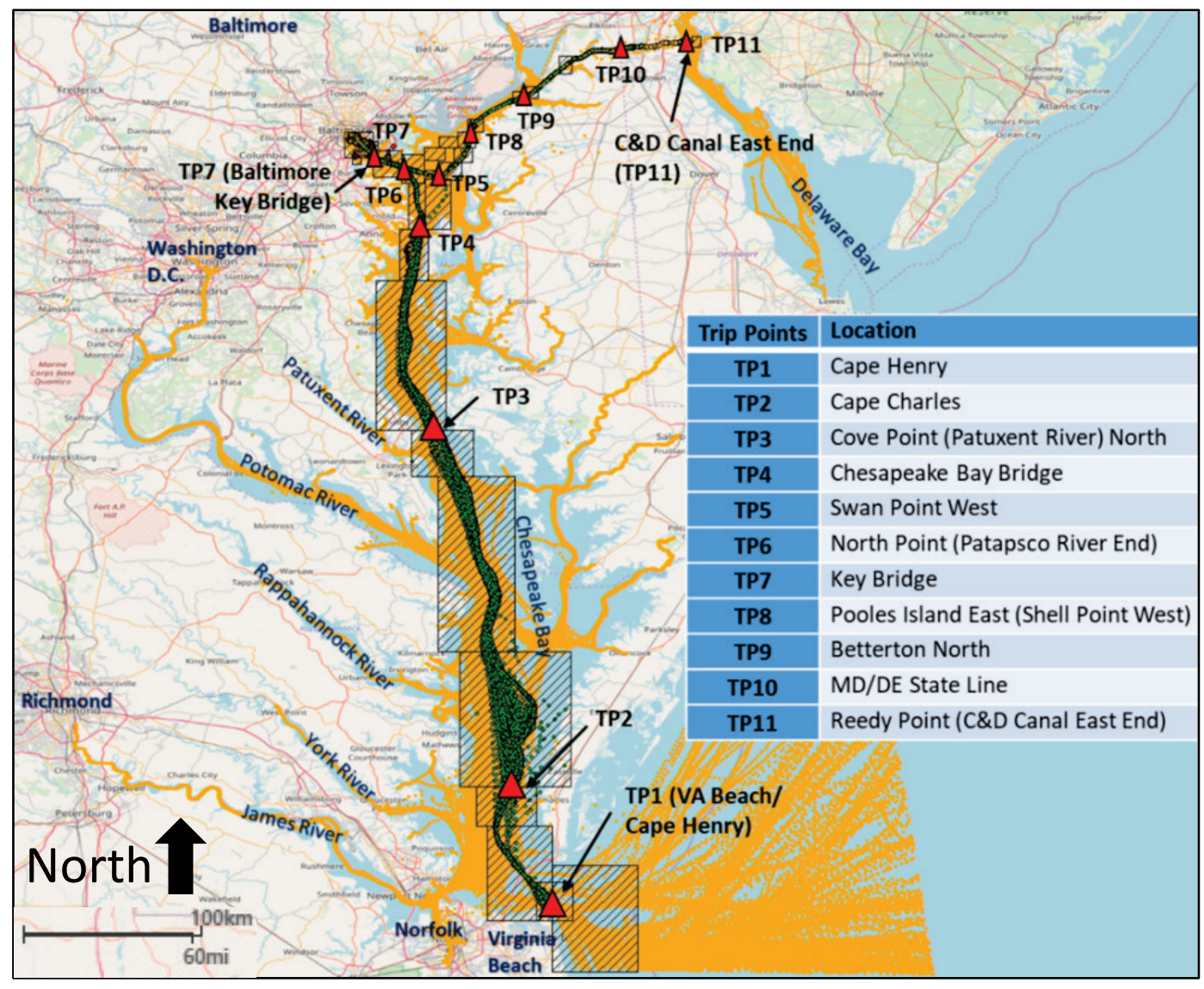




\subsection{AIS data preparation}

USCG NAIS records were obtained for calendar year 2016 for all vessels that appeared in an extended area around the Port of Baltimore including Chesapeake Bay and the C\&D Canal; data acquisition was performed via the AISAP software program (USACE 2018).

Unique vessel trips through the study area were identified by tracking the sequential AIS position reports for the respective vessels based on the MMSI identifier. Cruise ships, passenger ships, and recreational vessels were excluded from this study.

A trip was defined using the time stamps for each vessel at the predefined trip analysis points as shown above in Figure 2. The trip analysis points were assigned at the strategic locations to capture the vessel movements through the respective portions of the overall study area. The AIS data records were identified for each $\mathrm{TP}$, and only the records that represent the TPs were kept. This allowed for a reduction in data size and facilitated the calculation of travel time measures. In some cases, only partial trips were recorded along the Port of Baltimore strategic locations due to incomplete AIS records; those records were removed from further analysis. In the analysis presented here, only trips with full trip records (i.e., no missing TPs between $\mathrm{TP} 1$ and $\mathrm{TP} 7$ or between $\mathrm{TP} 11$ and $\mathrm{TP} 7$ ) were considered.

Some vessels remained at an anchorage area for an unusual amount of time or made a detour trip to other destination in the middle of a trip to and from the Port of Baltimore. Such trips would show up as outliers with unusually long travel times and are not representative of the normal range of conditions. It is common practice to remove extreme outliers to prevent them from skewing statistical results. To identify outlier trips to be removed from further analysis, scatter plots of Travel Time Inbound (TTIB) were prepared, shown in Figure 3 and Figure 4. In Figure 3, the C\&D Canal inbound trips show no significant travel time outliers; all records were retained. In Figure 4, some Virginia Beach inbound trips show outlier trip times starting at 1,000 min (in gray box). Based on the visual inspection of the travel time plots and GIS mapping, invalid trips and outliers were identified and removed by TAMTI researchers from any further analysis. Removing an inbound trip resulted in the removal of the subsequent outbound trip. 
Figure 3. TTIB for C\&D Canal inbound (CD-In) route, January - April 2016.

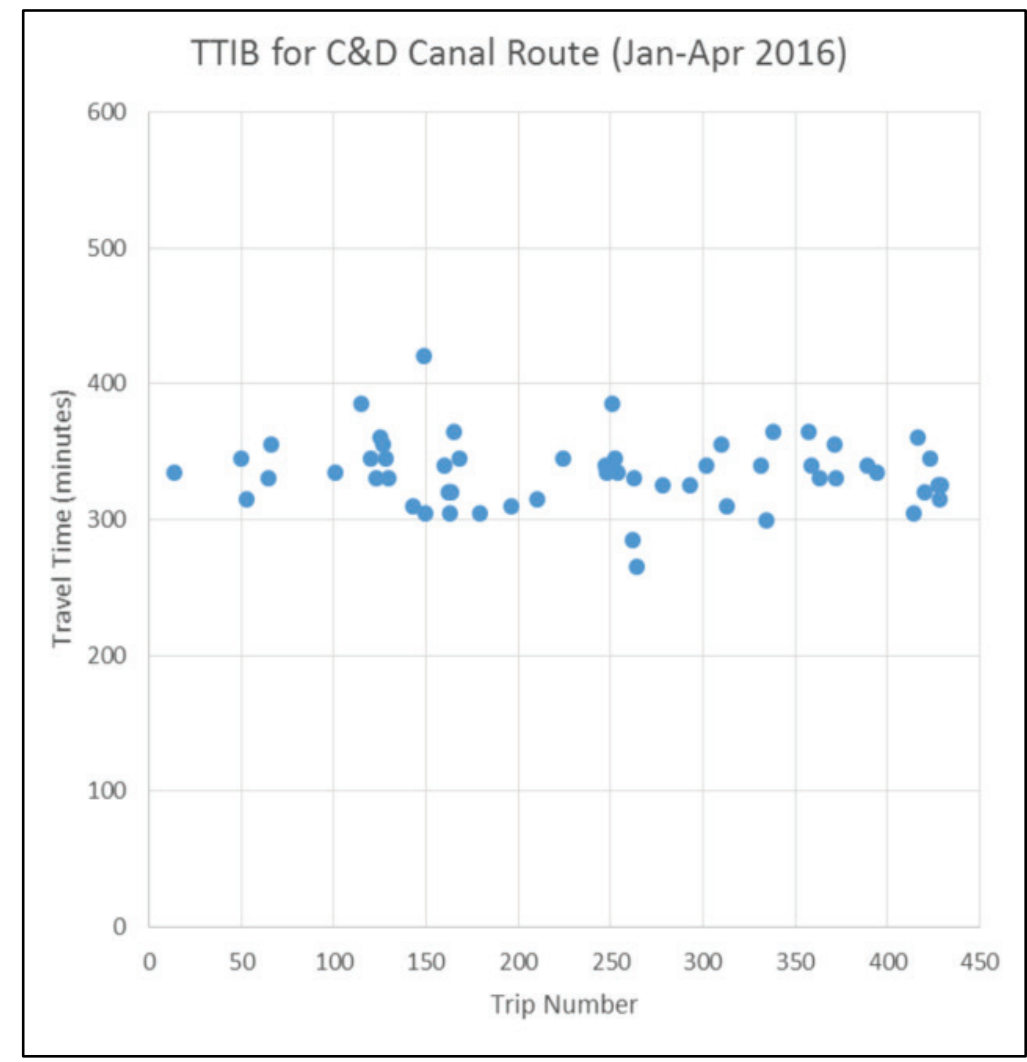

Figure 4. TTIB for Virginia Beach inbound (VB-In) route, January - April 2016.

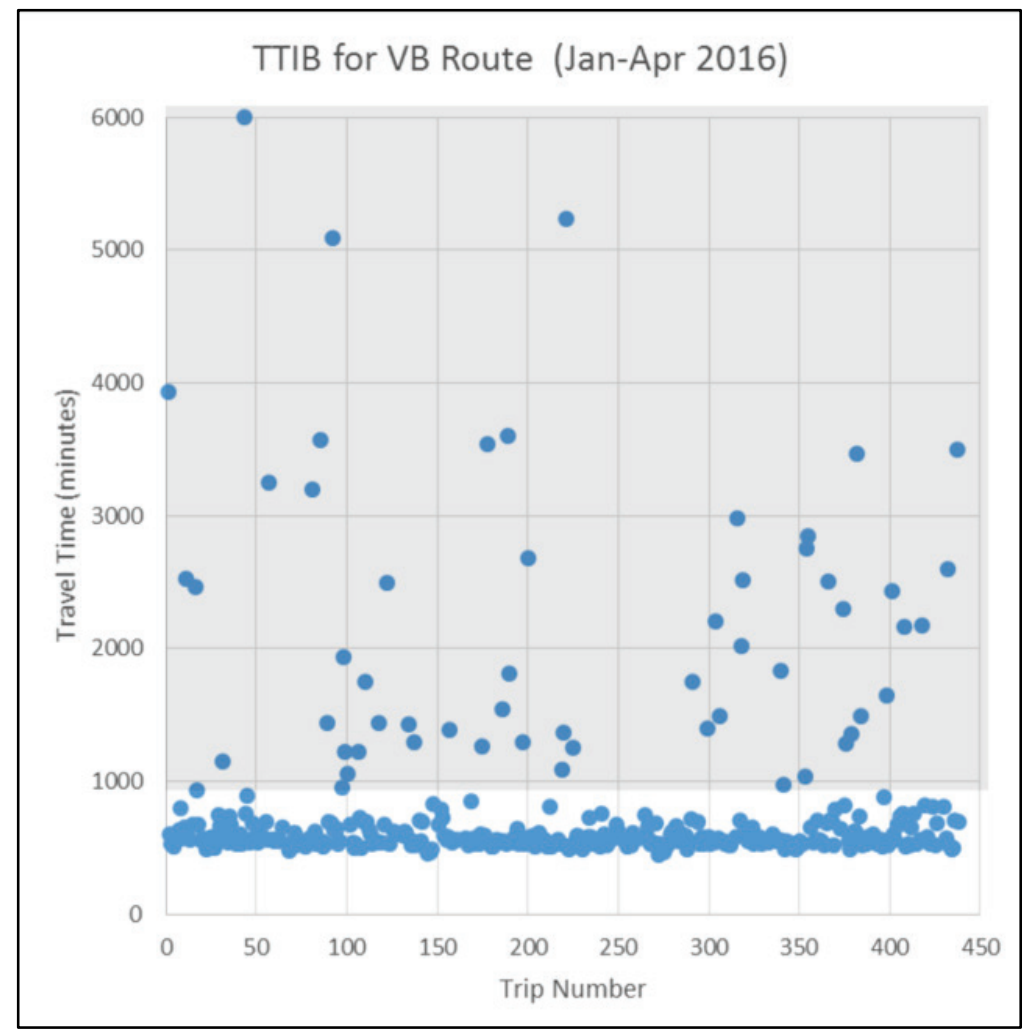


After data cleaning and filtering processes, the list of commercial cargocarrying ships to be analyzed was finalized by comparing the AIS identifying information to Lloyd's Register (LR) data. There were several reasons for combining the information from the AIS records with the LR database to identify the target vessels for this analysis:

- Multiple occurrences of vessel names and MMSI mismatches appear in operator-input AIS data. While vessel names are not necessary for this analysis, they provide an additional check on the overall completeness of vessel identification information.

- Vessel types from LR and AIS are not always consistent with one another. In the case of conflicting vessel types, this analysis deferred to the type indicated by LR given the well-known accuracy questions with AIS message fields entered by the vessel operators.

- LR provides more detailed ship-type classification than the vessel type information included in an AIS message.

\subsection{Input metric definition}

Some basic metrics were defined to calculate mobility measures for vessel traffic in the port area.

\subsubsection{Port Cycle Time (PCT)}

Port Cycle Time (PCT) represents the total elapsed time from the moment the vessel crosses the gateway point (i.e., TP1 for Virginia Beach route and TP11 for C\&D Canal route) until it exits via that gateway point. Unlike most US coastal port systems, the entering and exiting gateways can be different for the Port of Baltimore if a vessel uses different routes for inbound and outbound trips. In a previous study at the Port of Mobile, Alabama (Kruse et al. 2018), the total port system time metric was developed to account for vessels spending time in the outer anchorage area prior to entering the maintained channel. However, for the Port of Baltimore system, there is no comparable outer anchorage where vessels wait before entering the channel at Cape Henry (TP1). Therefore, PCT is used in this report.

There are four possible PCT routes for Baltimore as shown in Figure 5. There were unique PCT equations for each of the four possible routes; these are shown in Table 1. The following abbreviations are used throughout this document: 
- VB-In - Virginia Beach Inbound (i.e., passing Virginia Beach when traveling inbound to Baltimore)

- VB-Out - Virginia Beach Outbound

- CD-In - C\&D Canal Inbound (i.e., using the C\&D Canal when traveling inbound to Baltimore)

- CD-Out - C\&D Canal Outbound.

Figure 5. Routes PCT analysis.

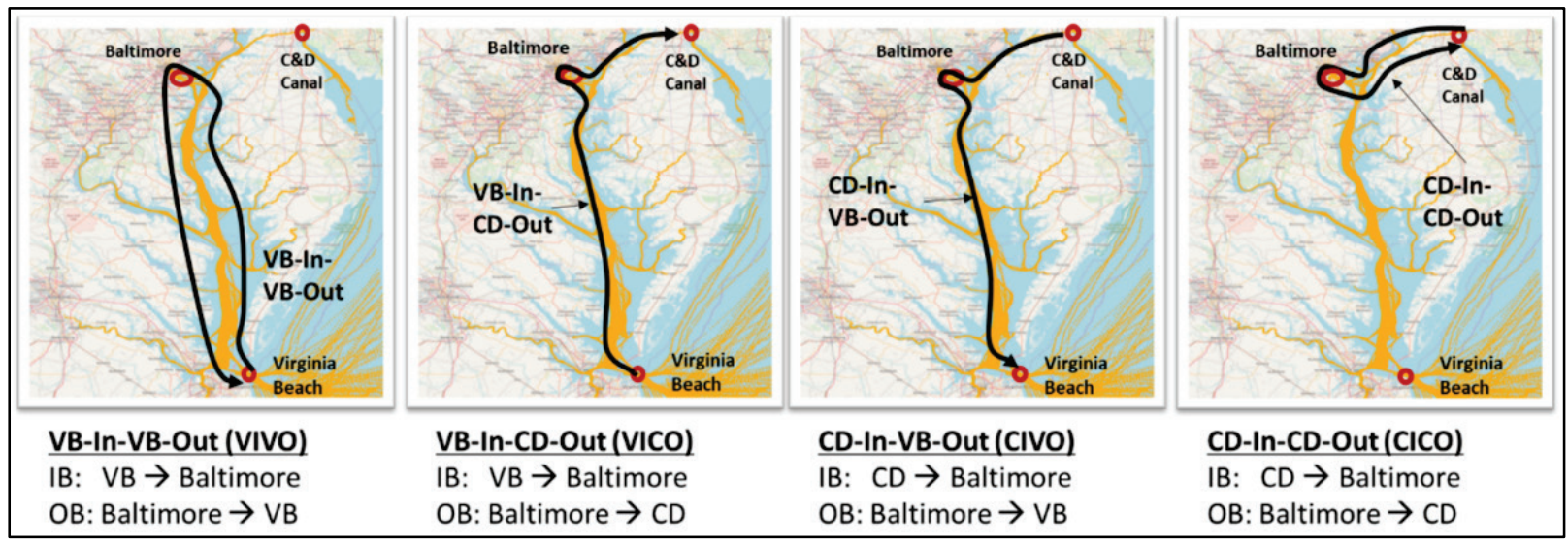

Table 1. Four types of port cycles with PCT equation.

\begin{tabular}{|c|c|c|c|}
\hline Types of PCT In-out & Inbound Route & Outbound Route & PCT Equation \\
\hline PCTvB-In-vB-out & Tp1 $\rightarrow$ TP7 & $\mathrm{TP} 7 \rightarrow \mathrm{TP} 1$ & Exit Time at TP1 - Entering Time at TP1 \\
\hline PCTvB-In-CD-Out & $\mathrm{TP} 1 \rightarrow \mathrm{Tp} 7$ & TP7 $\rightarrow$ Tp11 & Exit Time at Tp11 - Entering Time at TP1 \\
\hline PCT & $\mathrm{TP} 11 \rightarrow \mathrm{TP} 7$ & $\mathrm{TP} 7 \rightarrow \mathrm{Tp} 1$ & Exit Time at TP1 - Entering Time at TP11 \\
\hline PCT ${ }_{\text {CD-In-CD-Out }}$ & Tp11 $\rightarrow$ TP7 & $\mathrm{TP} 7 \rightarrow \mathrm{TP} 11$ & Exit Time at TP11 - Entering Time at TP11 \\
\hline
\end{tabular}

\subsubsection{Harbor Stay Hours (HSH)}

Harbor Stay Hours (HSH) represents the duration of time between an inbound vessel passing the Baltimore Key Bridge ( $\mathrm{TP}_{7}$ ), mooring at the dock for unloading/loading, and exiting under the Key Bridge (TP7), as shown in Figure 6. This is comparable to a dwell-time measurement, which has been used in other reports (e.g., USDOT 2021). This is the equation for calculating HSH: Harbor Stay Hours = Exit Time at TP7 Entering Time at $\mathrm{TP} 7$. 
Figure 6. Map of HSH route.

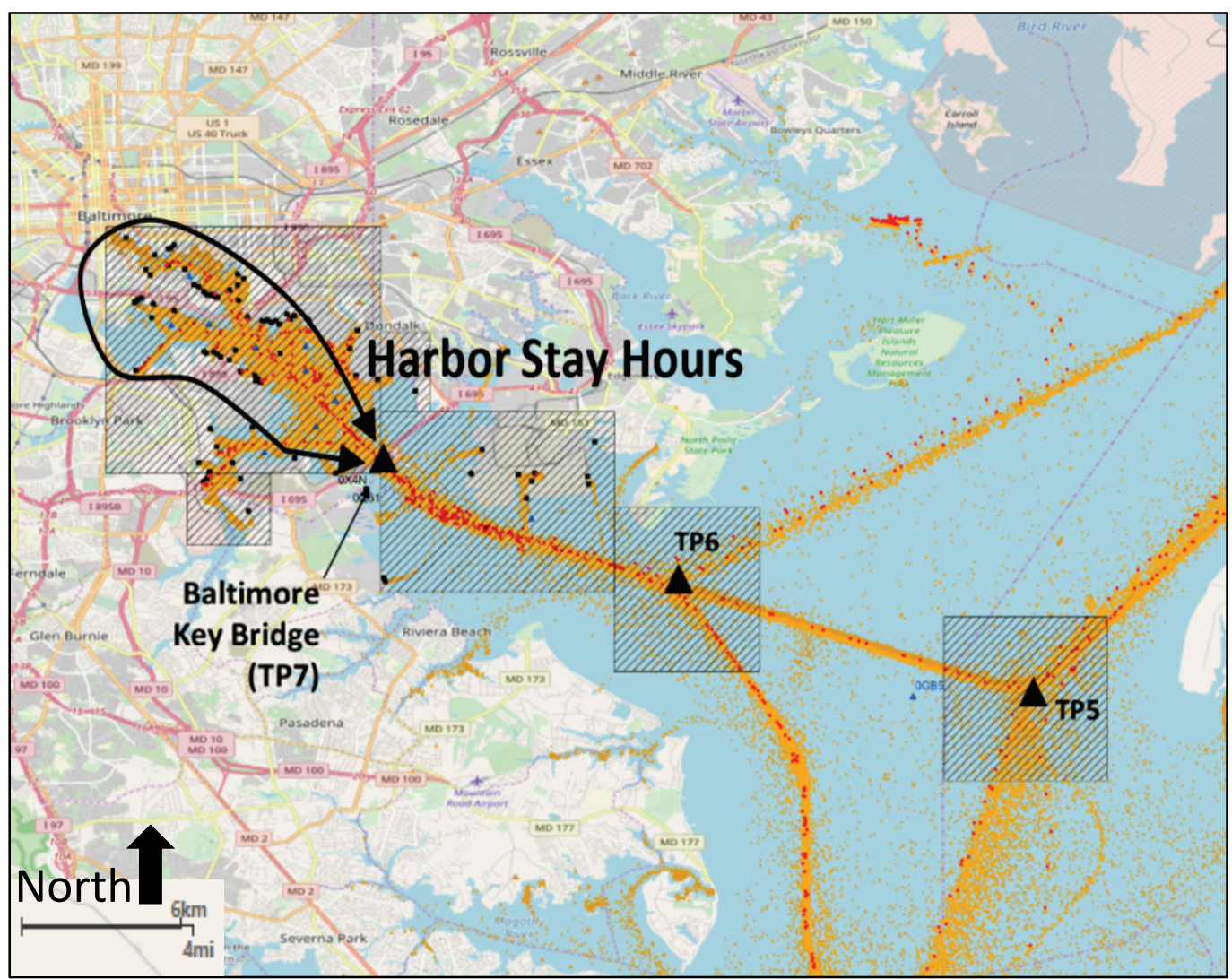

\subsubsection{Travel Time Inbound (TIB)}

TTIB represents the travel time from the point the vessel passes the inbound gateway point at each route (i.e., TP1 or TP11) until it enters the dock area, as delineated by the Baltimore Key Bridge (TP7). The TTIB measure represents the time that accrues between TP1 and TP7 for Virginia Beach Route and between TP11 and TP7 for C\&D Canal Route. Figure 7 and Table 2 show the paths and the equations for TTIB along the two inbound routes into Baltimore. 
Figure 7. Paths for inbound transit time analysis.

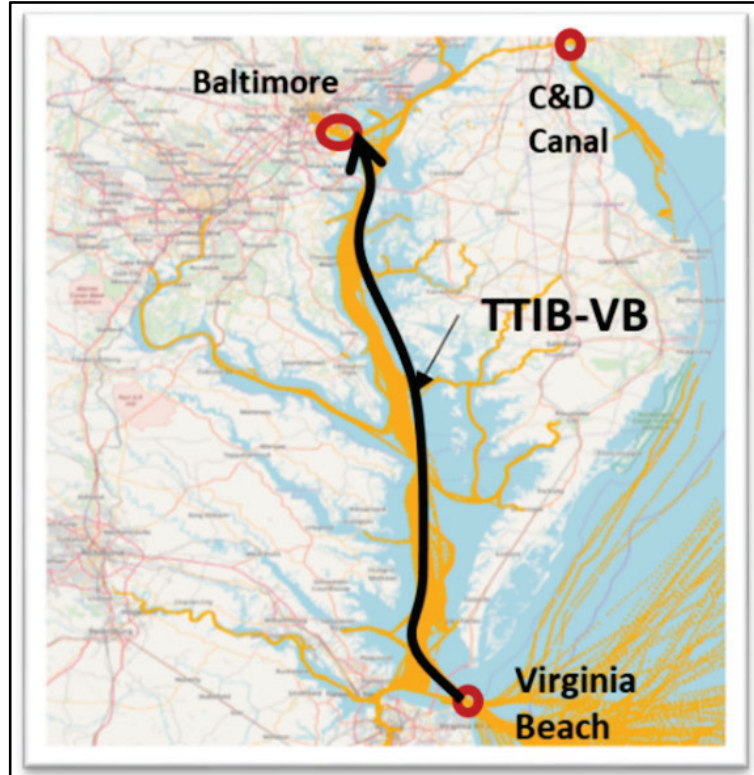

VB-In: VB $\rightarrow$ Baltimore

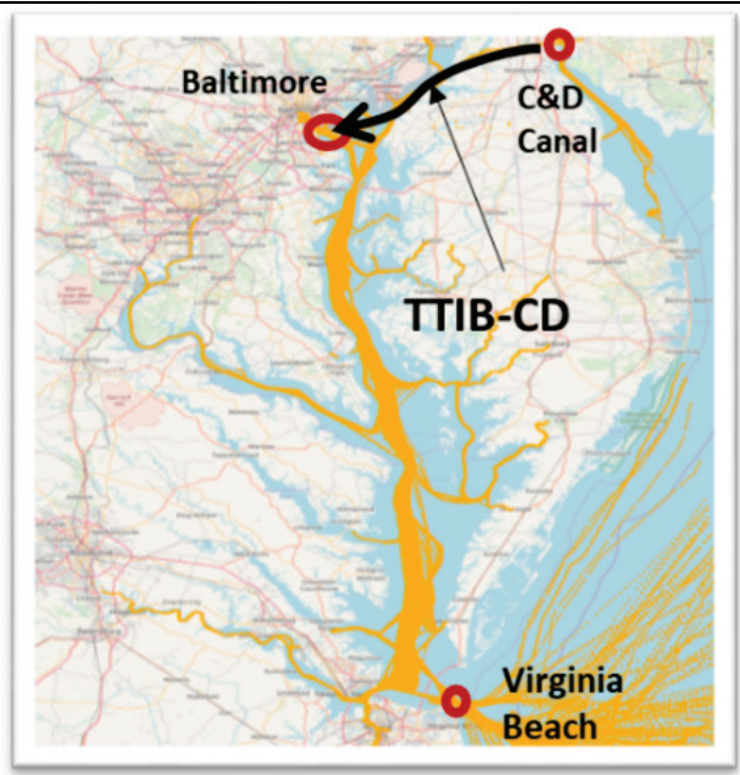

CD-In: $C D \rightarrow$ Baltimore

Table 2. Two TTIB calculations.

\begin{tabular}{|l|l|l|}
\hline Types of TTIB & Inbound Route & TTIB Equation \\
\hline TTIBVB-In & TP1 $\rightarrow$ TP2 $\rightarrow$ TP3 $\rightarrow$ TP4 $(\rightarrow$ TP5 $\rightarrow$ TP6 $\rightarrow$ TP7 & Time at TP7 - time at TP1 \\
\hline TTIB CD-In & TP11 $\rightarrow$ TP10 $\rightarrow$ TP9 $\rightarrow$ TP8 $(\rightarrow$ TP5 $) \rightarrow$ TP6 $\rightarrow$ TP7 & Time at TP7 - time at TP11 \\
\hline
\end{tabular}

\subsubsection{Travel Time Outbound (TTOB)}

TTOB represents the travel time from the point the vessel leaves the dock area (marked by the Baltimore Key Bridge, $\mathrm{TP}_{7}$ ) until it exits the gateway point (i.e., TP1 or TP11) on its way out. This represents the time that accrues between $\mathrm{TP} 7$ and $\mathrm{TP} 1$ for Virginia Beach Route and between $\mathrm{TP} 7$ and TP11 for C\&D Canal Route. Figure 8 and Table 3 show the paths and the equations for TTOB along the two routes. 
Figure 8. Paths for outbound transit time analysis.

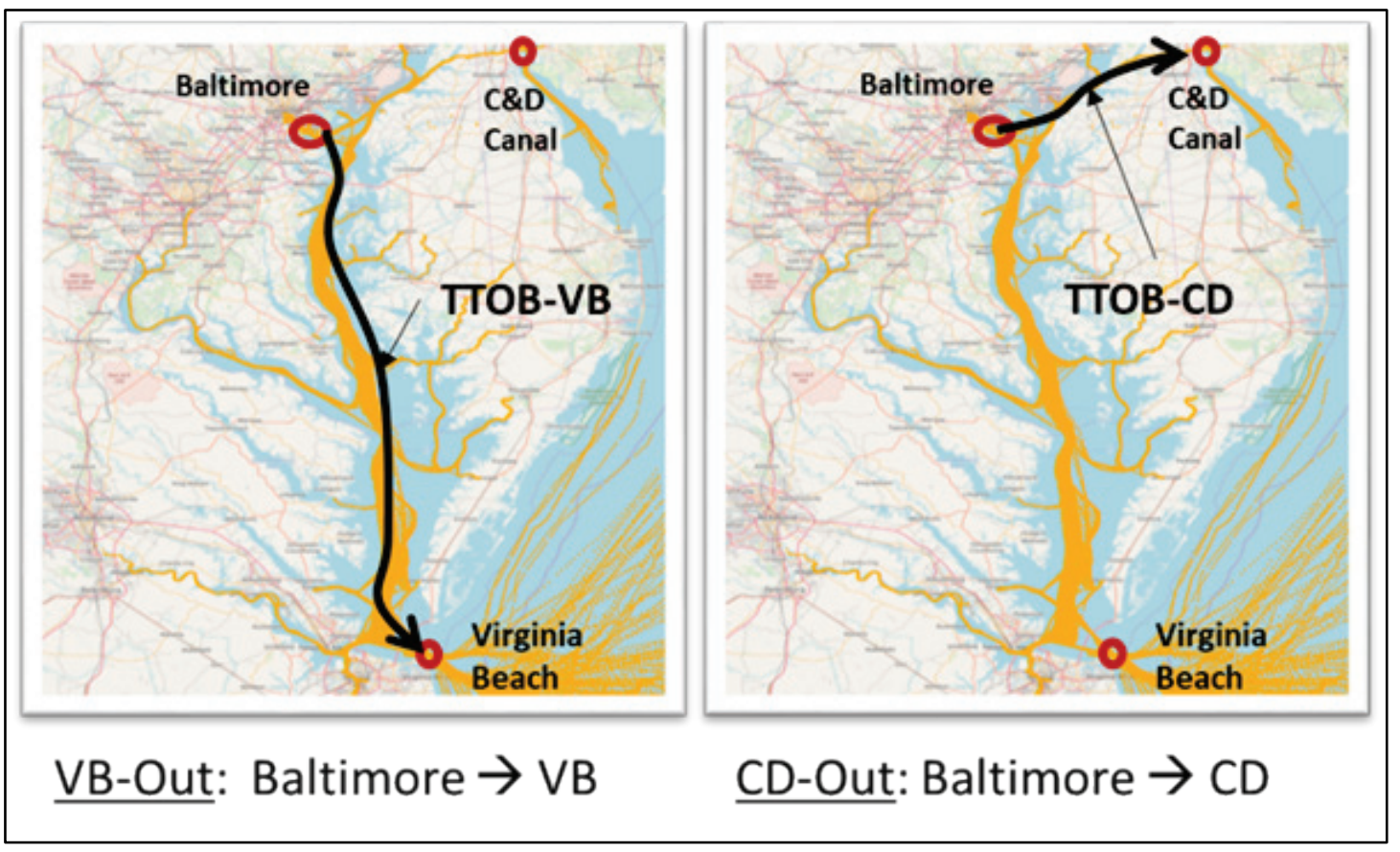

Table 3. Two types of travel time outbound (TTOB) and calculations.

\begin{tabular}{|l|l|l|}
\hline Types of TTOB & Outbound Route & TTOB Equation \\
\hline TTOBvB-0ut & TP7 $\rightarrow$ TP6 $(\rightarrow$ TP5 $) \rightarrow$ TP4 $\rightarrow$ TP3 $\rightarrow$ TP2 $\rightarrow$ TP1 & $\begin{array}{l}\text { exit time at TP1 - } \\
\text { exit time at TP7 }\end{array}$ \\
\hline TTOB $_{\text {CD-0ut }}$ & TP7 $\rightarrow$ TP6 $(\rightarrow$ TP5 $) \rightarrow$ TP8 $\rightarrow$ TP9 $\rightarrow$ TP10 $\rightarrow$ TP11 & $\begin{array}{l}\text { exit time at TP11 - } \\
\text { exit time at TP7 }\end{array}$ \\
\hline
\end{tabular}




\section{Results}

\subsection{Overall sample count analysis}

\subsubsection{Trip sample count by route}

After initial data processing, a total of 1,150 commercial trips from calendar year 2016 were identified for analysis. As shown in Table 4, most of the trips used the Chesapeake Bay (VB routes) for both inbound (VB-In) and outbound (VB-Out) transits, with only $1.5 \%$ of the trips using the C\&D Canal for both entrance and exit. The results show that $98.5 \%$ of vessel calls to the Port of Baltimore used the Chesapeake Bay Channel for at least one portion of the journey. This indicates that continued availability of the Chesapeake Bay navigation infrastructure (including anchorages) would be the highest priority for maintaining supply chain connections in and out of the Port of Baltimore. Detailed descriptions of route utilization by vessel type are presented below, starting in Section 3.4.

Table 4. Trip sample count for 2016.

\begin{tabular}{|l|l|l|}
\hline Trip Route & Trip Sample Size & Percentage of Trips \\
\hline VB-In-VB-Out & 822 & $71.5 \%$ \\
\hline VB-In-CD-Out & 186 & $16.2 \%$ \\
\hline CD-In-VB-Out & 125 & $11 \%$ \\
\hline CD-In-CD-Out & 17 & $1.5 \%$ \\
\hline Total & 1,150 & \\
\hline
\end{tabular}

\subsubsection{Daily patterns of vessel arrival time}

The number of arrival trips were analyzed by time of day to observe possible trends and patterns at the Port of Baltimore. When plotted by hour of day, there are two distinctive peaks: the highest peak between 4 a.m. and 6 a.m. and the second peak between 4 p.m. and 8 p.m. (Figure 9). A more detailed plot by hour and day of week is found in Appendix A. 
Figure 9. Arrival count by hour of day.

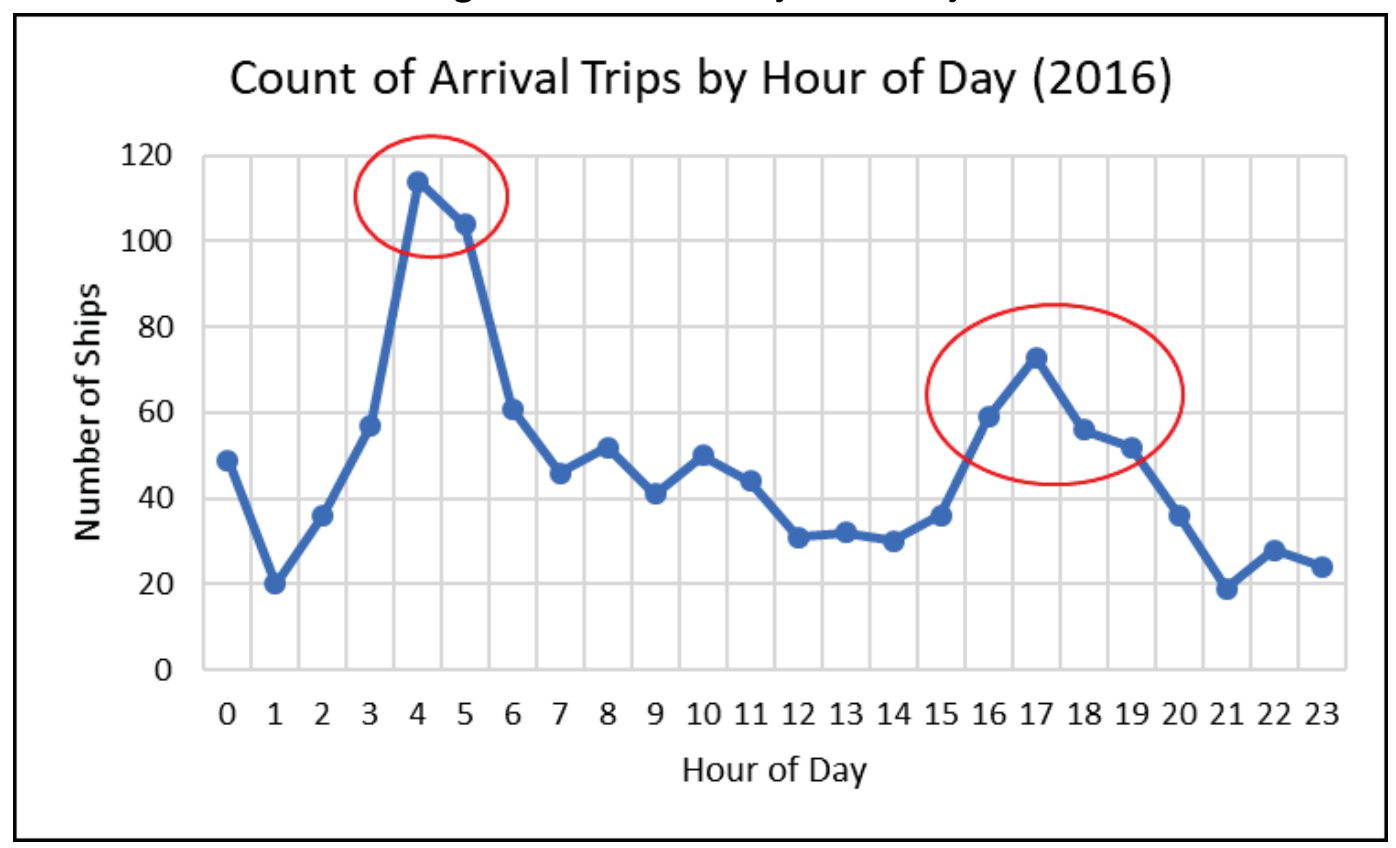

Figure 10 (panel A) displays a count of vessel arrivals by day of week for the entire year 2016. By day of week, Friday had the lowest number of ship arrivals while Tuesday had the highest number. This is likely mostly influenced by port operating hours (Monday-Friday 0600-1700) (Ports America Chesapeake 2021) rather than any physical waterway parameters. The monthly arrival count plot in Figure 10 (panel B) shows a relatively consistent number of vessel arrivals across all months of the year (approximately 80-110 arrivals per month), although August and March had slightly more arrivals than the other months of the year.

Figure 10. Plots of arrival count by day of week (A) and by month (B).
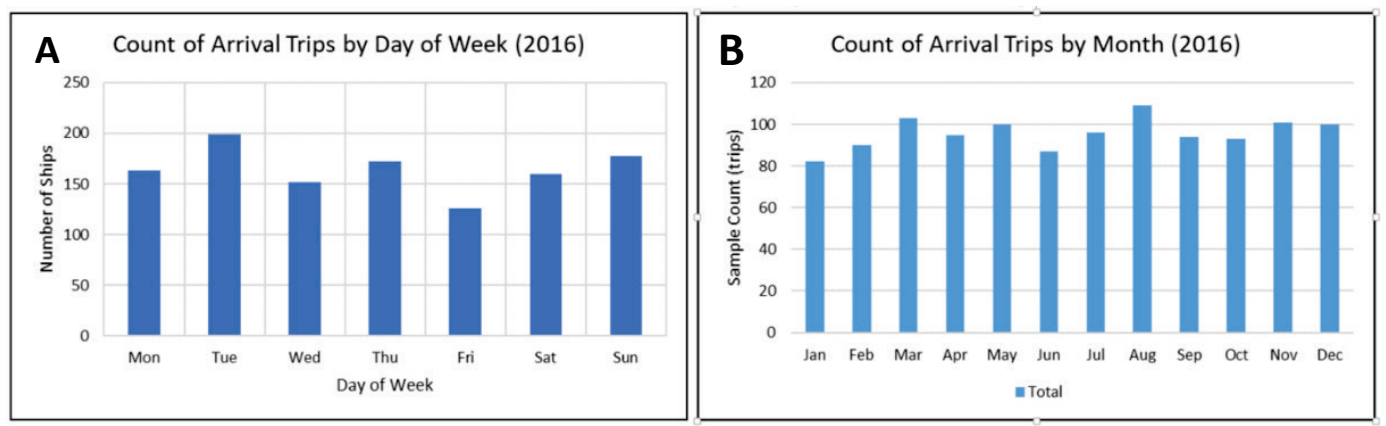

\subsection{Overall travel time analysis}

Basic statistical analysis was performed to obtain the travel time measures introduced in Section 2.5. Table 5 shows summary statistics of each 
measure by route. The most trafficked route (VB-In-VB-Out) had a mean PCT of $64 \mathrm{hr}$, with a mean TTIB time of $11.3 \mathrm{hr}$ and mean TTOB time of 10.0 hr. Median values are presented in Tables 9, 10, 11, and 14 for different vessel type and route combinations, with additional median values reported in the Appendix B tables.

Table 5. Overall summary statistics for PCT, HSH, TTIB, TTOB.

\begin{tabular}{|l|l|l|l|l|l|l|}
\hline \multirow{4}{*}{ Travel Time Metrics } & Route & Trip Count & $\begin{array}{l}\text { Mean } \\
\text { (hours) }\end{array}$ & $\begin{array}{l}\text { Standard } \\
\text { Deviation } \\
\text { (hours) }\end{array}$ & $\begin{array}{l}\text { Minimum } \\
\text { (hours) }\end{array}$ & $\begin{array}{l}\text { Maximum } \\
\text { (hours) }\end{array}$ \\
\hline \multirow{4}{*}{$\begin{array}{l}\text { PCT } \\
\text { (Port Cycle Time) }\end{array}$} & VB-In-VB-Out & 822 & 64.1 & 48.2 & 24.6 & 475.3 \\
\cline { 2 - 7 } & VB-In-CD-Out & 186 & 50.1 & 34.7 & 19.7 & 327.9 \\
\cline { 2 - 8 } & CD-In-VB-Out & 125 & 46.7 & 24.8 & 22.4 & 160.3 \\
\cline { 2 - 8 } $\begin{array}{l}\text { HSH } \\
\text { (Harbor Stay Hours) }\end{array}$ & CD-In-CD-Out & 17 & 53.7 & 43.3 & 20.1 & 163.7 \\
\hline \multirow{2}{*}{$\begin{array}{l}\text { TTIB } \\
\text { (Travel Time Inbound) }\end{array}$} & All routes & 1,125 & 37.3 & 37.9 & 2.9 & 443.4 \\
\hline \multirow{2}{*}{$\begin{array}{l}\text { TTOB } \\
\text { (Travel Time Outbound) }\end{array}$} & CD-In & 980 & 11.3 & 7.3 & 7.6 & 76.3 \\
\cline { 2 - 8 } & VB-Out & 139 & 5.6 & 0.4 & 4.8 & 7.4 \\
\hline
\end{tabular}

Though the mean transit times were fairly consistent between inbound and outbound vessels, the standard deviation for TTIB on the VB-In route was more than double that of TTOB on the VB-Out route $(7.3 \mathrm{hr}$ compared to $3.3 \mathrm{hr}$ ). This is presumably due to inbound vessels spending time in the two anchorage areas located within Chesapeake Bay, thereby increasing the variability of the observed travel times on that portion of the journey but remaining within the bounds of outlier determination as presented in Figure 4. Reasons for waiting at anchorage in Chesapeake Bay are not included in the AIS records but may include traffic management, customs requirements, maintenance, etc. The C\&D Canal route showed very consistent transit times regardless of direction of travel, with a mean TTIB of $5.6 \mathrm{hr}$ and mean TTOB of $5.6 \mathrm{hr}$, and both measures had relatively small standard deviations of under $1 \mathrm{hr}$. Additional information regarding traffic and safety restrictions in the C\&D Canal under different vessel arrival scenarios, as managed by local vessel pilots, is provided in Section 3.7, below. 
Table 5 shows that the mean HSH duration for all vessels regardless of entrance route was $37.3 \mathrm{hr}$. As shown in the standard deviation column in Table 5, HSH had a standard deviation of $37.9 \mathrm{hr}$, slightly higher than the mean. That the HSH measure displayed higher variability than TTIB or TTOB measure is not entirely surprising as vessels entering the Port of Baltimore carry a variety of cargo with a variety of handling practices. This cargo includes liquid bulk petrochemicals, containerized cargo, and dry bulk cargo ranging from coal to sugar (USACE 2021). In 2016, the Port of Baltimore handled over 16 million tons of coal; over 3 million tons of petroleum products; over 6 million tons of crude materials such as sand, stone, woodchips, and clay; and over 7 million tons in the combined categories of manufactured goods and manufactured equipment (USACE 2021). By 2019, this had grown to over 21 million tons of coal, over 4 million tons of petroleum products, and over 7 million tons of crude materials (USACE 2021). In addition to cargo handling, any vessel support activities that took place inside the inner harbor area (maintenance, refueling, waiting for inspections) would contribute to an increase in $\mathrm{HSH}$.

The mean PCT for all vessels had high variability as expected from the fact that it includes TTIB, TTOB, and the HSH, which can include idle times and service times at the dock. Given the low variability in the TTIB and TTOB measures across all routes, and the large variability in $\mathrm{HSH}$, it is clear that activities within the harbor areas are the main driver of variation in mean PCT, not travel activities in the Chesapeake Bay channels or the C\&D Canal. These measures will be analyzed in detail by ship type and ship size group in the following sections.

\subsection{Overall performance measure results}

\subsubsection{Performance measures developed}

For the metrics of PCT, HSH, TTIB, and TTOB, the following performance fluidity measures were calculated by vessel types and size-based sub-groups.

- Baseline Travel Time (BTT) - the 25th percentile travel time of a set of trips. This measure identifies a free-flow traffic condition or minimum amount of travel time necessary to complete the trip.

- Travel Time Index (TTI) - the median of the ratios of each individual observed trip travel time to the BTT (25th percentile). In other words, the median travel time divided by the $25^{\text {th }}$ percentile value. 
- Planning Time Index (PTI) - the ratio of the 8oth percentile travel time of a set of trips to the BTT for the set of trips.

The results of these calculations are presented later in this section.

\subsubsection{Percentiles used for mobility measures}

To conduct mobility analyses, a baseline of comparison is needed to know how the port is operating as compared to normal or unobstructed conditions. Like the Port of Mobile study (Kruse et al. 2018), this study used the 25th percentile travel time as a baseline condition. Median travel time was used to calculate the TTI and 8oth percentile travel time for planning time index. Appendix B includes comprehensive performance measures based on two calculated percentiles (15th and 25th percentile travel times), average conditions (mean and median travel times), and variability conditions (80th and 95th percentile travel times). These measures provide additional information about the travel time statistical distributions calculated during this project.

\subsubsection{Overall analysis results}

Overall fluidity performance measures were calculated by routes irrespective of vessel type and vessel size (Table 6). Most BTTs via the Chesapeake Bay (VB route) had more than $30 \mathrm{hr}$ of PCT. The VB-In-VBOut PCT trip has a TTI value of 1.34 , which means that the average trip required $34 \%$ longer to complete than the $25^{\text {th }}$ percentile trip used to establish the baseline. The TTI values are much lower at TTIB and TTOB trips for both routes with only $5 \%$ to $7 \%$ longer than baseline transit times. Both the TTIB and TTOB measures include anchorage time(s) that occurred within the Chesapeake Bay but not any time spent in outer anchorage areas outside of the Virginia Beach boundary.

The large PTI values for PCT and HSH trips are due to the amount of variability in trip times through the system based on differences in cargo types, ship size, dock operations, etc. The PTI for the VB-In-VB-Out PCT is 2.29 using the 8oth percentile as the numerator, which means that a vessel would require at least $129 \%$ extra time above the BTT to ensure it would exit the port on time, or by its scheduled exit time, $80 \%$ of the time. The key conclusion from these results is that the majority of variability in overall PCT is due to the variability in $\mathrm{HSH}$, not from associated channel conditions or channel restrictions. 
Table 6. Overall performance measures, 2016.

\begin{tabular}{|c|c|c|c|c|c|}
\hline $\begin{array}{l}\text { Performance } \\
\text { Measure }\end{array}$ & Routes & $\begin{array}{l}\text { Baseline } \\
\text { Travel Time } \\
\text { (BTT) } \\
\text { (hours) }\end{array}$ & $\begin{array}{l}\text { Travel Time Index } \\
\text { (TTI) (Median/ } \\
25^{\text {th }} \text { percentile) }\end{array}$ & $\begin{array}{l}\text { Planning Time } \\
\text { Index (PTI) }\left(80^{\text {th }}\right. \\
\text { percentile/ } \\
\left.25^{\text {th }} \text { percentile }\right)\end{array}$ & $\begin{array}{l}\text { Number of } \\
\text { Trips }\end{array}$ \\
\hline \multirow{4}{*}{$\begin{array}{l}\text { PCT } \\
\text { (Port Cycle Time) }\end{array}$} & VB-In-VB-Out & 35.8 & 1.34 & 2.29 & 822 \\
\hline & VB-In-CD-Out & 34.4 & 1.17 & 1.77 & 186 \\
\hline & CD-In-VB-Out & 32.4 & 1.22 & 1.74 & 125 \\
\hline & CD-In-CD-Out & 24.8 & 1.51 & 2.65 & 17 \\
\hline $\begin{array}{l}\text { HSH } \\
\text { (Harbor Stay Hours) }\end{array}$ & All routes & 17.2 & 1.48 & 2.79 & 1125 \\
\hline \multirow{2}{*}{$\begin{array}{l}\text { TTIB } \\
\text { (Travel Time } \\
\text { Inbound) }\end{array}$} & VB-In & 8.9 & 1.06 & 1.25 & 980 \\
\hline & CD-In & 5.3 & 1.05 & 1.13 & 139 \\
\hline \multirow{2}{*}{$\begin{array}{l}\text { TTOB } \\
\text { (Travel Time } \\
\text { Outbound) }\end{array}$} & VB-Out & 8.8 & 1.05 & 1.22 & 919 \\
\hline & CD-Out & 5.1 & 1.07 & 1.11 & 200 \\
\hline
\end{tabular}

\subsection{Vessel type analysis results}

Though the performance measures described in the previous section show the overall port freight fluidity condition, it is important to consider various vessel types separately because of their different physical and operational characteristics. Table 7 shows the ship type groups used in the analysis. A single ship type (vehicle carrier) accounted for a large portion of the cargo traffic at the Port of Baltimore; thus, a separate ship-type group was established to represent these vessels.

Table 7. Cargo ship type group with ship type details.

\begin{tabular}{|l|l|}
\hline Ship Type Group & Ship Type \\
\hline \multirow{4}{*}{ Bulk } & Bulk carrier \\
\cline { 2 - 2 } & Bulk carrier, self-discharging \\
\cline { 2 - 2 } & Ore carrier \\
\hline \multirow{2}{*}{ Chemical } & Chemical tanker \\
\cline { 2 - 2 } & Chemical/products tanker \\
\hline \multirow{2}{*}{ Container Ship-Fully Cellular } & Container ship (fully cellular) \\
\hline \multirow{3}{*}{ General Cargo Ship } & General cargo ship \\
\cline { 2 - 2 } & $\begin{array}{l}\text { General cargo ship with roll on-roll off (ro-ro) } \\
\text { facility) }\end{array}$ \\
\cline { 2 - 2 } & Open hatch cargo ship \\
\hline
\end{tabular}




\begin{tabular}{|l|l|}
\hline Ship Type Group & Ship Type \\
\hline \multirow{4}{*}{ Other } & Asphalt/bitumen tanker \\
\cline { 2 - 2 } & Container/ro-ro cargo ship \\
\cline { 2 - 2 } & Ro-ro cargo ship \\
\hline \multirow{4}{*}{ Tanker } & Bulk/oil carrier (obo**) \\
\cline { 2 - 2 } & Crude oil tanker \\
\cline { 2 - 2 } & Crude/oil products tanker \\
\cline { 2 - 2 } & Products tanker \\
\hline Vehicle Carrier & Vehicle Carrier \\
\hline
\end{tabular}

Figure 11 shows the distribution of the cargo traffic by ship-type group. Vehicle carriers clearly dominate traffic, with containerships and bulk carriers competing for second place.

Figure 11. Cargo traffic at Port of Baltimore by ship-type group, 2016.

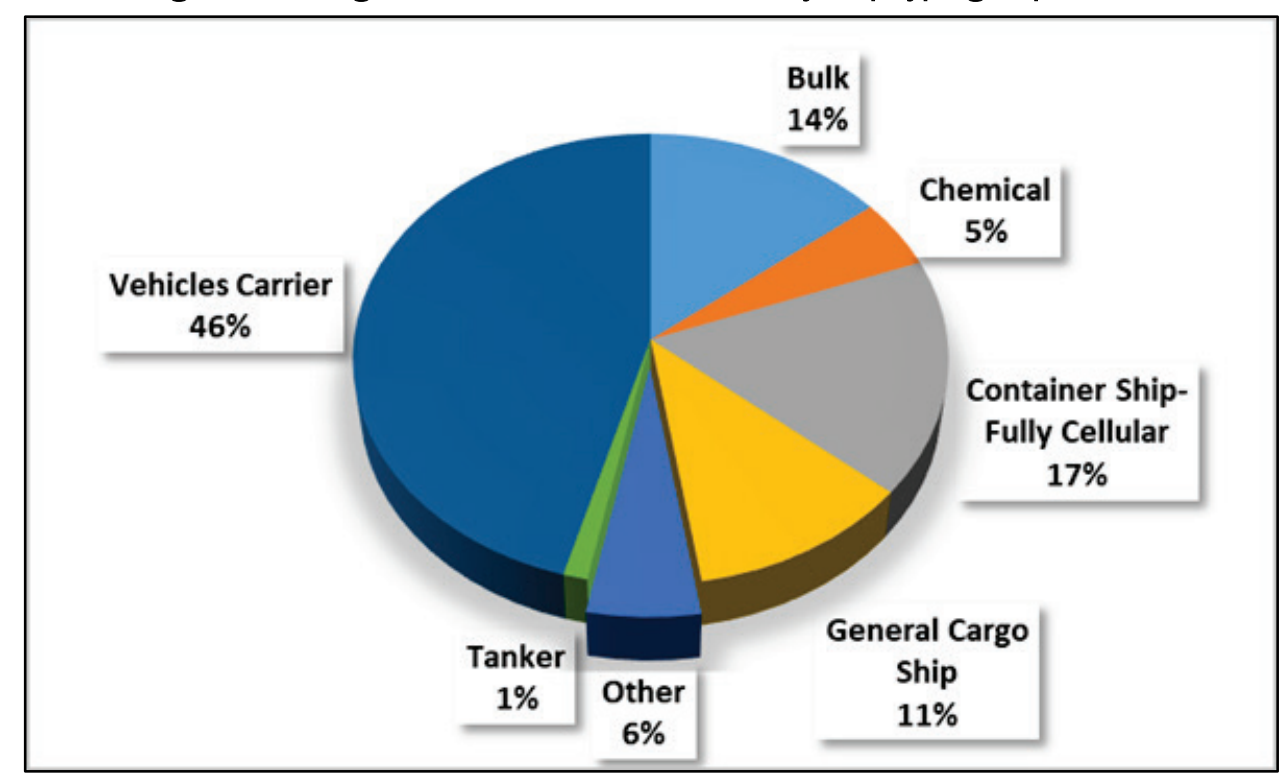

Table 8 shows that most of ship-type groups used the VB route for inbound and outbound transits. Notably, none of the fully cellular container ships in this sample used the C\&D Canal while approximately half of inbound chemical tankers used the C\&D Canal. This could be due to trade connections involving industrial petrochemical operations in the Philadelphia area and larger Delaware Bay region, but such detailed investigations of specific supply chains were beyond the scope of this study. Figures 12 and 13 present the data from Table 8 in graphical form. 
Table 8. Cargo traffic by ship-type group by inbound and outbound route, 2016.

\begin{tabular}{|l|l|l|l|l|}
\hline \multirow{2}{*}{ Ship-Type Group } & \multicolumn{3}{l|}{ Inbound Path } & \multicolumn{2}{l|}{ Outbound Path } \\
\cline { 2 - 6 } & CD-In & VB-In & CD-Out & VB-Out \\
\hline Bulk & 8 & 136 & 19 & 125 \\
\hline Chemical & 26 & 31 & 6 & 51 \\
\hline Container Ship - Fully Cellular & 0 & 195 & 0 & 195 \\
\hline General Cargo Ship & 13 & 107 & 19 & 101 \\
\hline Other & 5 & 59 & 13 & 51 \\
\hline Tanker & 4 & 10 & 6 & 8 \\
\hline Vehicles Carrier & 83 & 442 & 137 & 388 \\
\hline Total & 139 & 980 & 200 & 919 \\
\hline
\end{tabular}

Figure 12. Inbound cargo traffic grouped by ship type, 2016.

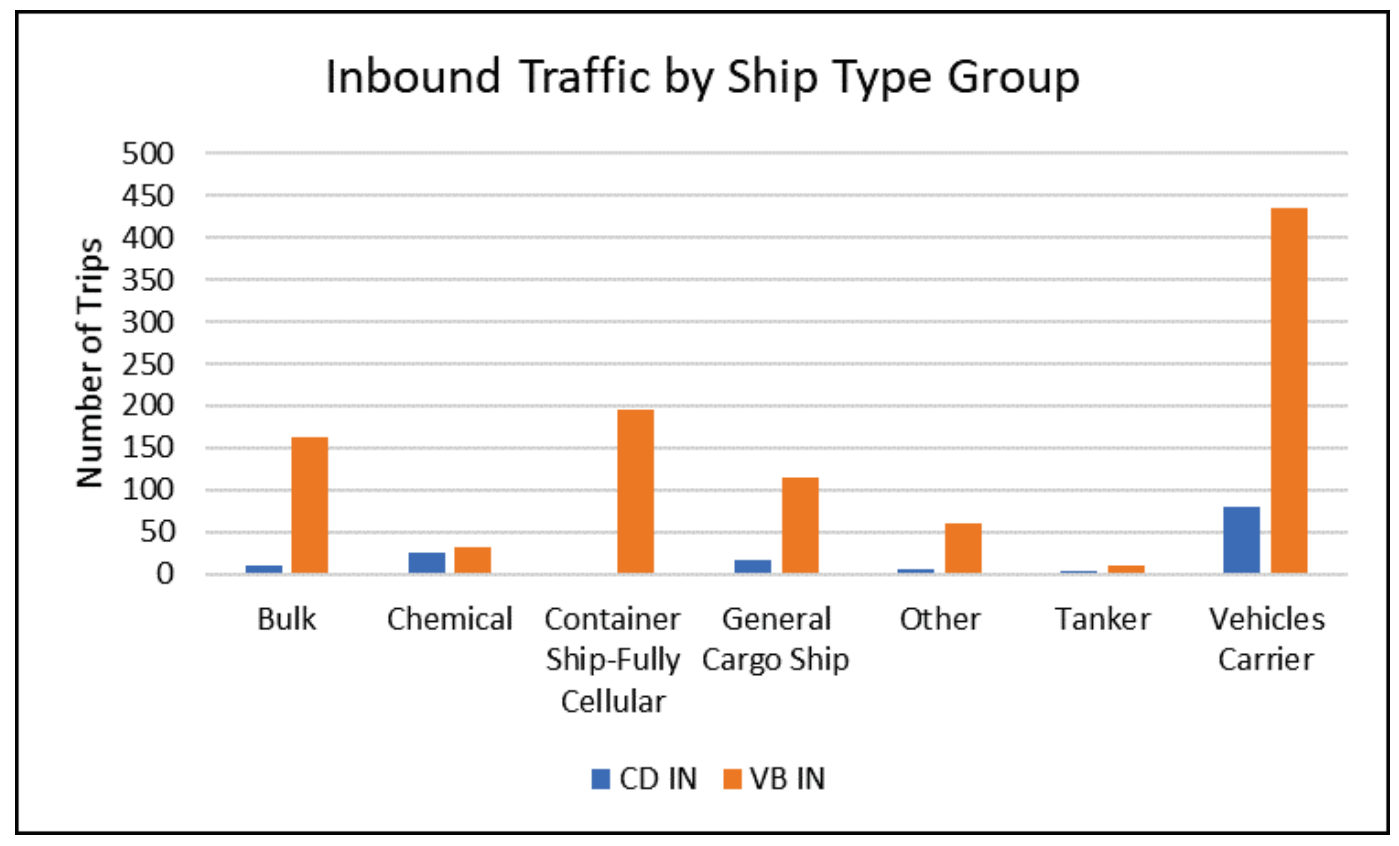


Figure 13. Outbound cargo traffic grouped by ship type, 2016.

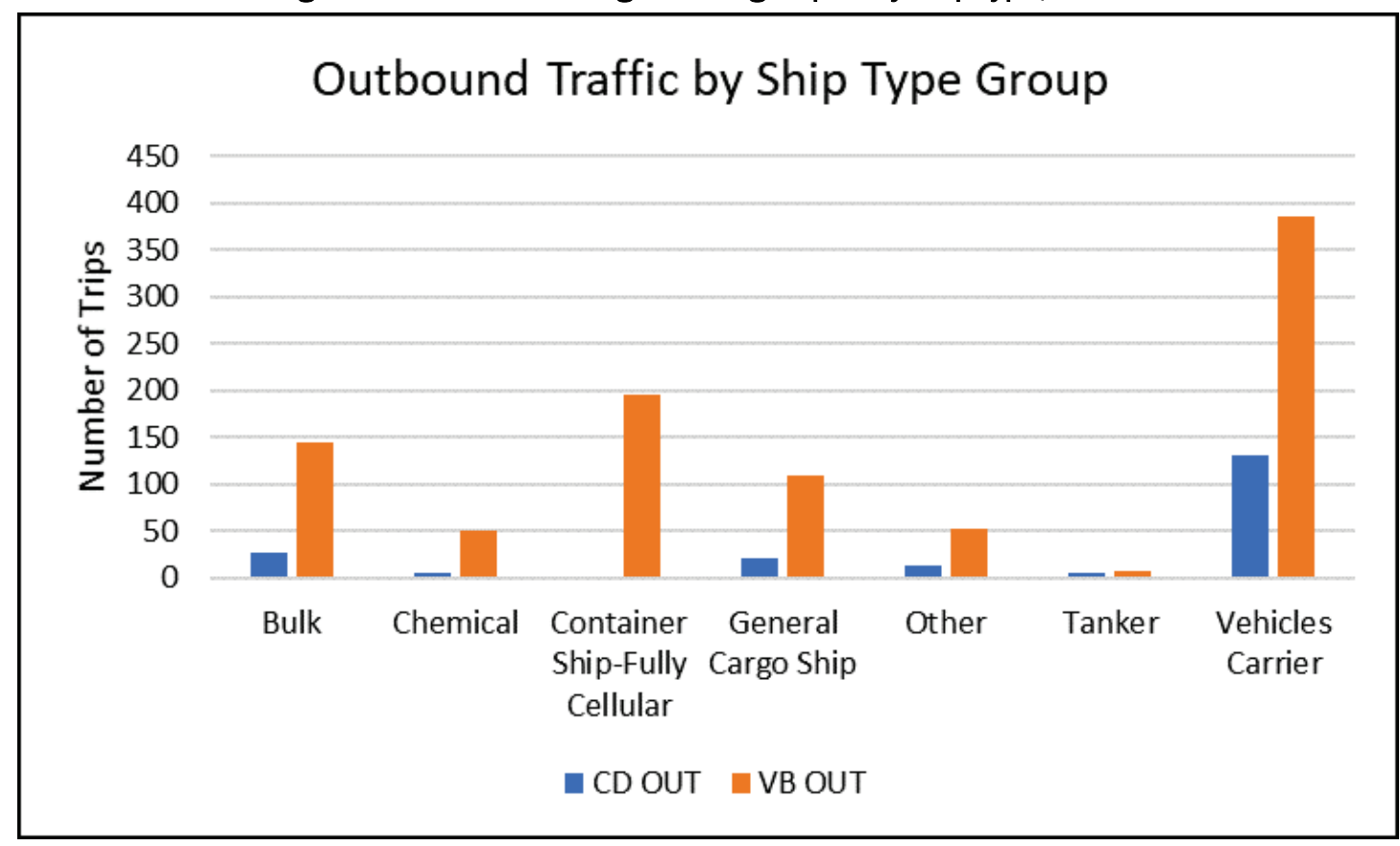

Figure 14 is a series of scatter plots of PCT across the entire year of data, broken out by each ship-type group (bulk, chemical, container ship-fully cellular, general cargo ship, tanker, and vehicles carrier). Figure 14 illustrates the clear distinction in the PCT variation among the ship-type groups. Bulk vessels have large variability, with multiple instances in the 50-200 hr range while container ships and vehicle carriers have very consistent and short PCT hours with almost all instances under $100 \mathrm{hr}$. This further supports the idea that vessel type, and the practices associated with various cargo and vessel type, is the driving factor in PCT variability, rather than travel-based influences occurring in the C\&D Canal or Chesapeake Bay routes. 
Figure 14. PCT plots by ship-type group.

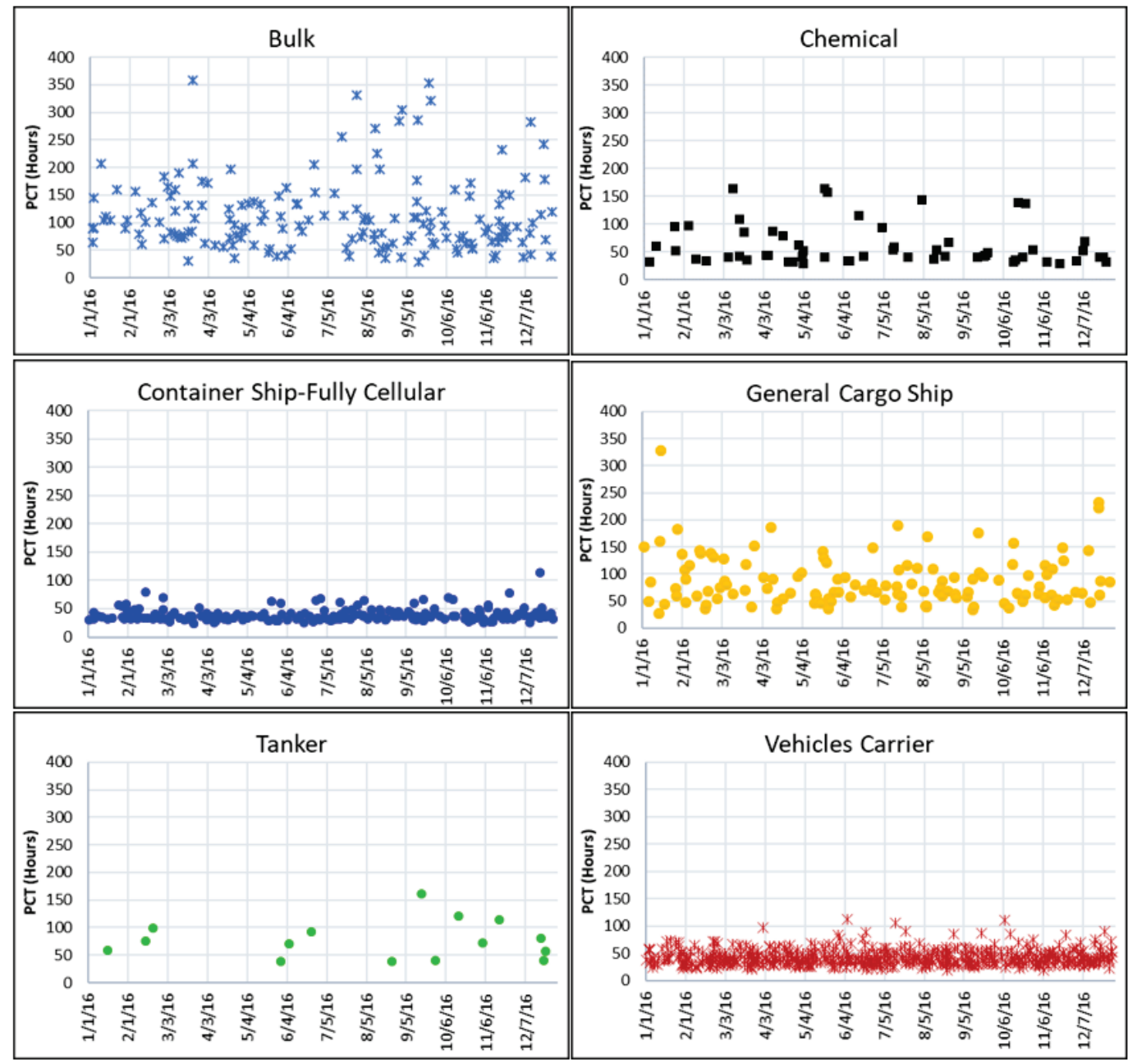

Table 9 and Table 10 show inbound and outbound transit time statistics by ship-type group by route. Regardless of ship-type group, CD inbound and CD outbound routes show very consistent transit times with small variability. In contrast, VB inbound and VB outbound routes show various mean transit times and standard deviations between the ship-type groups. For example, VB-In bulk carriers take longer time with higher variability while container ships and vehicles carriers have very consistent and short transit times. 
Table 9. TTIB hours by ship-type group by route, 2016.

\begin{tabular}{|l|l|l|l|l|l|l|l|}
\hline IB Path & Ship Type Group & Count & Mean & $\begin{array}{l}\text { Standard } \\
\text { Deviation }\end{array}$ & Median & Minimum & Maximum \\
\hline \multirow{4}{*}{ CD-In } & Bulk & 8 & 5.8 & 0.4 & 5.8 & 5.1 & 6.3 \\
\cline { 2 - 8 } & Chemical & 26 & 5.8 & 0.6 & 5.7 & 4.9 & 7.4 \\
\cline { 2 - 8 } & $\begin{array}{l}\text { Container Ship- } \\
\text { Fully Cellular }\end{array}$ & 0 & NA & NA & NA & NA & NA \\
\cline { 2 - 8 } & $\begin{array}{l}\text { General Cargo } \\
\text { Ship }\end{array}$ & 13 & 5.8 & 0.5 & 5.8 & 5 & 7 \\
\cline { 2 - 8 } & Other & 5 & 6 & 0.4 & 6.1 & 5.5 & 6.3 \\
\cline { 2 - 8 } & Tanker & 4 & 5.8 & 0.4 & 5.7 & 5.4 & 6.3 \\
\cline { 2 - 8 } & Vehicles Carrier & 83 & 5.6 & 0.4 & 5.5 & 4.8 & 7 \\
\hline \multirow{5}{*}{ VB-In } & 136 & 18.6 & 14.2 & 12.1 & 9.1 & 76.3 \\
\cline { 2 - 8 } & Bulk & 31 & 12.7 & 6.6 & 11.2 & 9.5 & 41.5 \\
\cline { 2 - 8 } & $\begin{array}{l}\text { Chemical } \\
\text { Fully Cellular }\end{array}$ & 195 & 9.2 & 1.4 & 8.9 & 7.6 & 21.5 \\
\cline { 2 - 8 } & $\begin{array}{l}\text { General Cargo } \\
\text { Ship }\end{array}$ & 107 & 12.2 & 7.4 & 10.2 & 8.6 & 54.3 \\
\cline { 2 - 8 } & Other & 59 & 10.7 & 6.8 & 9.2 & 7.8 & 59.6 \\
\cline { 2 - 7 } & Tanker & 10 & 11.4 & 0.8 & 11.3 & 9.8 & 12.5 \\
\cline { 2 - 7 } & Vehicles Carrier & 442 & 9.8 & 3.7 & 9.2 & 8 & 58.9 \\
\hline
\end{tabular}

Table 10. TTOB hours by ship-type group by route, 2016 .

\begin{tabular}{|c|c|c|c|c|c|c|c|}
\hline OB Path & Ship Type Group & Count & Mean & $\begin{array}{l}\text { Standard } \\
\text { Deviation }\end{array}$ & Median & Minimum & Maximum \\
\hline \multirow{7}{*}{ CD-Out } & Bulk & 19 & 5.7 & 0.5 & 5.8 & 4.8 & 6.7 \\
\hline & Chemical & 6 & 5.4 & 0.3 & 5.4 & 5 & 5.8 \\
\hline & $\begin{array}{l}\text { Container Ship- } \\
\text { Fully Cellular }\end{array}$ & 0 & NA & NA & NA & NA & NA \\
\hline & $\begin{array}{l}\text { General Cargo } \\
\text { Ship }\end{array}$ & 19 & 5.4 & 0.6 & 5.3 & 4.5 & 6.5 \\
\hline & Other & 13 & 5.2 & 0.3 & 5.2 & 4.8 & 5.7 \\
\hline & Tanker & 6 & 6.1 & 0.6 & 6 & 5.5 & 7.1 \\
\hline & Vehicles Carrier & 137 & 5.4 & 0.6 & 5.3 & 4.6 & 10.7 \\
\hline \multirow{7}{*}{ VB-Out } & Bulk & 125 & 12.9 & 3 & 12.6 & 8.4 & 39.8 \\
\hline & Chemical & 51 & 11.3 & 3.5 & 10.8 & 9.3 & 34.9 \\
\hline & $\begin{array}{l}\text { Container Ship- } \\
\text { Fully Cellular } \\
\end{array}$ & 195 & 9.2 & 2.8 & 8.8 & 7.7 & 44.8 \\
\hline & $\begin{array}{l}\text { General Cargo } \\
\text { Ship }\end{array}$ & 101 & 10.1 & 1.4 & 10 & 8.3 & 18.9 \\
\hline & Other & 51 & 10.1 & 5.1 & 8.9 & 8 & 44.8 \\
\hline & Tanker & 8 & 19.9 & 18.5 & 11 & 9.7 & 60.8 \\
\hline & Vehicles Carrier & 388 & 9.1 & 0.8 & 9 & 7.9 & 22.5 \\
\hline
\end{tabular}


Table 11 shows PCT performance measures by route and vessel type. As observed in the previous scatter plots, bulk carrier PCT hours showed higher mean times with higher variability than any other group/travel direction combination. In general, container ships and vehicle carriers have relatively small TTI and PTI values. Container ships using the Chesapeake Bay in both directions have a TTI of 1.14, which means that, on average, the PCT trip takes only $14 \%$ longer to complete than the baseline (25th percentile) trip. For vehicle carriers using the Chesapeake Bay in both directions, the PTI is 1.69, which means that a vehicle carrier must allow at least $69 \%$ extra time above the baseline travel time to ensure it will exit the port on time $80 \%$ of the time.

Table 11. PCT performance measures by route and vessel type.

\begin{tabular}{|c|c|c|c|c|c|c|}
\hline \multirow{2}{*}{$\begin{array}{l}\text { PCT Route } \\
\text { Code* }\end{array}$} & \multirow[b]{2}{*}{ Vessel Type } & \multicolumn{2}{|c|}{ Travel Time } & \multirow{2}{*}{\begin{tabular}{|l} 
TI \\
Median/25th \\
Percentile \\
\end{tabular}} & \multirow{2}{*}{$\begin{array}{l}\text { PTI } \\
80^{\text {th }} / 25^{\text {th }} \\
\text { Percentile }\end{array}$} & \multirow{2}{*}{$\begin{array}{l}\text { Number of } \\
\text { Trips }\end{array}$} \\
\hline & & Mean & Median & & & \\
\hline \multirow{8}{*}{$\begin{array}{l}\text { VB-In-VB- } \\
\text { Out }\end{array}$} & Total & 64.1 & 47.9 & 1.34 & 2.29 & 822 \\
\hline & Bulk & 123.6 & 105 & 1.38 & 2.16 & 135 \\
\hline & Chemical & 72 & 52.8 & 1.28 & 2.77 & 26 \\
\hline & $\begin{array}{l}\text { Container Ship-Fully } \\
\text { Cellular }\end{array}$ & 38.9 & 36.5 & 1.14 & 1.37 & 195 \\
\hline & General Cargo Ship & 90 & 74.3 & 1.23 & 2.13 & 98 \\
\hline & Other & 52.5 & 46 & 1.25 & 1.77 & 51 \\
\hline & Tanker & 107.1 & 107.1 & 1.41 & 1.6 & 6 \\
\hline & Vehicle Carrier & 46.2 & 41.5 & 1.26 & 1.69 & 311 \\
\hline \multirow{7}{*}{$\begin{array}{l}\text { VB-In-CD- } \\
\text { Out }\end{array}$} & Total & 50.1 & 40.2 & 1.17 & 1.77 & 186 \\
\hline & Bulk & 86 & 71.7 & 1.38 & 2.19 & 21 \\
\hline & Chemical & 60.4 & 62.3 & 1.45 & 1.89 & 5 \\
\hline & General Cargo Ship & 81.8 & 56.9 & 1.21 & 2.03 & 16 \\
\hline & Other & 42.3 & 36.2 & 1.09 & 1.77 & 9 \\
\hline & Tanker & 44.7 & 41 & 1.03 & 1.46 & 4 \\
\hline & Vehicle Carrier & 40.8 & 38.5 & 1.22 & 1.49 & 131 \\
\hline \multirow{7}{*}{$\begin{array}{l}\text { CD-In-VB- } \\
\text { Out }\end{array}$} & Total & 46.7 & 39.5 & 1.22 & 1.74 & 125 \\
\hline & Bulk & 76.3 & 61.8 & 1.58 & 3.05 & 8 \\
\hline & Chemical & 47.1 & 41.3 & 1.26 & 1.62 & 25 \\
\hline & General Cargo Ship & 70.3 & 61 & 1.47 & 2.48 & 12 \\
\hline & Other & 57.1 & 57.1 & 1 & 1 & 1 \\
\hline & Tanker & 82.2 & 82.2 & 1.13 & 1.26 & 2 \\
\hline & Vehicle Carrier & 38.7 & 38.2 & 1.31 & 1.49 & 77 \\
\hline \multirow{2}{*}{$\begin{array}{l}\text { CD-In-CD- } \\
\text { Out }\end{array}$} & Total & 53.7 & 37.3 & 1.51 & 2.65 & 17 \\
\hline & Chemical & 163.7 & 163.7 & 1 & 1 & 1 \\
\hline
\end{tabular}




\begin{tabular}{|c|c|c|c|c|c|c|}
\hline \multirow{6}{*}{$\begin{array}{l}\text { PCT Route } \\
\text { Code* }\end{array}$} & \multirow[b]{2}{*}{ Vessel Type } & \multicolumn{2}{|c|}{ Travel Time } & \multirow{2}{*}{$\begin{array}{l}\text { TाI } \\
\text { Median/25th } \\
\text { Percentile }\end{array}$} & \multirow{2}{*}{$\begin{array}{l}\text { PTI } \\
80^{\text {th }} / 25^{\text {th }} \\
\text { Percentile }\end{array}$} & \multirow{2}{*}{$\begin{array}{l}\text { Number of } \\
\text { Trips }\end{array}$} \\
\hline & & Mean & Median & & & \\
\hline & General Cargo Ship & 86.7 & 79.5 & 1.56 & 2.95 & 4 \\
\hline & Other & 40.7 & 40.7 & 1.12 & 1.26 & 4 \\
\hline & Tanker & 47.5 & 47.5 & 1.25 & 1.5 & 2 \\
\hline & Vehicle Carrier & 24 & 22.3 & 1.05 & 1.16 & 6 \\
\hline
\end{tabular}

*CD: C\&D Canal route; VB: Virginia Beach (Chesapeake Bay) route

\subsection{Vessel size analysis}

This section shows the analysis results by vessel size. The overall length of each vessel was grouped together into the following categories:

- Under $500 \mathrm{ft}$

- $500-699 \mathrm{ft}$

- $700-899 \mathrm{ft}$

- Over $900 \mathrm{ft}$.

Figure 15 shows cargo trip distribution by ship size. Vessels in the 500$699 \mathrm{ft}$ category dominate vessel calls (65\% of the total for 2016), with vehicle carriers being the dominant type in that category. The only vessels in the largest size group of over $900 \mathrm{ft}$ were the bulk and containershipfully cellular types; this size group made up only $14 \%$ of the vessel calls to the Port of Baltimore in 2016.

Figure 15. Cargo traffic by ship-size group.

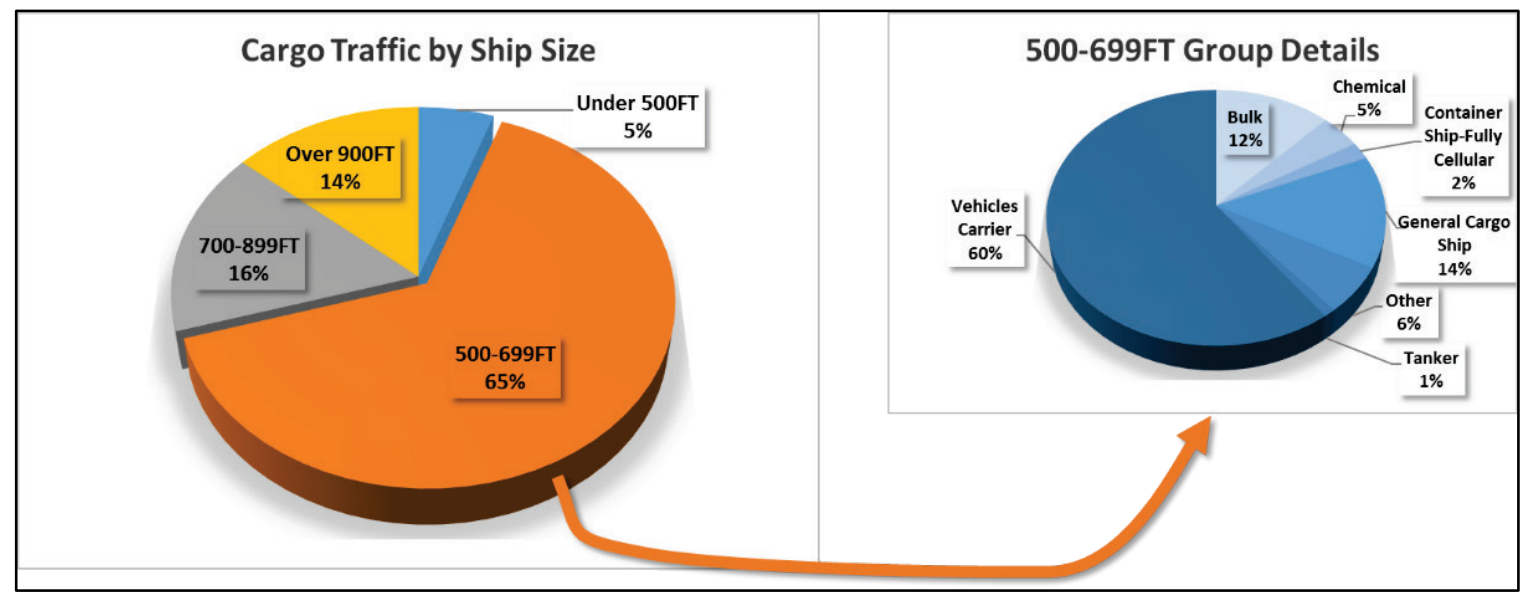

Table 12 provides a more detailed cross tabulation of the trip distribution between ship type and ship size. In the table, chemical ships and general cargo ships are relatively small $(<700 \mathrm{ft})$. Vehicle carriers and tankers are 
all mid-size ( $>500 \mathrm{ft}$ and $<900 \mathrm{ft}$ ). Containerships account for a high percentage of the largest size group, with bulk carriers accounting for the remainder.

Table 12. Trip distribution of ship type and ship size.

\begin{tabular}{|c|c|c|c|c|c|}
\hline Ship Type Ship Size & $\begin{array}{l}\text { Under } \\
500 \mathrm{ft}\end{array}$ & $\begin{array}{l}500- \\
699 \mathrm{ft}\end{array}$ & $\begin{array}{l}700- \\
899 \mathrm{ft}\end{array}$ & $\begin{array}{l}\text { Over } \\
900 \mathrm{ft}\end{array}$ & $\begin{array}{l}\text { Ship Size } \\
\text { Total }\end{array}$ \\
\hline Bulk & 4 & 91 & 48 & 28 & 171 \\
\hline Chemical & 25 & 32 & 0 & 0 & 57 \\
\hline Container Ship-Fully Cellular & 0 & 16 & 55 & 125 & 196 \\
\hline General Cargo Ship & 23 & 106 & 1 & 0 & 130 \\
\hline Other & 10 & 45 & 7 & 3 & 65 \\
\hline Tanker & 0 & 8 & 7 & 0 & 15 \\
\hline Vehicle Carrier & 0 & 450 & 66 & 0 & 516 \\
\hline Ship Type Total & 62 & 748 & 184 & 156 & 1150 \\
\hline
\end{tabular}

Scatter plots were prepared to observe the variability and possible trend patterns of each ship size group. Figure 16 shows clear distinctions among the ship size groups. Vessels with 500-699 ft lengths have large PCT variability due to a wide variety of ship types while the largest ship group (over $900 \mathrm{ft}$ ) has small PCT variability mainly due to the predominance of container ships.

Figure 16. PCT plots by ship-size group.

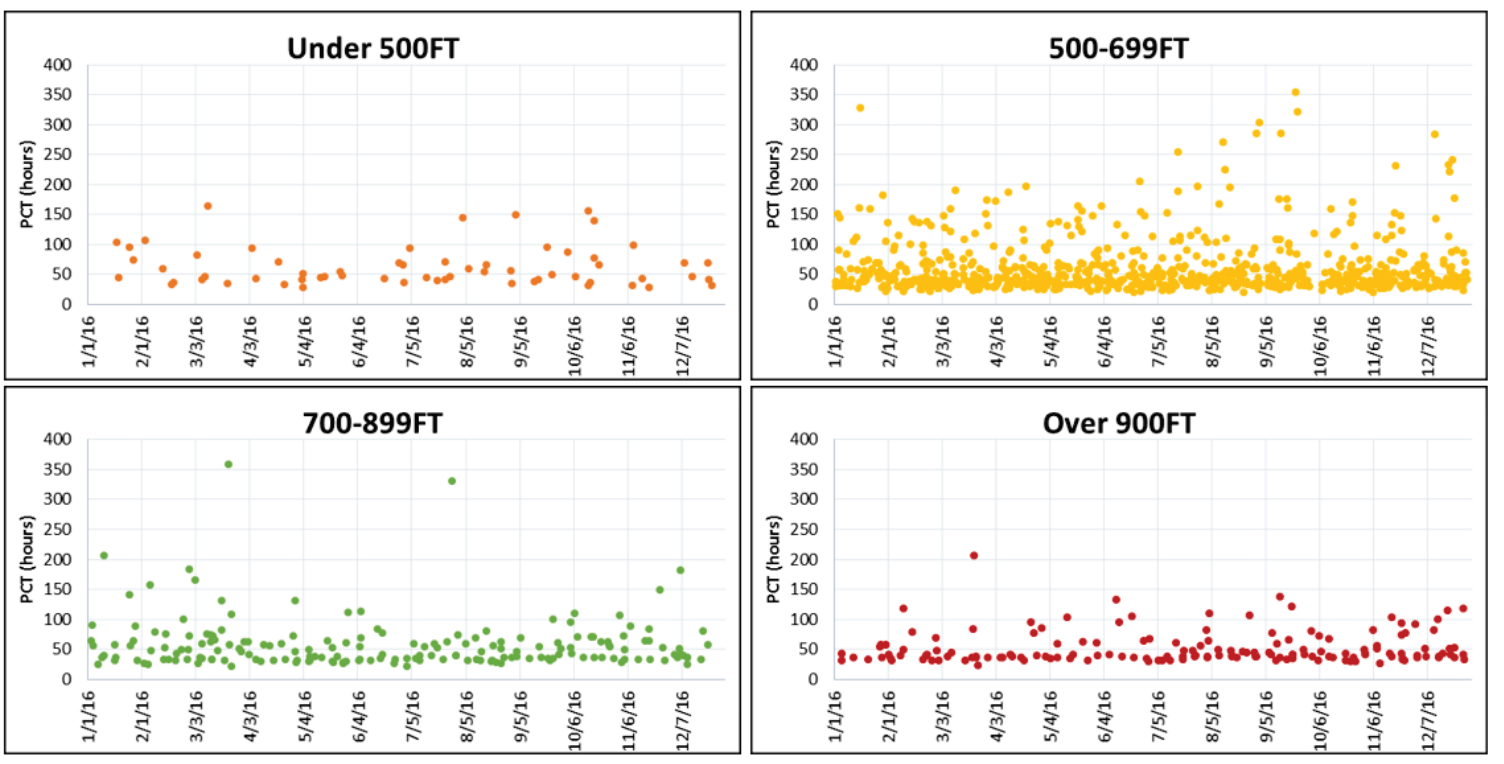


Table 13 shows the number of inbound or outbound trips per each ship-size group. Smaller vessels use the C\&D Canal more often than larger vessels. Only one vessel over $900 \mathrm{ft}$ in length used the $\mathrm{C} \& \mathrm{D}$ canal for an inbound trip

Table 13. Number of trips by vessel size by route.

\begin{tabular}{|l|l|l|l|l|}
\hline \multirow{2}{*}{ Ship Size Group } & \multicolumn{2}{|l|}{ Inbound Path } & \multicolumn{2}{l|}{ Outbound Path } \\
\cline { 2 - 5 } & CD-In & VB-In & CD-Out & VB-Out \\
\hline Under $500 \mathrm{ft}$ & 25 & 37 & 11 & 51 \\
\hline $500-699 \mathrm{ft}$ & 106 & 643 & 174 & 575 \\
\hline $700-899 \mathrm{ft}$ & 10 & 174 & 18 & 166 \\
\hline Over $900 \mathrm{ft}$ & 1 & 154 & 0 & 155 \\
\hline
\end{tabular}

Table 14 shows PCT performance measures by route and vessel size. As observed in the previous scatter plots, the largest ships (over $900 \mathrm{ft}$ in length) have small TTI and PTI values. The VB-In-VB-Out route TTI of the largest group is 1.12, which means that, on average, the PCT trip takes only $12 \%$ longer to complete than the baseline trip. The PTI for the VB-In-VBOut route for the most populated vessel size group (500-699 ft) is 2.57, which means that a vessel 500-699 ft in length must allow at least $157 \%$ extra time above the baseline travel time to ensure it will exit the port on time $80 \%$ of the time. Comprehensive performance measure calculations for HSH, TTIB, and TTOB can be found in Appendix B.

Table 14. PCT performance measures by route and vessel size.

\begin{tabular}{|c|c|c|c|c|c|c|}
\hline \multirow{2}{*}{$\begin{array}{l}\text { PCT Route } \\
\text { Code* }\end{array}$} & \multirow[b]{2}{*}{ Vessel Size } & \multicolumn{2}{|c|}{ Travel Time } & \multirow{2}{*}{$\begin{array}{l}\text { TI } \\
\text { Median/25th } \\
\text { Percentile }\end{array}$} & \multirow{2}{*}{$\begin{array}{l}\text { PTI } \\
80^{\text {th }} / 25^{\text {th }} \\
\text { Percentile }\end{array}$} & \multirow[b]{2}{*}{$\begin{array}{l}\text { Number of } \\
\text { Trips }\end{array}$} \\
\hline & & Mean & Median & & & \\
\hline \multirow{5}{*}{$\begin{array}{l}\text { VB-In-VB- } \\
\text { Out }\end{array}$} & Total & 64.1 & 47.9 & 1.34 & 2.29 & 822 \\
\hline & Under $500 \mathrm{ft}$ & 75.3 & 66.5 & 1.43 & 2.12 & 31 \\
\hline & $500-699 \mathrm{ft}$ & 67.5 & 50.5 & 1.44 & 2.57 & 479 \\
\hline & $700-899 \mathrm{ft}$ & 63.1 & 48.4 & 1.43 & 2.21 & 158 \\
\hline & Over $900 \mathrm{ft}$ & 52.0 & 40.5 & 1.12 & 1.87 & 154 \\
\hline \multirow{4}{*}{$\begin{array}{l}\text { VB-In-CD- } \\
\text { Out }\end{array}$} & Total & 50.1 & 40.2 & 1.17 & 1.77 & 186 \\
\hline & Under $500 \mathrm{ft}$ & 64.2 & 51.8 & 1.12 & 2.05 & 6 \\
\hline & $500-699 \mathrm{ft}$ & 49.9 & 39.8 & 1.18 & 1.80 & 164 \\
\hline & $700-899 \mathrm{ft}$ & 47.1 & 47.0 & 1.32 & 1.72 & 16 \\
\hline
\end{tabular}




\begin{tabular}{|c|c|c|c|c|c|c|}
\hline \multirow{2}{*}{$\begin{array}{l}\text { PCT Route } \\
\text { Code* }\end{array}$} & \multirow{2}{*}{ Vessel Size } & \multicolumn{2}{|c|}{ Travel Time } & \multirow{2}{*}{$\begin{array}{l}\text { TाI } \\
\text { Median/25th } \\
\text { Percentile }\end{array}$} & \multirow{2}{*}{$\begin{array}{l}\text { PTI } \\
80^{\text {th }} / 25^{\text {th }} \\
\text { Percentile }\end{array}$} & \multirow[b]{2}{*}{$\begin{array}{l}\text { Number of } \\
\text { Trips }\end{array}$} \\
\hline & & Mean & Median & & & \\
\hline \multirow{5}{*}{$\begin{array}{l}\text { CD-In-VB- } \\
\text { Out }\end{array}$} & Total & 46.7 & 39.5 & 1.22 & 1.74 & 125 \\
\hline & Under $500 \mathrm{ft}$ & 47.8 & 41.3 & 1.26 & 1.68 & 20 \\
\hline & $500-699 \mathrm{ft}$ & 46.4 & 39.5 & 1.21 & 1.65 & 96 \\
\hline & $700-899 \mathrm{ft}$ & 45.6 & 29.0 & 1.04 & 2.62 & 8 \\
\hline & Over $900 \mathrm{ft}$ & 57.1 & 57.1 & 1.00 & 1.00 & 1 \\
\hline \multirow{4}{*}{$\begin{array}{l}\text { CD-In-CD- } \\
\text { Out }\end{array}$} & Total & 53.7 & 37.3 & 1.51 & 2.65 & 17 \\
\hline & Under $500 \mathrm{ft}$ & 51.3 & 44.2 & 1.19 & 1.87 & 5 \\
\hline & $500-699 \mathrm{ft}$ & 57.8 & 35.1 & 1.57 & 4.85 & 10 \\
\hline & $700-899 \mathrm{ft}$ & 39.2 & 39.2 & 1.84 & 2.69 & 2 \\
\hline
\end{tabular}

* CD: C\&D route; VB: Virginia Beach (Chesapeake Bay) route.

\subsection{C\&D canal analysis - effect of pilot restrictions}

Many federally maintained waterways are subjected to operational restrictions imposed by the local pilot associations due to navigation safety concerns. In addition to specifying the maximum vessel dimensions and sailing draft for individual ships transiting a waterway, these constraints may also apply to the combined dimensions of vessels passing under two-way traffic conditions. According to direct correspondence with the Association of Maryland Pilots (2019), the following restrictions applied to all vessels going through the C\&D Canal in 2016 and are still in place:

1. Maximum permitted sailing draft in the canal is $33.5 \mathrm{ft}$.

2. The combined beam of passing ships cannot exceed $165 \mathrm{ft}$.

Challenges presented by validating the sailing drafts of vessels underway against the draft field entries broadcast via AIS messages make it difficult to identify occurrences of vessel transits being prohibited due to exceedance of the maximum draft. Furthermore, since these restrictions on waterway traffic operations are publicized by the pilots and known to marine vessel operators, any such draft-exceedance events would seemingly indicate a straightforward case of error, misunderstanding, or communications breakdown on the part of said operators. In contrast, the second restriction defined above pertaining to the combined beams of (two-way traffic) passing vessels represents at least a somewhat random constraint in that it may be invoked at any time depending on prevailing 
traffic conditions. The lead times for invoking these restrictions are not sufficiently long to give vessel operators many options that do not cause at least some disruptive effect on normal operations, with the worst case being to simply wait out the waterway closure event and incurring the associated delay costs. Among the many promising research avenues enabled by AIS data, the ability to isolate and measure the prevalence of two-way combined vessel dimension restrictions represents a significant step forward for evaluating the overall levels of service provided by the as-built dimensions of federally authorized navigation channels. This study demonstrates the use of AIS data for an initial evaluation of said restrictions along the C\&D Canal.

\subsubsection{Case 1: Some outbound trips are blocked by wide inbound vessels}

Figure 17 illustrates a situation where an inbound ship with large beam (IB2 in the figure) is moving along the canal. Some outbound ships with large beam ( $\mathrm{OB}_{3}$ or $\left.\mathrm{OB}_{4}\right)$ are blocked because the sum of the two vessels' beams is greater than $165 \mathrm{ft}$ while the other outbound ships (OB1 or OB2) are free to travel along the canal because their combined beam is not large enough to exceed $165 \mathrm{ft}$ when summed with the IB2 beam. In the following analysis, only the potentially conflicting trips were counted to observe the effect of Restriction 2. It is assumed that by this point, the vessels have departed the harbor area ( $\left.\mathrm{TP}_{7}\right)$ and have planned a course through the C\&D Canal. 
Figure 17. Illustration of Case 1: Outbound trips are blocked by wide inbound vessels.

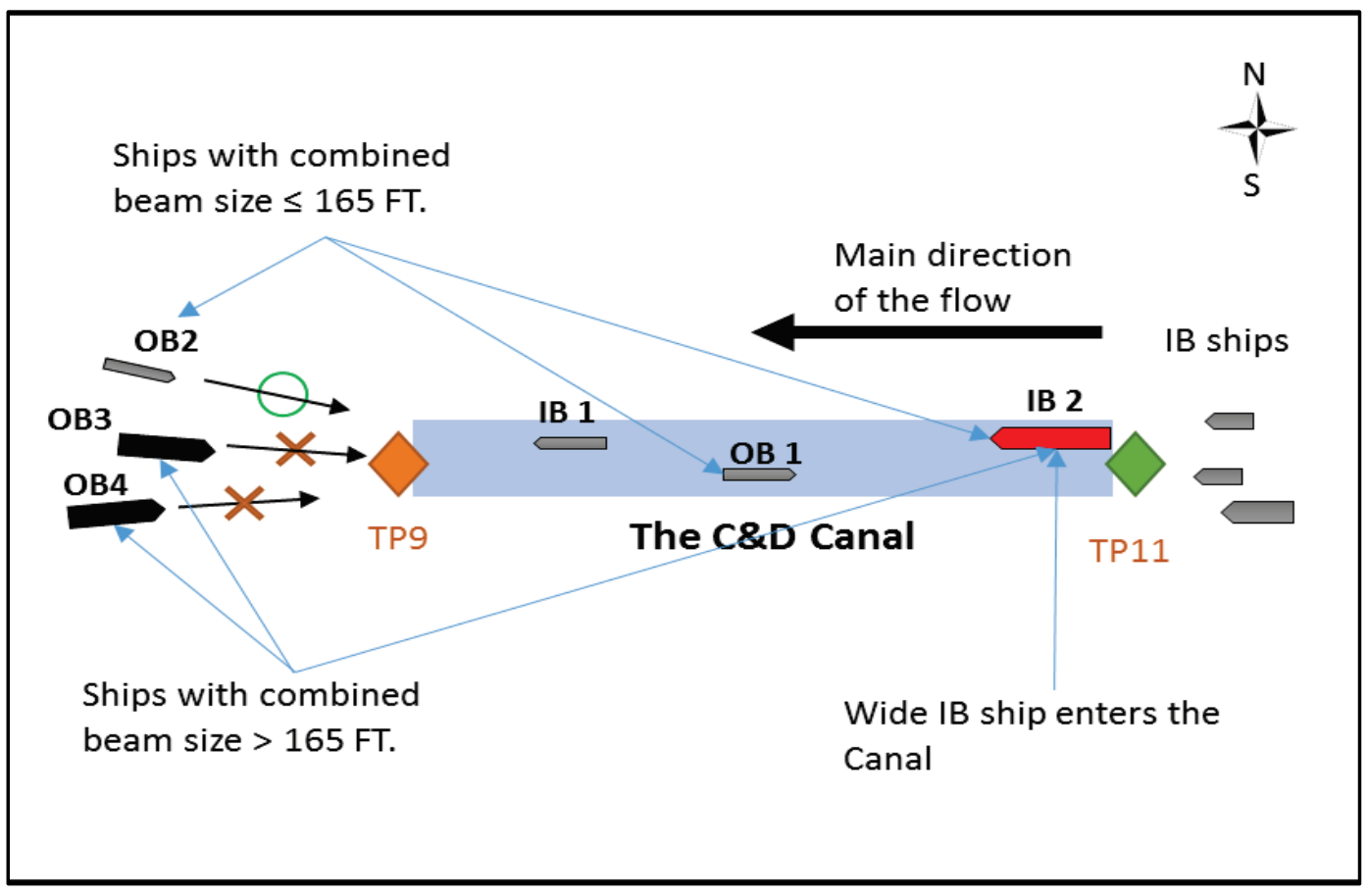

Examination of what happens immediately preceding the entrance of an inbound vessel with large beam into the canal-at which time the channel is restricted for trips that exceed the combined beam limitation-is shown in Figure 18. This Figure 18 shows the number of possible conflicting outbound trips that entered the C\&D Canal in the $10 \mathrm{hr}$ preceding the time at which the channel is restricted. An important nuance to this analysis is that a whether or not a ship would be considered wide enough to block the channel is dependent on the size of oncoming traffic. The proportions of many, but not all, ocean-going vessels include a beam close to or over 82.5 ft. Examples of vessels that called at the Port of Baltimore in 2016 include cargo ship Clipper New York (length $472.4 \mathrm{ft}$, beam 72.2ft), cargo ship Atlantic Star (length $971.1 \mathrm{ft}$, beam $124.7 \mathrm{ft}$ ), tanker ship Chemical Pioneer (length $685.7 \mathrm{ft}$, beam $98.4 \mathrm{ft}$ ), and tanker ship Griya Flores (length $255.9 \mathrm{ft}$, beam $39.4 \mathrm{ft}$ ). Table 12 shows the distribution of ship type and ship size for the trips examined in this analysis, the largest share (65\%) fell in the 500-699 $\mathrm{ft}$ length range.

The chart in Figure 18 shows a noticeable peak at 3 to $4 \mathrm{hr}$ and 4 to $5 \mathrm{hr}$ before the canal is restricted. Considering the average transit time to pass the C\&D Canal is $3 \mathrm{hr}$, the peak traffic may be due to rush of outbound ships before the canal is restricted by the incoming vessel with a large beam. It might also be influenced by land-based scheduling factors. 
Figure 18. Hourly outbound trips before the canal is blocked.

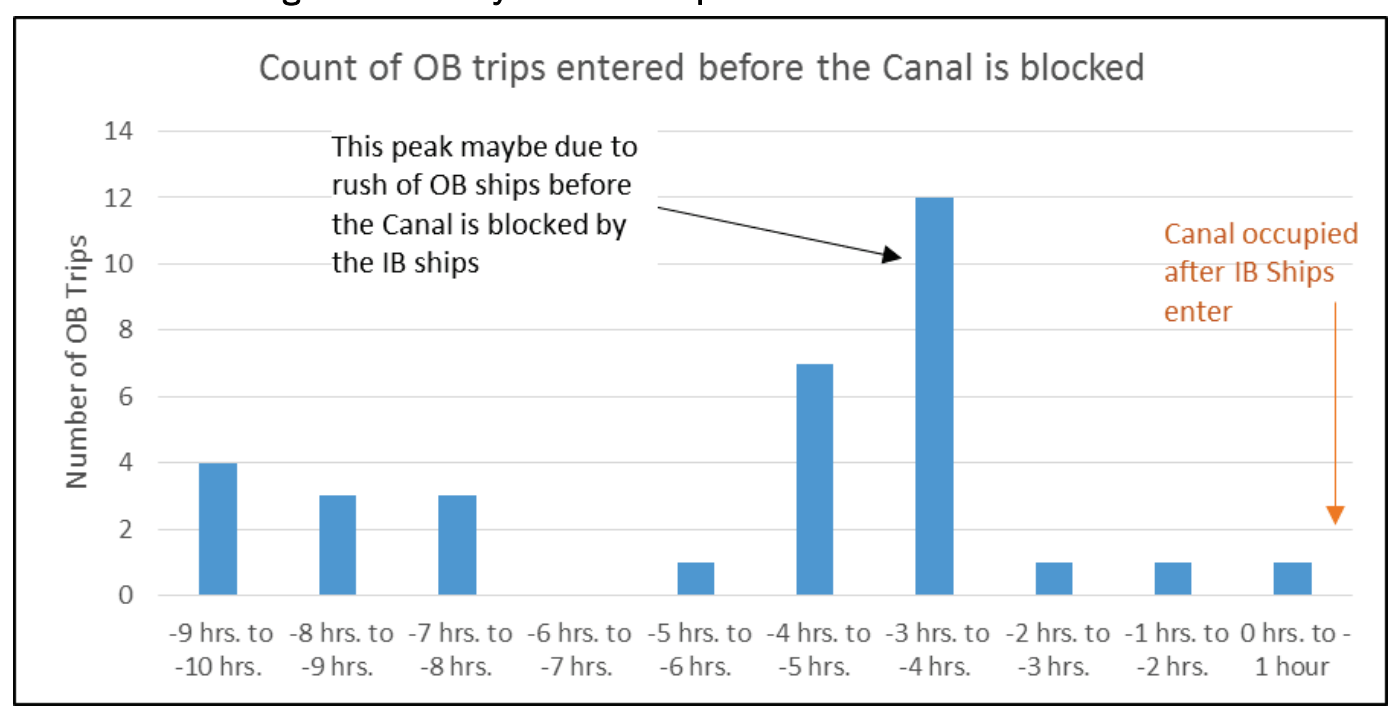

\subsubsection{Case 2: Canal is freed when inbound vessel exits the canal.}

This case focuses on the hours after wide inbound vessels exit the canal at TP9. Figure 19 illustrates the situation where an inbound ship with wide beam (IB1) exits and the canal is freed. In the following analysis, only the potentially conflicting trips such as $\mathrm{OB}_{3}$ and $\mathrm{OB} 4$ with wide beam were counted to see the effect of Restriction 2.

Figure 19. Illustration of Case 2: Canal is freed when inbound vessel exits the canal.

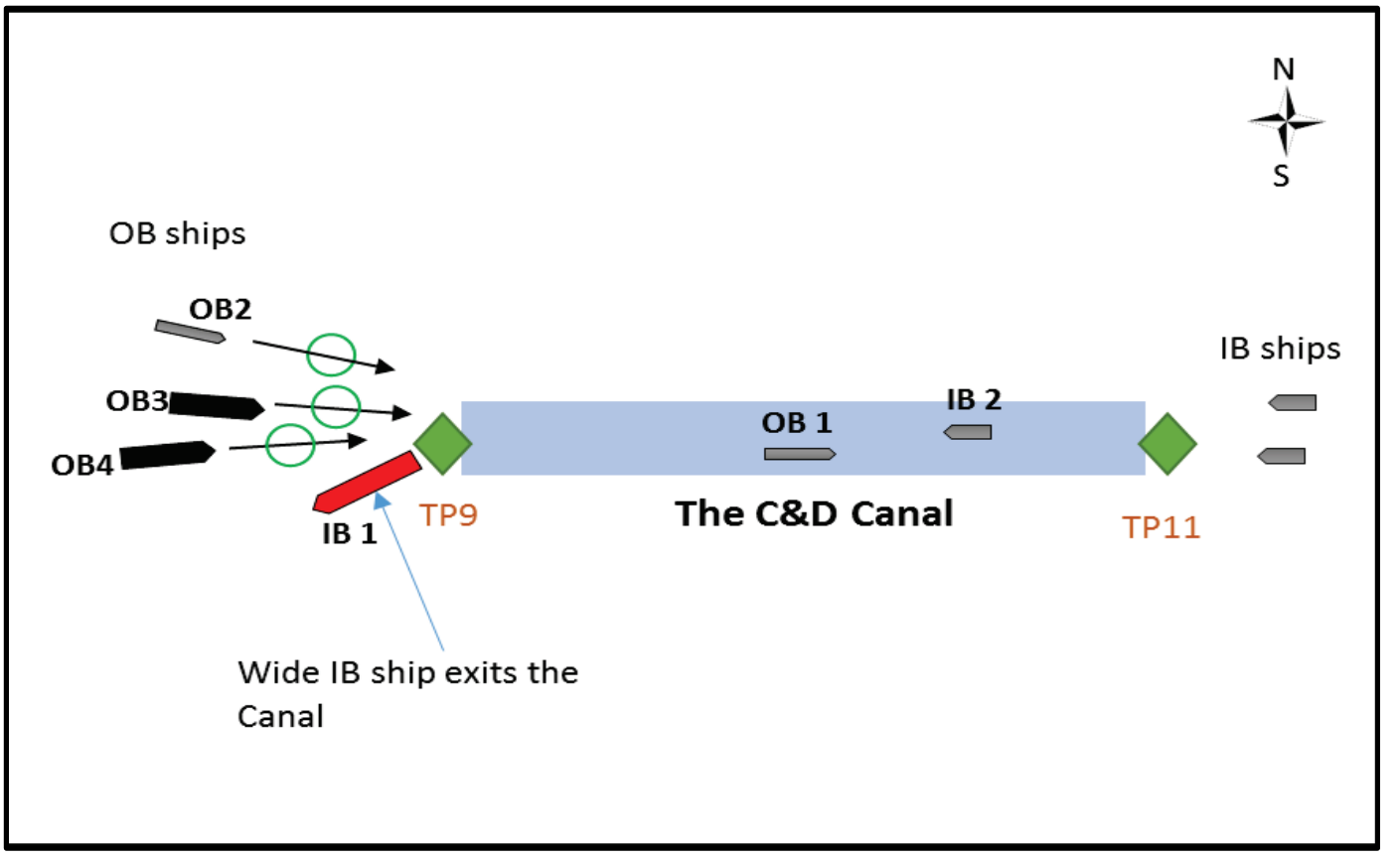


Figure 20 shows the number of outbound trips by hour starting at the time the C\&D Canal is freed. In the chart, time zero is the point at which the wide ship exits the canal at TP9 toward the Port of Baltimore and the canal is freed. If there is a queue of outbound wide vessels waiting to move past TP9 until the incoming wide vessel arrives and exits TP9, the number of outbound vessels during the first hour (i.e., o hr to $1 \mathrm{hr}$ ) would be higher than usual traffic. However, the number of trips during the first hour is five and two trips for the second hour. They are within the usual variability of the counts during the $10 \mathrm{hr}$ sample period. From the observation shown in Figure 20, it is not clear whether the vessels are waiting in queue before TP9 or not.

Figure 20. Count of outbound trips after the canal is freed.

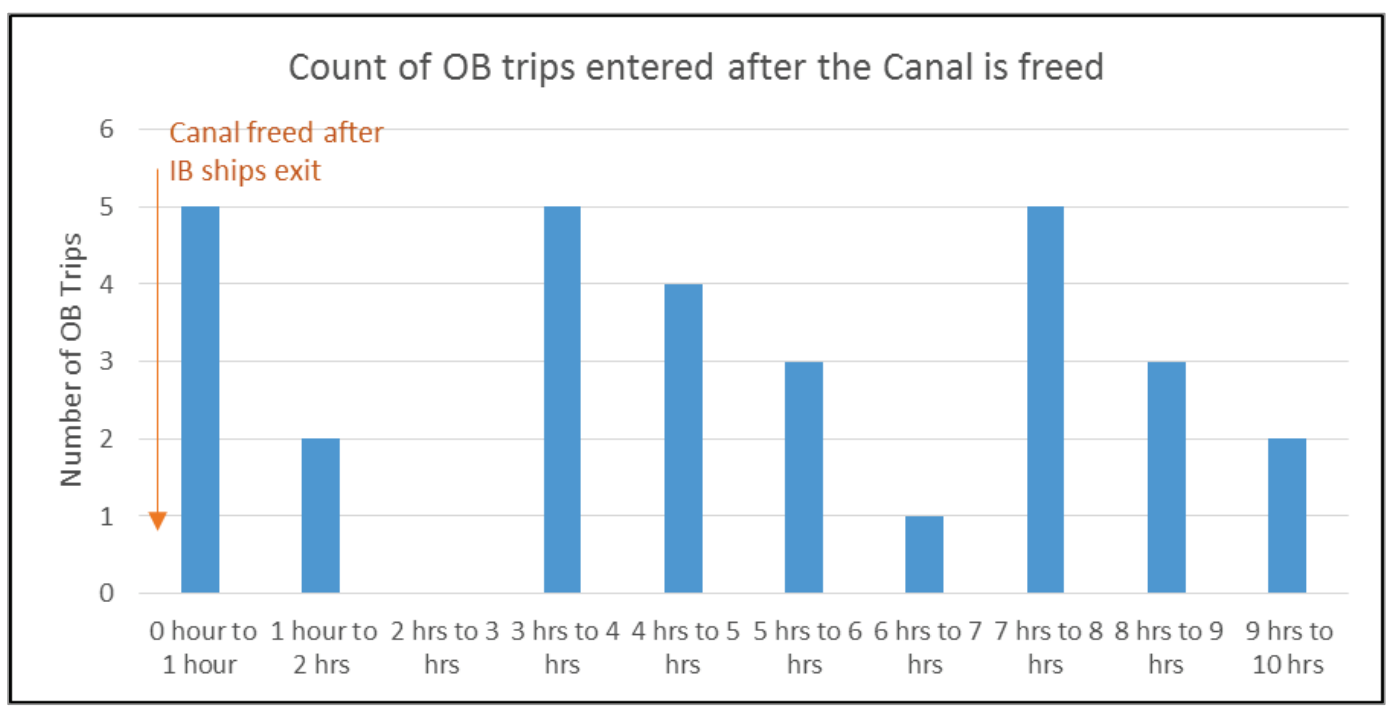

\subsubsection{Case 3: Inbound trips are blocked by wide outbound vessels.}

Case 3 is the reverse of Case 1. Figure 21 illustrates the situation where an outbound ship with large beam (OB2) is moving along the canal. Some inbound ships with large beam (IB4 or IB5) are blocked because the sum of the two vessels' beams is greater than $165 \mathrm{ft}$ while the other inbound ships (IB1 - IB3) are free to travel along the canal because their combined beam is not large enough to exceed $165 \mathrm{ft}$ when summed with the OB2 beam. In the following analysis, only the potentially conflicting trips were counted to see the effect of Restriction 2. 
Figure 21. Illustration of Case 3: Inbound trips are blocked by wide outbound vessels.

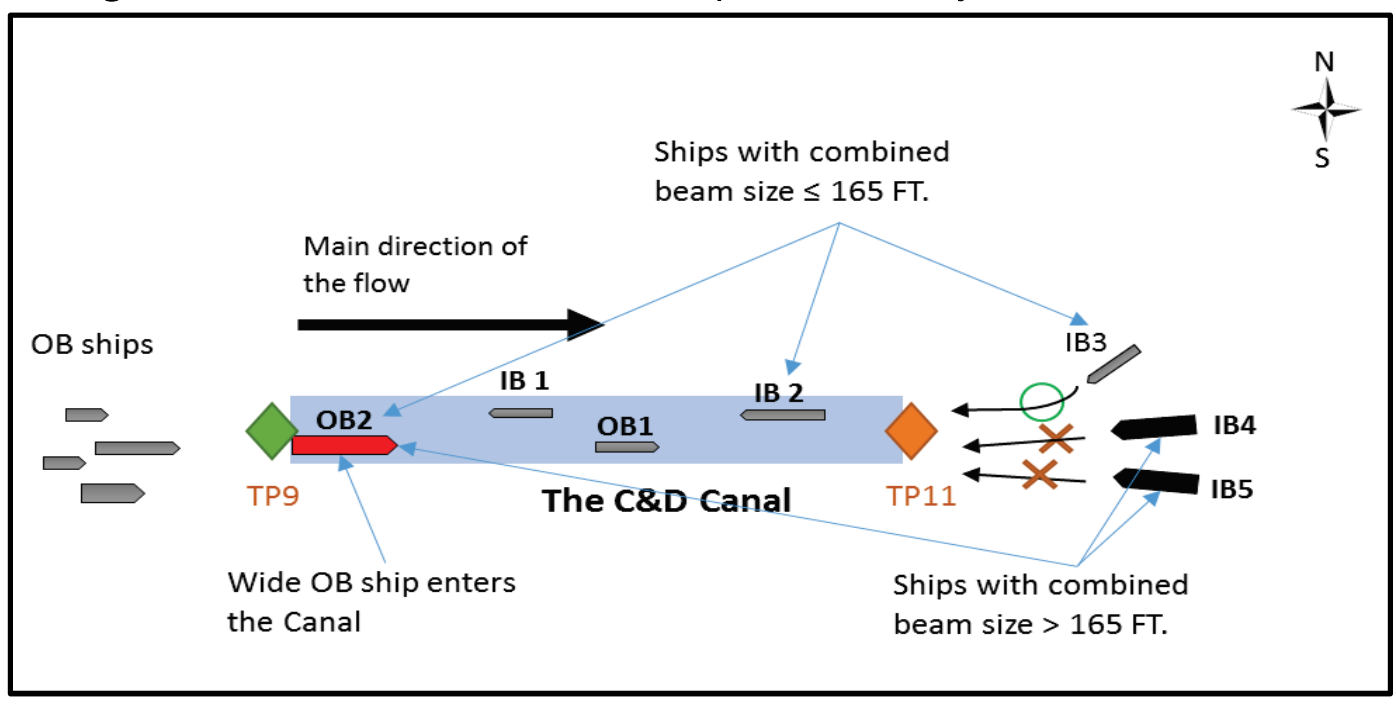

Figure 22 shows the number of possible conflicting inbound trips that entered the C\&D Canal in the $10 \mathrm{hr}$ preceding the time at which the channel is restricted by a wide outbound vessel. Like Case 1, the chart shows a noticeable peak at 3 to $4 \mathrm{hr}$ before the canal is blocked. However, Case 3 has more conflicting trips within the $3 \mathrm{hr}$ time frame. These results could be subject to further detailed analysis to determine whether vessels are using the midway holding area to cross or if the results were due to errors in the original data.

Figure 22. Count of inbound (IB) trips before the canal is blocked.

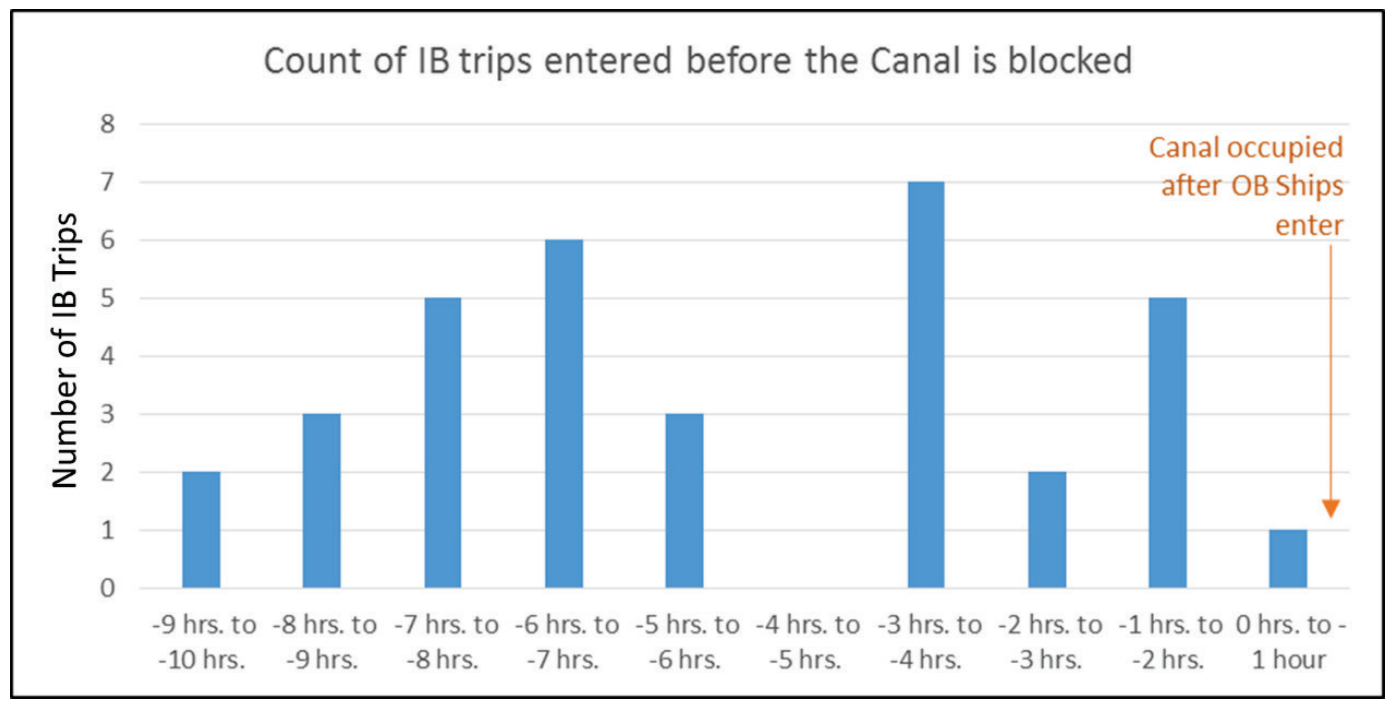




\subsubsection{Case 4: Canal is freed when outbound vessel exits the canal.}

Case 4 is the reverse of Case 2. This case focuses on the hours after wide outbound vessels exit the canal at TP11. Figure 23 illustrates the situation where an outbound ship with wide beam (OB1) exits and the canal is freed for inbound vessels. In the following analysis, the conflicting trips such as IB4 and IB5 with wide beam were counted to see the effect of Restriction 2.

Figure 23. Illustration of Case 4: Canal is freed when outbound vessel exits the canal.

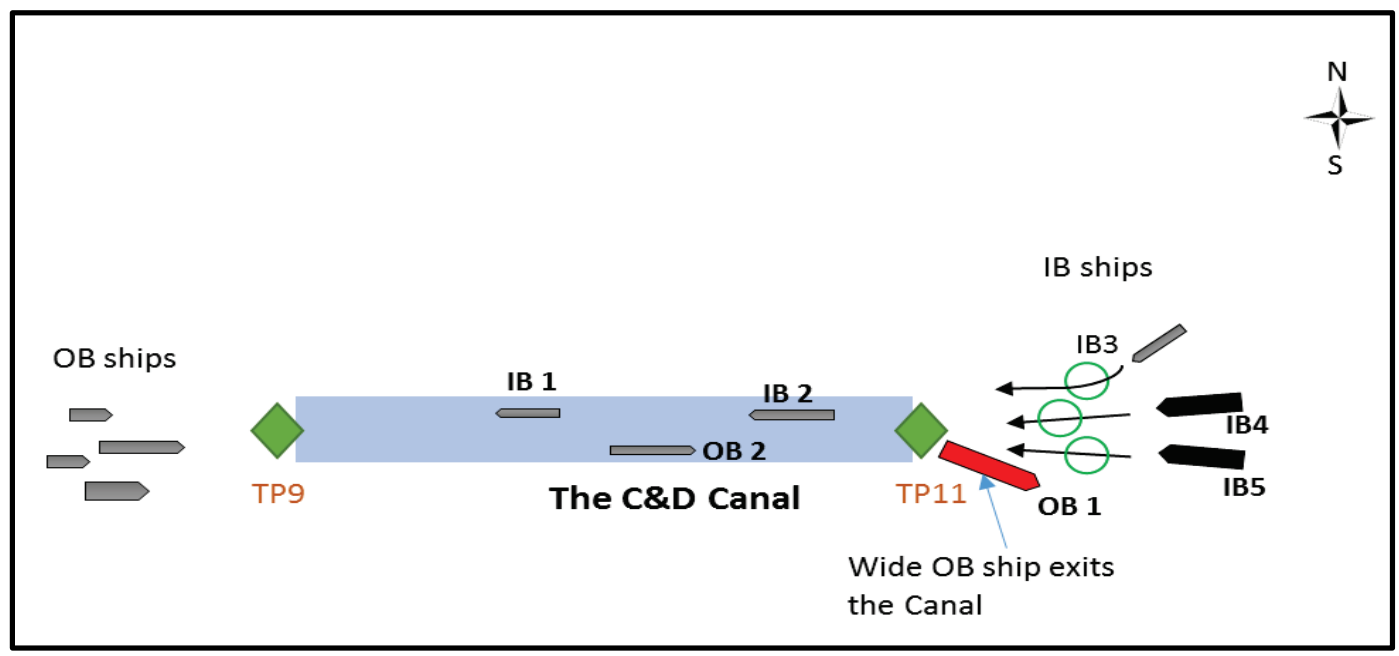

Figure 24 shows the number of inbound trips by hour starting at the time the C\&D Canal is reopened for normal traffic. If there is a queue of inbound wide vessels waiting outside TP11 until the outgoing wide vessel exits TP11, the number of inbound vessels during the first hour (i.e., o hr to $1 \mathrm{hr}$ ) would be higher than usual traffic. The chart shows a noticeable peak at $\mathrm{o}$ to $1 \mathrm{hr}$ after the canal is opened for inbound traffic. The peak traffic may be due to the number of vessels waiting outside TP11. Comparing Case 2 and Case 4, it seems incoming vessels are more prone to wait before they enter the C\&D Canal than outgoing vessels. However, this observation is based on a single year of data and would benefit from repeat analysis across additional years. Additional consideration of schedule differences between vessel types might reveal further patterns, or whether waiting at an anchorage impacts the expected transit schedule. 
Figure 24. Count of IB trips after the canal is freed.

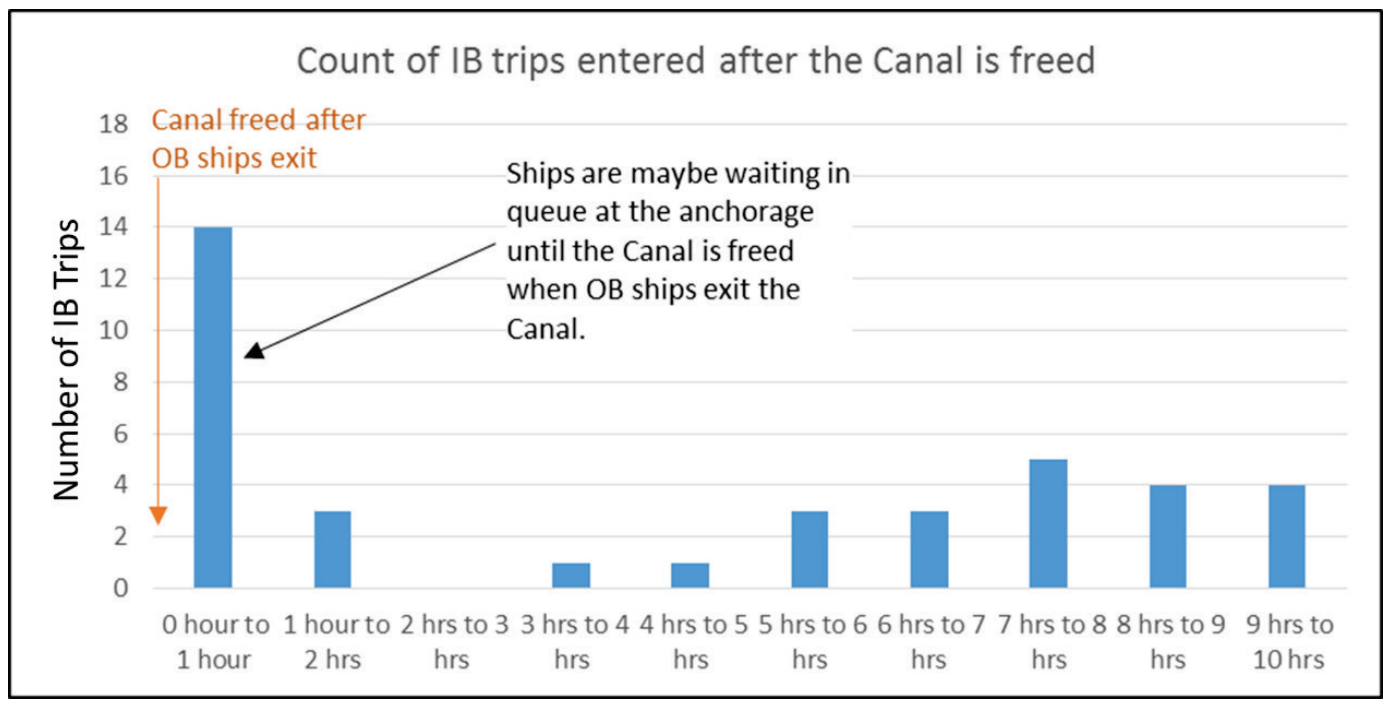




\section{Conclusions and Recommendations}

\subsection{Conclusions}

The development of maritime mobility metrics supports the USACE navigation mission by providing quantitative insights into how commercial vessels are utilizing navigation infrastructure such as channels and anchorages. The study presents multiple metrics that can be derived from AIS vessel position data and are in keeping with the standards commonly used in metrics for surface transportation. The PCT, HSH, TTIB, and TTOB measures presented in this report have parallel measures that are widely used in roadway analysis but are less commonly applied in a maritime context.

This study also demonstrates the use of AIS to evaluate the frequency and duration of delay events caused by pilot restrictions on the combined dimensions of vessels passing in a two-way traffic scenario. Though future work is needed to directly attribute observed vessel delays to restrictionbased closure events, the approach documented here nonetheless shows promise for measuring the true impacts of this and similar vessel traffic restrictions nationwide. Robust treatments across many months or even years of traffic conditions was not possible prior to the advent of AIS data for archiving vessel traffic patterns.

Highlights of the findings from this analysis of the 2016 AIS data for vessel traffic calling at the Port of Baltimore include the following:

- When plotted by hour of day, there are two distinctive peaks for the number of arrival trips; the highest peak is between 4 a.m. and 6 a.m. and the second peak is between 4 p.m. and 8 p.m.

- Friday shows the smallest number of ship arrivals while Tuesday has the largest.

- The monthly arrival count plot shows a relatively flat trend pattern, although August and March had slightly more arrivals than the other months of the year in 2016.

- The mean travel times are consistent between inbound (VB-In: 11.3, CD-In: $5.6 \mathrm{hr}$ ) and outbound (VB-Out: 10.0, CD-Out: $5.5 \mathrm{hr}$ ), but inbound has much more variation (standard deviation: VB-In: 7.3, CDIn: $0.4 \mathrm{hr}$ ) than outbound travel times (standard deviation: VB-Out 3.3 , CD-Out $0.6 \mathrm{hr}$ ). 
- The large PTI values for PCT and HSH trips are due to the amount of variability in trip times through the system based on differences in cargo types, ship size, dock operations, etc.

- Vehicle carriers account for the largest portion (46\%) of the cargo traffic at the Port of Baltimore.

- The C\&D Canal beam restriction results in an apparent rush of outbound ships $3-4$ hours before the canal is restricted by an inbound vessel (Figure 18).

The Port of Baltimore is unusual in having two separate deep-water approaches to the local entrance channel, both of which offer some protection from the open ocean. While this study indicates that the Chesapeake Bay (VB) route is the most heavily utilized with $71.5 \%$ of included trips using it for both their inbound and outbound travel in the study area, the fact that there are two deep-water routes could provide important redundancy in the event of a channel blockage affecting one of those approaches. However, the AIS-based analysis showed that no container ships used the C\&D Canal, while approximately half of inbound chemical tankers did. The C\&D Canal is crossed by multiple bridges, and the required vertical clearance (known as air gap or air draft) could restrict vessels from using that route regardless of draft. The key finding from this analysis is that the majority of variability in overall PCT is due to the variability in $\mathrm{HSH}$, not from associated channel conditions or channel restrictions.

Comparison of the AIS data to additional data sources indicated that AIS records are complete in that they account for $98 \%$ of the trips in the Vessel Entrances and Clearances database provided by the U.S. Customs and Border Protection (CBP) - an official record of vessels that cleared U.S. Customs. One caution in relying solely on AIS data for all information about physical characteristics and ship type is that there are discrepancies in vessel characteristics provided via AIS as compared to those published by well-established sources such as LR. Thus, this study recommends using a supplemental vessel characteristic database when analyzing AIS data.

\subsection{Recommendations}

Research on the topic of maritime performance measures will continue; this will serve the national interest and support the broad sectors of the economy which rely on marine transportation for their supply chains. Quantifying transportation delay associated with specific elements of 
waterborne transportation infrastructure can reveal where investments may reduce costs to the nation. Additional case studies from other areas of the United States, especially those in different geographical areas, could provide insights into locally significant travel patterns that may impact navigation infrastructure maintenance planning. Research into freight fluidity that combines multiple modes (e.g., road and water) and geospatial scales is also of interest to a wide variety of national, state, and local freight transportation stakeholders such as the State of Maryland (Eisele et al. 2016). Future research efforts should consider these topics. 


\section{References}

Association of Maryland Pilots. 2019. The Association of Maryland Pilots: Homepage. http://marylandpilots.com/

Caltrans. 2021. Caltrans Traffic Cameras. Accessed 4 February 2021. https://cwwp2.dot.ca.gov/tools/cctvmobile.htm

DiJoseph, P. K., and K. N. Mitchell. 2015. "Estimating Vessel Travel Time Statistics for Inland Waterways with Automatic Identification System Data." Transportation Research Board Annual Meeting Compendium of Papers. Washington, DC: Transportation Research Board.

Dijoseph, P. K., K. N. Mitchell, B. J. Tetreault, and J. Marshall. 2019. Inland Marine Transportation System Travel Time Atlas via Automatic Identification System (AIS) Data: Ohio River, Upper Mississippi River, and Illinois River. ERDC/CHL TR-19-15. Vicksburg, MS: US Army Engineer Research and Development Center. http://chl.erdc.usace.army.mil

Eastern Transportation Coalition. 2021. I-95 Live Traffic View. Accessed 4 February 2021. https://tetcoalition.org/trafficview/

Eisele, W. L., L. P. Tardif, J. C. Villa, D. L. Schrank, and T. Lomax. 2011. "Evaluating global freight corridor performance for Canada." Journal of Transportation of the Institute of Transportation Engineers 1(1): 39-57. https://rosap.ntl.bts.gov/view/dot/20419/dot_20419_DS1.pdf?\#page=45

Eisele, W. L., R. M. Juster, K. F. Sadabadi, T. Jacobs, and S. Mahapatra. 2016. "Implementing Freight Fluidity in the State of Maryland." Transportation Research Record 2548(1): 62-70. https://doi.org/10.3141/2548-08

Farhadi, N., S. A. Parr, K. N. Mitchell, and B. Wolshon. 2016. "Use of Nationwide Automatic Identification System Data to Quantify Resiliency of Marine Transportation Systems.” Transportation Research Record 2549(1): 9-18. https://doi.org/10.3141/2549-02

IALA. 2008. Establishment of AIS as An Aid to Navigation: Report ID. International Association of Marine Aids to Navigation and Lighthouse Authorities. 1062. https://www.iala-aism.org/product/establishment-of-ais-as an-aid-to-navigation-1062/

IEC. 2001. 2001-12 Maritime Navigation and Radiocommunication Equipment and Systems - Automatic Identification Systems (AIS) - Part 2: Class A Shipborne Equipment of the Universal Automatic Identification System (AIS) - Operational and Performance Requirements, Methods of Test and Required Test Results. EC 61993- 2. International Electrotechnical Commission. https://www.iec.ch/index.htm

INRIX. 2021. INRIX National Traffic Scorecard. Accessed 4 February 2021. http://inrix.com/scorecard/ 
ITU-R. 2014. Recommendation ITU-R M.1371: Technical Characteristics for an Automatic Identification System Using Time Division Multiple Access in the VHF Maritime Mobile Frequency Band. International Telecommunications Union - Radiocommunication Sector. 1019. https://www.itu.int/rec/R -R EC M.1371/en

Kaneria, A., M. Hamidi, W. Zhu and B. Craig. 2019. "Traffic Simulation of Houston Ship Channel for Assessing the Impact of Waterway Closures on Vessel Waiting Time." Journal of Waterway, Port, Coastal, and Ocean Engineering 145(4): 04019014.

Kress, M. M., K. N. Mitchell, P. K. DiJoseph, J. S. Rainey, M. Chambers, J. Hsieh, and W. J. Lillycrop. 2016. Marine Transportation System Performance Measures Research. ERDC-CHL TR-16-8. Vicksburg, MS: US Army Engineer Research and Development Center. https://apps.dtic.mil/dtic/tr/fulltext/u2/1011845.pdf

Kruse, C. J., K. N. Mitchell, P. K. DiJoseph, D. H. Kang, D. L. Schrank, and W. L. Eisele. 2018. "Developing and Implementing a Port Fluidity Performance Measurement Methodology using Automatic Identification System Data." Transportation Research Record 2672(11): 30-40.

Mitchell, K. N., and B. N. Scully. 2014. "Waterway Performance Monitoring via Automatic Identification System (AIS) Data." Transportation Research Record: Journal of Transportation 2426(1): 20-26.

Mitchell, K. N., P. K. DiJoseph, M. Chambers, and M. M. Kress. 2019. Inland Marine Transportation System Fluidity: Case Studies from the Ohio River, Lower Mississippi River, and Gulf Intracoastal Waterway. ERDC-CHL TR-19-21. Vicksburg, MS: US Army Engineer Research and Development Center. https://apps.dtic.mil/sti/pdfs/AD1085137.pdf

NAB (Baltimore District). 2021. Baltimore Harbor \& Channels, MD \& VA. Fact Sheet. February 1, 2021. PDF File. Accessed 17 December 2021. https://usace.contentdm.oclc.org/digital/collection/p16021coll11/id/5121

PIANC. 2019. Guidelines and Recommendations for River Information Services. InCom Working Group Report Number 125/I-2019. Permanent International Association of Navigation Congresses (The World Association for Waterborne Transportation Infrastructure). https://www.pianc.org/publications/inland-navigationcommission/wg125-1

Ports America Chesapeake. 2021. "Seagirt Terminal Information: Gate Hours." Accessed 17 December 2021. https://www.pachesapeake.com/GateHours?Siteld=Seagirt

Roy, U., and X. Wu. 2019. "AIS-Data Based Vessel Traffic's Characteristics and Travel Behaviour Analysis: A Case Study at Houston Ship Channel." Journal of Ocean Technology 14(4): 59-74.

Scully, B., and K. N. Mitchell. 2015. Archival Automatic Identification System (AIS) Data for Navigation Project Performance Evaluation. ERDC/CHL CHETN-IX-4O. Vicksburg, MS: US Army Engineer Research and Development Center. http://chl.erdc.usace.army.mil/chetn

Schrank, D., B. Eisele, and T. Lomax. 2019. 2019 Urban Mobility Report. College Station, TX: The Texas A\&M University System, Texas Transportation Institute. 
Tardif, L-P. 2014. "Fluidity Overview and Implementation: The Canadian Experience." Developing Freight Fluidity Performance Measures: Supply Chain Perspective on Freight System Performance. Transportation Research Circular E-C187. Washington, DC: Transportation Research Board. http://onlinepubs.trb.org/onlinepubs/circulars/ec187.pdf

Touzinsky, K. F., B. M. Scully, K. N. Mitchell, and M. M. Kress. 2018. "Using Empirical Data to Quantify Port Resilience: Hurricane Matthew and the Southeastern Seaboard." J. of Waterway, Port, Coastal, and Ocean Engineering 144(4). https://doi.org/10.1061/(ASCE)WW.1943-5460.0000446

Turnbull, K. F. 2014. Developing Freight Fluidity Performance Measures: Supply Chain Perspective on Freight System Performance. Summary of a Workshop. Transportation Research Circular E-C187. Washington, DC: Transportation Research Board. http://onlinepubs.trb.org/onlinepubs/circulars/ec187.pdf

USACE (US Army Corps of Engineers). 2018. AIS Analysis Package (AISAP). Software package. Vicksburg, MS: US Army Engineer Research and Development Center. https://aisap.usacegis.us/aisap_portal/home.html

USACE. 2020. "Navigation." Washington, DC: Headquarters, US Army Corps of Engineers. http://www.usace.army.mil/Missions/Civil-Works/Navigation/

USACE. 2021. Data for Downloading. Washington, DC: US Army Corps of Engineers, Waterborne Commerce Statistics Center. https://publibrary.planusace.us/\#/series/Data\%20for\%20Downloading

USCG. 2018. Automatic Identification System Overview. Washington DC: US Coast Guard. http://www.navcen.uscg.gov/?pageName=AISmain

US Code of Regulations. 2019. Title 33 - Navigation and Navigable Waters. "Part 164Navigation Safety Regulations.” 33 C.F.R. § 164.46. Washington, DC. https://www.govinfo.gov/content/pkg/CFR-2019-title33-vol2/xml/CFR-2019-title33-vol2part164.xml

USDOT (US Department of Transportation). 2017. Port Performance Freight Statistics Program: Annual Report to Congress 2016. Washington, DC: US Department of Transportation, Bureau of Transportation Statistics.

https://www.bts.gov/archive/publications/port_performance_freight_statistics_annual_report/ $\underline{2016}$

USDOT. 2018. Port Performance Freight Statistics Program: Annual Report to Congress 2017. Washington, DC: US Department of Transportation, Bureau of Transportation Statistics. https://doi.org/10.21949/1502450

USDOT. 2019. Port Performance Freight Statistics Program: Annual Report to Congress 2018. Washington, DC: US Department of Transportation, Bureau of Transportation Statistics. https://rosap.ntl.bts.gov/view/dot/39609

USDOT. 2020. Port Performance Freight Statistics in 2018: Annual Report to Congress 2019. Washington, DC. US Department of Transportation, Bureau of Transportation Statistics. https://rosap.ntl.bts.gov/view/dot/43525 
USDOT. 2021. Port Performance Freight Statistics in 2019: Annual Report to Congress 2020. Washington, DC. US Department of Transportation, Bureau of Transportation Statistics. https://doi.org/10.21949/1520450

Wu, X., A. L. Mehta, V. A. Zaloom, and B. N. Craig. 2016. "Analysis of Waterway Transportation in Southeast Texas Waterway Based on AIS Data." Ocean Engineering 121: 196-209.

Wu, X., A. Rahman, and V. A. Zaloom. 2018. "Study of Travel Behavior of Vessels in Narrow Waterways Using AIS Data-A Case Study in Sabine-Neches Waterways." Ocean Engineering 147: 399-413. 


\section{Appendix A: Arrival Count Plot by Hour by Day of Week}

Figure A-1 presents the arrival count plot by hour by the day of the week.

Figure A-1. Arrival count plot by hour by day of week.

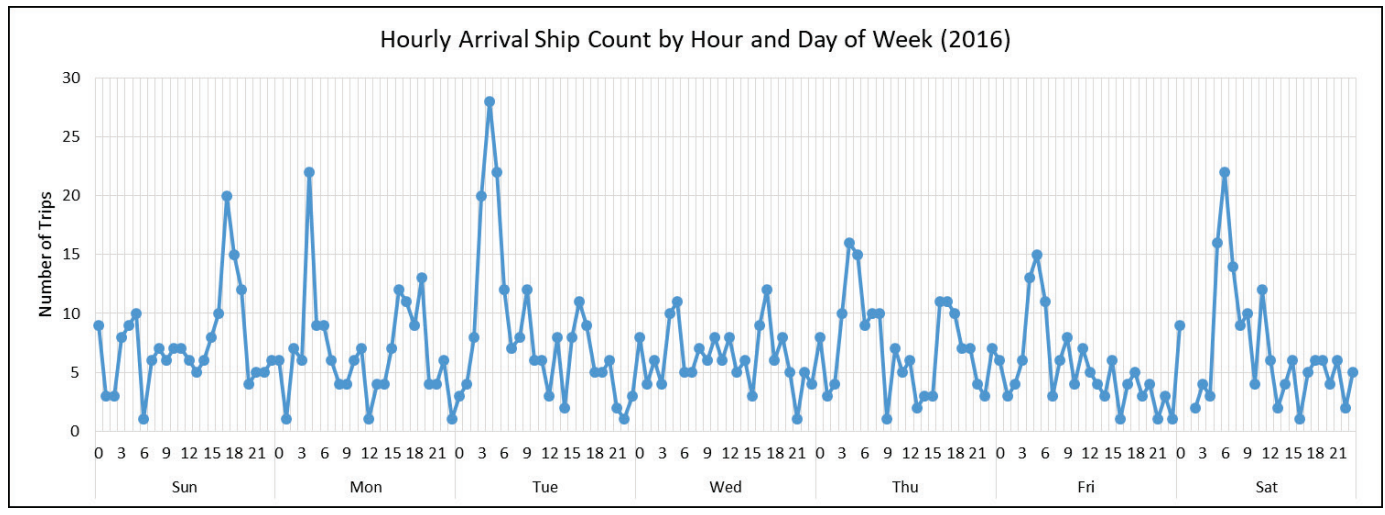




\section{Appendix B: Complete Calculations Results for Output Measures}

Tables B-1 through B-9 present detailed results of calculated measures (PCT, TTIB, TTOB, HSH) in multiple combinations of route, route and vessel type, or route and vessel size.

Figure B-1 presents the monthly average HSH by ship-type group in 2016, and Figure B-2 presents the monthly arrival count by ship-type group across all months of 2016. 
Table B-1. Overall performance measures by route, in hours.

\begin{tabular}{|c|c|c|c|c|c|c|c|c|c|c|c|c|c|c|c|c|}
\hline \multirow[b]{2}{*}{ 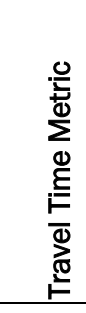 } & \multirow[b]{2}{*}{ 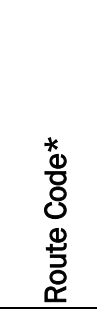 } & \multicolumn{4}{|c|}{ Travel Time Index (TTI) } & \multicolumn{4}{|c|}{ Planning Time Index (PTI) } & \multicolumn{6}{|c|}{ Travel Time (TT) } & \multirow[b]{2}{*}{ 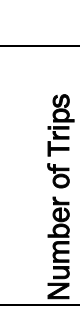 } \\
\hline & & 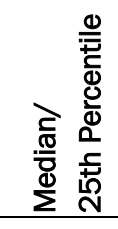 & 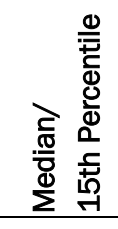 & 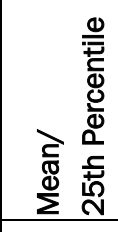 & 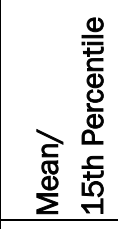 & 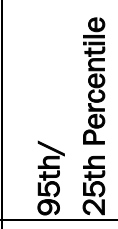 & 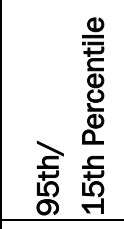 & 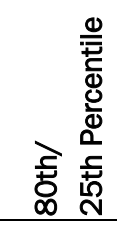 & 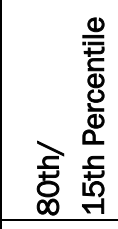 & 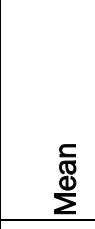 & $\begin{array}{l}\frac{.}{0} \\
\frac{0}{8} \\
\frac{0}{\Sigma}\end{array}$ & 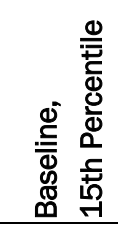 & 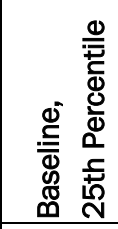 & 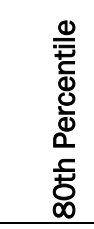 & 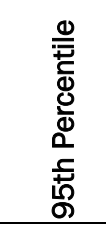 & \\
\hline \multirow{4}{*}{ РCT } & $\begin{array}{l}\text { CD-In } \\
\text { - CD- } \\
\text { Out }\end{array}$ & 1.51 & 1.68 & 2.17 & 2.42 & 6.61 & 7.38 & 2.65 & 2.96 & 53.7 & 37.3 & 22.2 & 24.8 & 65.6 & 163.7 & 17 \\
\hline & $\begin{array}{l}\text { CD-Int } \\
\text { - VB- } \\
\text { Out }\end{array}$ & 1.22 & 1.38 & 1.44 & 1.63 & 3.17 & 3.58 & 1.74 & 1.97 & 46.7 & 39.5 & 28.7 & 32.4 & 56.5 & 102.7 & 125 \\
\hline & $\begin{array}{l}\text { VB-In } \\
- \text { CD- } \\
\text { Out }\end{array}$ & 1.17 & 1.35 & 1.46 & 1.68 & 3.05 & 3.53 & 1.77 & 2.04 & 50.1 & 40.2 & 29.8 & 34.4 & 60.8 & 105.1 & 186 \\
\hline & $\begin{array}{l}\text { VB-In } \\
\text { - VB- } \\
\text { Out }\end{array}$ & 1.34 & 1.48 & 1.79 & 1.98 & 4.39 & 4.85 & 2.29 & 2.53 & 64.1 & 47.9 & 32.3 & 35.8 & 81.8 & 156.8 & 822 \\
\hline \multirow{2}{*}{ TTIB } & $C D$ & 1.05 & 1.06 & 1.06 & 1.08 & 1.22 & 1.24 & 1.13 & 1.14 & 5.6 & 5.6 & 5.3 & 5.3 & 6.0 & 6.5 & 139 \\
\hline & VB & 1.06 & 1.08 & 1.27 & 1.30 & 2.38 & 2.43 & 1.25 & 1.28 & 11.3 & 9.4 & 8.8 & 8.9 & 11.2 & 21.2 & 980 \\
\hline \multirow{2}{*}{ ТТОВ } & $C D$ & 1.07 & 1.08 & 1.07 & 1.09 & 1.25 & 1.28 & 1.11 & 1.13 & 5.5 & 5.4 & 5.0 & 5.1 & 5.7 & 6.4 & 200 \\
\hline & VB & 1.05 & 1.07 & 1.14 & 1.17 & 1.59 & 1.62 & 1.22 & 1.25 & 10.0 & 9.2 & 8.6 & 8.8 & 10.7 & 13.9 & 919 \\
\hline $\mathrm{HSH}$ & All & 1.48 & 1.83 & 2.17 & 2.68 & 6.17 & 7.61 & 2.79 & 3.45 & 37.3 & 25.4 & 13.9 & 17.2 & 48.0 & 105.9 & 1125 \\
\hline
\end{tabular}

* CD: C\&D Canal route, VB: Virginia Beach (Chesapeake Bay) Route

PCT: Port Cycle Time

TTIB: Travel Time Inbound

TTOB: Travel Time Outbound

HSH: Harbor Stay Hours 
Table B-2. PCT performance measures by route and vessel type, in hours.

\begin{tabular}{|c|c|c|c|c|c|c|c|c|c|c|c|c|c|c|c|c|}
\hline \multirow[b]{2}{*}{$\begin{array}{l}\text { PCT Route } \\
\text { Code* }\end{array}$} & \multirow[b]{2}{*}{ Vessel Type } & \multicolumn{5}{|c|}{ Travel Time Index } & \multicolumn{4}{|c|}{ Planning Time Index } & \multicolumn{5}{|c|}{ Travel Time } & \multirow[b]{2}{*}{ 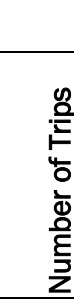 } \\
\hline & & 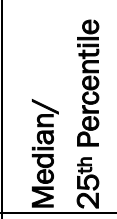 & 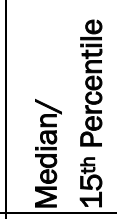 & 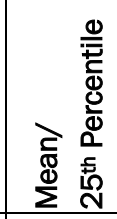 & 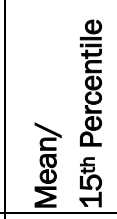 & 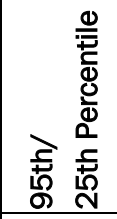 & 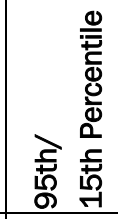 & 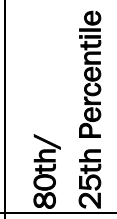 & 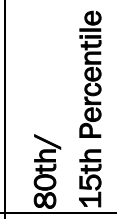 & $\stackrel{\mathbb{\Phi}}{\stackrel{\complement}{\Sigma}}$ & $\begin{array}{l}\frac{.}{\sigma} \\
\overline{\frac{\sigma}{\sigma}} \\
\Sigma\end{array}$ & 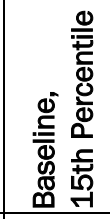 & 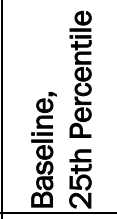 & 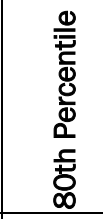 & 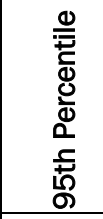 & \\
\hline \multirow{6}{*}{ CD-In-CD-Out } & Total & 1.51 & 1.68 & 2.17 & 2.42 & 6.61 & 7.38 & 2.65 & 2.96 & 53.7 & 37.3 & 22.2 & 24.8 & 65.6 & 163.7 & 17 \\
\hline & Chemical & 1.00 & 1.00 & 1.00 & 1.00 & 1.00 & 1.00 & 1.00 & 1.00 & 163.7 & 163.7 & 163.7 & 163.7 & 163.7 & 163.7 & 1 \\
\hline & \begin{tabular}{|l|} 
General \\
Cargo Ship
\end{tabular} & 1.56 & 2.17 & 1.69 & 2.36 & 2.95 & 4.12 & 2.95 & 4.12 & 86.7 & 79.5 & 36.7 & 51.1 & 150.9 & 150.9 & 4 \\
\hline & Other & 1.12 & 1.15 & 1.12 & 1.15 & 1.26 & 1.29 & 1.26 & 1.29 & 40.7 & 40.7 & 35.5 & 36.4 & 45.9 & 45.9 & 4 \\
\hline & Tanker & 1.25 & 1.25 & 1.25 & 1.25 & 1.50 & 1.50 & 1.50 & 1.50 & 47.5 & 47.5 & 38.0 & 38.0 & 57.1 & 57.1 & 2 \\
\hline & $\begin{array}{l}\text { Vehicle } \\
\text { Carrier }\end{array}$ & 1.05 & 1.11 & 1.13 & 1.20 & 1.58 & 1.67 & 1.16 & 1.23 & 24.0 & 22.3 & 20.1 & 21.3 & 24.8 & 33.5 & 6 \\
\hline \multirow{7}{*}{ CD-In-VB-Out } & Total & 1.22 & 1.38 & 1.44 & 1.63 & 3.17 & 3.58 & 1.74 & 1.97 & 46.7 & 39.5 & 28.7 & 32.4 & 56.5 & 102.7 & 125 \\
\hline & Bulk & 1.58 & 1.69 & 1.95 & 2.09 & 4.10 & 4.39 & 3.05 & 3.26 & 76.3 & 61.8 & 36.5 & 39.0 & 119.0 & 160.3 & 8 \\
\hline & Chemical & 1.26 & 1.31 & 1.44 & 1.50 & 2.96 & 3.07 & 1.62 & 1.68 & 47.1 & 41.3 & 31.5 & 32.7 & 53.0 & 96.8 & 25 \\
\hline & $\begin{array}{l}\text { General } \\
\text { Cargo Ship }\end{array}$ & 1.47 & 1.54 & 1.70 & 1.78 & 3.47 & 3.63 & 2.48 & 2.60 & 70.3 & 61.0 & 39.5 & 41.4 & 102.7 & 143.5 & 12 \\
\hline & Other & 1.00 & 1.00 & 1.00 & 1.00 & 1.00 & 1.00 & 1.00 & 1.00 & 57.1 & 57.1 & 57.1 & 57.1 & 57.1 & 57.1 & 1 \\
\hline & Tanker & 1.13 & 1.13 & 1.13 & 1.13 & 1.26 & 1.26 & 1.26 & 1.26 & 82.2 & 82.2 & 72.8 & 72.8 & 91.6 & 91.6 & 2 \\
\hline & $\begin{array}{l}\text { Vehicle } \\
\text { Carrier }\end{array}$ & 1.31 & 1.40 & 1.33 & 1.42 & 2.19 & 2.35 & 1.49 & 1.59 & 38.7 & 38.2 & 27.3 & 29.2 & 43.3 & 64.0 & 77 \\
\hline
\end{tabular}




\begin{tabular}{|c|c|c|c|c|c|c|c|c|c|c|c|c|c|c|c|c|}
\hline \multirow{7}{*}{ VB-In-CD-Out } & Total & 1.17 & 1.35 & 1.46 & 1.68 & 3.05 & 3.53 & 1.77 & 2.04 & 50.1 & 40.2 & 29.8 & 34.4 & 60.8 & 105.1 & 186 \\
\hline & Bulk & 1.38 & 1.79 & 1.65 & 2.15 & 2.96 & 3.85 & 2.19 & 2.85 & 86.0 & 71.7 & 40.0 & 52.1 & 113.8 & 154.1 & 21 \\
\hline & Chemical & 1.45 & 1.81 & 1.40 & 1.75 & 2.22 & 2.78 & 1.89 & 2.36 & 60.4 & 62.3 & 34.4 & 43.0 & 81.1 & 95.6 & 5 \\
\hline & $\begin{array}{l}\text { General } \\
\text { Cargo Ship }\end{array}$ & 1.21 & 1.28 & 1.75 & 1.85 & 7.00 & 7.40 & 2.03 & 2.14 & 81.8 & 56.9 & 44.3 & 46.9 & 95.0 & 327.9 & 16 \\
\hline & Other & 1.09 & 1.10 & 1.28 & 1.28 & 1.84 & 1.85 & 1.77 & 1.78 & 42.3 & 36.2 & 32.9 & 33.1 & 58.6 & 60.8 & 9 \\
\hline & Tanker & 1.03 & 1.06 & 1.12 & 1.15 & 1.46 & 1.50 & 1.46 & 1.50 & 44.7 & 41.0 & 38.8 & 39.8 & 58.2 & 58.2 & 4 \\
\hline & $\begin{array}{l}\text { Vehicle } \\
\text { Carrier }\end{array}$ & 1.22 & 1.37 & 1.30 & 1.46 & 2.07 & 2.32 & 1.49 & 1.67 & 40.8 & 38.5 & 28.0 & 31.4 & 46.8 & 65.1 & 131 \\
\hline \multirow{8}{*}{ VB-In-VB-Out } & Total & 1.34 & 1.48 & 1.79 & 1.98 & 4.39 & 4.85 & 2.29 & 2.53 & 64.1 & 47.9 & 32.3 & 35.8 & 81.8 & 156.8 & 822 \\
\hline & Bulk & 1.38 & 1.52 & 1.62 & 1.79 & 3.74 & 4.13 & 2.16 & 2.39 & 123.6 & 105.0 & 68.9 & 76.2 & 164.4 & 284.9 & 135 \\
\hline & Chemical & 1.28 & 1.32 & 1.74 & 1.80 & 3.79 & 3.91 & 2.77 & 2.86 & 72.0 & 52.8 & 40.1 & 41.3 & 114.6 & 156.7 & 26 \\
\hline & $\begin{array}{l}\text { Container } \\
\text { Ship-Fully } \\
\text { Cellular }\end{array}$ & 1.14 & 1.17 & 1.22 & 1.25 & 1.98 & 2.04 & 1.37 & 1.41 & 38.9 & 36.5 & 31.1 & 32.0 & 43.7 & 63.3 & 195 \\
\hline & $\begin{array}{l}\text { General } \\
\text { Cargo Ship }\end{array}$ & 1.23 & 1.42 & 1.49 & 1.73 & 3.03 & 3.50 & 2.13 & 2.46 & 90.0 & 74.3 & 52.2 & 60.3 & 128.6 & 182.6 & 98 \\
\hline & Other & 1.25 & 1.38 & 1.42 & 1.58 & 2.31 & 2.56 & 1.77 & 1.97 & 52.5 & 46.0 & 33.3 & 36.9 & 65.5 & 85.3 & 51 \\
\hline & Tanker & 1.41 & 1.54 & 1.41 & 1.54 & 2.13 & 2.32 & 1.60 & 1.74 & 107.1 & 107.1 & 69.8 & 75.9 & 121.3 & 161.6 & 6 \\
\hline & $\begin{array}{l}\text { Vehicle } \\
\text { Carrier }\end{array}$ & 1.26 & 1.35 & 1.40 & 1.50 & 2.19 & 2.35 & 1.69 & 1.82 & 46.2 & 41.5 & 30.8 & 33.1 & 56.0 & 72.5 & 311 \\
\hline
\end{tabular}

* CD: C\&D Canal route, VB: Virginia Beach (Chesapeake Bay) route. 
Table B-3. PCT performance measures by route and vessel size, in hours.

\begin{tabular}{|c|c|c|c|c|c|c|c|c|c|c|c|c|c|c|c|c|}
\hline \multirow[b]{2}{*}{$\begin{array}{l}\text { PCT } \\
\text { Route Code* }\end{array}$} & \multirow[b]{2}{*}{ Vessel Size } & \multicolumn{4}{|c|}{ Travel Time Index } & \multicolumn{4}{|c|}{ Planning Time Index } & \multicolumn{6}{|c|}{ Travel Time } & \multirow[b]{2}{*}{ 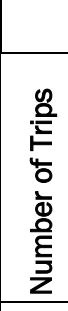 } \\
\hline & & 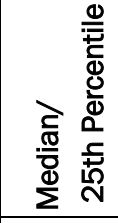 & 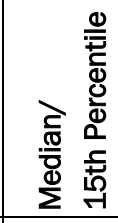 & 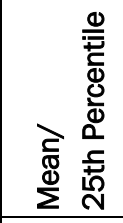 & 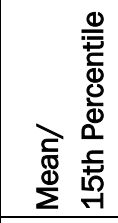 & 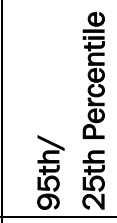 & 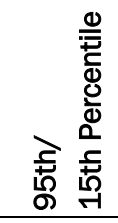 & 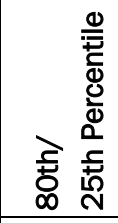 & 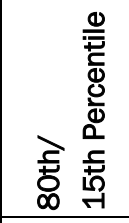 & 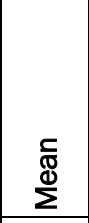 & 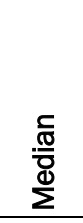 & 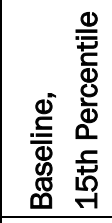 & 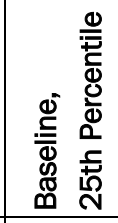 & 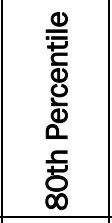 & 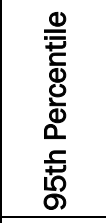 & \\
\hline \multirow{4}{*}{ CD-In-CD-Out } & Total & 1.51 & 1.68 & 2.17 & 2.42 & 6.61 & 7.38 & 2.65 & 2.96 & 53.7 & 37.3 & 22.2 & 24.8 & 65.6 & 163.7 & 17 \\
\hline & Under $500 \mathrm{ft}$ & 1.19 & 1.24 & 1.38 & 1.44 & 2.51 & 2.63 & 1.87 & 1.96 & 51.3 & 44.2 & 35.5 & 37.3 & 69.7 & 93.5 & 5 \\
\hline & $500-699 \mathrm{ft}$ & 1.57 & 1.58 & 2.59 & 2.61 & 7.33 & 7.38 & 4.85 & 4.88 & 57.8 & 35.1 & 22.2 & 22.3 & 108.3 & 163.7 & 10 \\
\hline & $700-899 \mathrm{ft}$ & 1.84 & 1.84 & 1.84 & 1.84 & 2.69 & 2.69 & 2.69 & 2.69 & 39.2 & 39.2 & 21.3 & 21.3 & 57.1 & 57.1 & 2 \\
\hline \multirow{5}{*}{ CD-In-VB-Out } & Total & 1.22 & 1.38 & 1.44 & 1.63 & 3.17 & 3.58 & 1.74 & 1.97 & 46.7 & 39.5 & 28.7 & 32.4 & 56.5 & 102.7 & 125 \\
\hline & Under $500 \mathrm{ft}$ & 1.26 & 1.29 & 1.46 & 1.49 & 3.07 & 3.13 & 1.68 & 1.72 & 47.8 & 41.3 & 32.1 & 32.8 & 55.0 & 100.4 & 20 \\
\hline & $500-699 \mathrm{ft}$ & 1.21 & 1.36 & 1.42 & 1.60 & 3.15 & 3.54 & 1.65 & 1.86 & 46.4 & 39.5 & 29.0 & 32.6 & 53.9 & 102.7 & 96 \\
\hline & $700-899 \mathrm{ft}$ & 1.04 & 1.05 & 1.64 & 1.66 & 4.05 & 4.09 & 2.62 & 2.65 & 45.6 & 29.0 & 27.5 & 27.8 & 72.8 & 112.5 & 8 \\
\hline & Over $900 \mathrm{ft}$ & 1.00 & 1.00 & 1.00 & 1.00 & 1.00 & 1.00 & 1.00 & 1.00 & 57.1 & 57.1 & 57.1 & 57.1 & 57.1 & 57.1 & 1 \\
\hline \multirow{4}{*}{ VB-In-CD-Out } & Total & 1.17 & 1.35 & 1.46 & 1.68 & 3.05 & 3.53 & 1.77 & 2.04 & 50.1 & 40.2 & 29.8 & 34.4 & 60.8 & 105.1 & 186 \\
\hline & Under $500 \mathrm{ft}$ & 1.12 & 1.17 & 1.38 & 1.45 & 2.06 & 2.16 & 2.05 & 2.14 & 64.2 & 51.8 & 44.3 & 46.4 & 95.0 & 95.6 & 6 \\
\hline & $500-699 \mathrm{ft}$ & 1.18 & 1.34 & 1.48 & 1.68 & 3.25 & 3.68 & 1.80 & 2.04 & 49.9 & 39.8 & 29.8 & 33.7 & 60.8 & 109.5 & 164 \\
\hline & $700-899 \mathrm{ft}$ & 1.32 & 1.76 & 1.32 & 1.77 & 2.04 & 2.73 & 1.72 & 2.30 & 47.1 & 47.0 & 26.7 & 35.7 & 61.3 & 72.7 & 16 \\
\hline \multirow{5}{*}{ VB-In-VB-Out } & Total & 1.34 & 1.48 & 1.79 & 1.98 & 4.39 & 4.85 & 2.29 & 2.53 & 64.1 & 47.9 & 32.3 & 35.8 & 81.8 & 156.8 & 822 \\
\hline & Under $500 \mathrm{ft}$ & 1.43 & 1.61 & 1.62 & 1.82 & 3.37 & 3.79 & 2.12 & 2.39 & 75.3 & 66.5 & 41.3 & 46.5 & 98.7 & 156.6 & 31 \\
\hline & $500-699 \mathrm{ft}$ & 1.44 & 1.60 & 1.92 & 2.14 & 4.96 & 5.51 & 2.57 & 2.85 & 67.5 & 50.5 & 31.6 & 35.1 & 90.2 & 174.2 & 479 \\
\hline & $700-899 \mathrm{ft}$ & 1.43 & 1.52 & 1.87 & 1.99 & 4.65 & 4.94 & 2.21 & 2.35 & 63.1 & 48.4 & 31.8 & 33.8 & 74.5 & 156.8 & 158 \\
\hline & Over $900 \mathrm{ft}$ & 1.12 & 1.22 & 1.44 & 1.57 & 2.97 & 3.23 & 1.87 & 2.04 & 52.0 & 40.5 & 33.2 & 36.1 & 67.5 & 107.1 & 154 \\
\hline
\end{tabular}

* CD: C\&D Canal route, VB: Virginia Beach (Chesapeake Bay) route. 
Table B-4. TTIB performance measures by route and vessel type, in hours.

\begin{tabular}{|c|c|c|c|c|c|c|c|c|c|c|c|c|c|c|c|c|}
\hline \multirow[b]{2}{*}{ IB Path* } & \multirow[b]{2}{*}{ Vessel Type } & \multicolumn{4}{|c|}{ Travel Time Index } & \multicolumn{4}{|c|}{ Planning Time Index } & \multicolumn{6}{|c|}{ Travel Time } & \multirow[b]{2}{*}{ 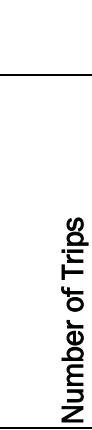 } \\
\hline & & 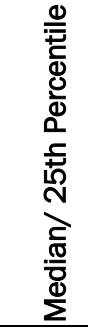 & 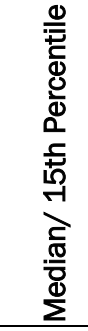 & 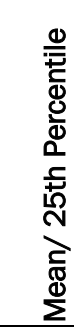 & 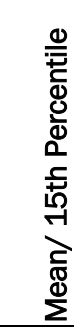 & 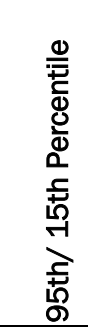 & 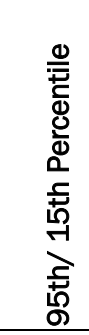 & 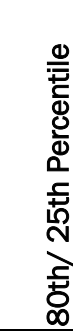 & 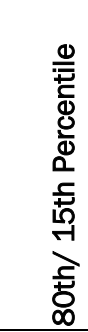 & 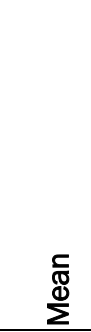 & 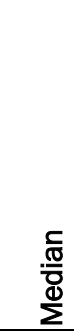 & 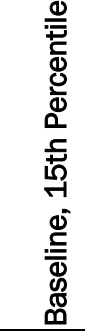 & 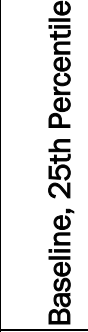 & 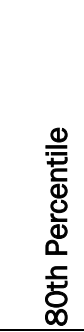 & 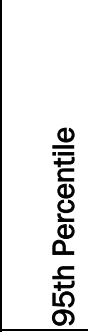 & \\
\hline \multirow{8}{*}{ CD-In } & Total & 1.05 & 1.06 & 1.06 & 1.08 & 1.22 & 1.24 & 1.13 & 1.14 & 5.6 & 5.6 & 5.3 & 5.3 & 6.0 & 6.5 & 139 \\
\hline & Bulk & 1.03 & 1.05 & 1.03 & 1.05 & 1.13 & 1.15 & 1.11 & 1.13 & 5.8 & 5.8 & 5.5 & 5.6 & 6.2 & 6.3 & 8 \\
\hline & Chemical & 1.03 & 1.06 & 1.05 & 1.08 & 1.24 & 1.28 & 1.09 & 1.13 & 5.8 & 5.7 & 5.3 & 5.5 & 6.0 & 6.8 & 26 \\
\hline & $\begin{array}{l}\text { Container Ship-Fully } \\
\text { Cellular }\end{array}$ & NA & NA & NA & NA & NA & NA & NA & NA & NA & NA & NA & NA & NA & NA & 0 \\
\hline & General Cargo Ship & 1.06 & 1.08 & 1.07 & 1.08 & 1.29 & 1.31 & 1.14 & 1.16 & 5.8 & 5.8 & 5.3 & 5.4 & 6.2 & 7.0 & 13 \\
\hline & Other & 1.07 & 1.11 & 1.04 & 1.09 & 1.10 & 1.15 & 1.09 & 1.14 & 6.0 & 6.1 & 5.5 & 5.8 & 6.3 & 6.3 & 5 \\
\hline & Tanker & 1.04 & 1.05 & 1.05 & 1.07 & 1.14 & 1.15 & 1.14 & 1.15 & 5.8 & 5.7 & 5.4 & 5.5 & 6.3 & 6.3 & 4 \\
\hline & Vehicle Carrier & 1.05 & 1.06 & 1.06 & 1.07 & 1.22 & 1.24 & 1.10 & 1.11 & 5.6 & 5.5 & 5.2 & 5.3 & 5.8 & 6.4 & 83 \\
\hline \multirow{8}{*}{ VB-In } & Total & 1.06 & 1.08 & 1.27 & 1.30 & 2.38 & 2.43 & 1.25 & 1.28 & 11.3 & 9.4 & 8.8 & 8.9 & 11.2 & 21.2 & 980 \\
\hline & Bulk & 1.07 & 1.12 & 1.65 & 1.73 & 4.74 & 4.96 & 2.17 & 2.27 & 18.6 & 12.1 & 10.8 & 11.3 & 24.4 & 53.3 & 136 \\
\hline & Chemical & 1.08 & 1.14 & 1.23 & 1.29 & 3.08 & 3.24 & 1.18 & 1.24 & 12.7 & 11.2 & 9.8 & 10.3 & 12.2 & 31.8 & 31 \\
\hline & $\begin{array}{l}\text { Container Ship-Fully } \\
\text { Cellular }\end{array}$ & 1.05 & 1.07 & 1.08 & 1.11 & 1.27 & 1.30 & 1.13 & 1.15 & 9.2 & 8.9 & 8.3 & 8.5 & 9.6 & 10.8 & 195 \\
\hline & General Cargo Ship & 1.07 & 1.09 & 1.29 & 1.31 & 3.07 & 3.13 & 1.23 & 1.25 & 12.2 & 10.2 & 9.3 & 9.5 & 11.7 & 29.2 & 107 \\
\hline & Other & 1.05 & 1.06 & 1.22 & 1.24 & 1.73 & 1.75 & 1.17 & 1.18 & 10.7 & 9.2 & 8.7 & 8.8 & 10.3 & 15.2 & 59 \\
\hline & Tanker & 1.03 & 1.03 & 1.04 & 1.04 & 1.14 & 1.14 & 1.13 & 1.13 & 11.4 & 11.3 & 10.9 & 10.9 & 12.3 & 12.5 & 10 \\
\hline & Vehicle Carrier & 1.03 & 1.05 & 1.10 & 1.12 & 1.21 & 1.24 & 1.09 & 1.11 & 9.8 & 9.2 & 8.8 & 8.9 & 9.8 & 10.8 & 442 \\
\hline
\end{tabular}

* CD: C\&D Canal Route; VB: Virginia Beach (Chesapeake Bay) Route. 
Table B-5. TTIB performance measures by route and vessel size, in hours.

\begin{tabular}{|c|c|c|c|c|c|c|c|c|c|c|c|c|c|c|c|c|}
\hline \multirow[b]{2}{*}{ IB Path* } & \multirow[b]{2}{*}{$\begin{array}{l}\text { Vessel } \\
\text { Type }\end{array}$} & \multicolumn{4}{|c|}{ Travel Time Index } & \multicolumn{4}{|c|}{ Planning Time Index } & \multicolumn{6}{|c|}{ Travel Time } & \multirow[b]{2}{*}{ 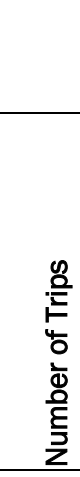 } \\
\hline & & 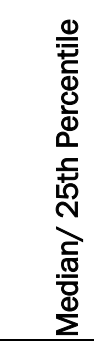 & 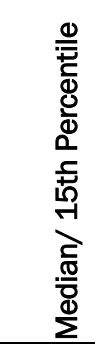 & 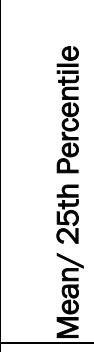 & 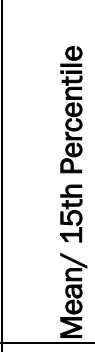 & 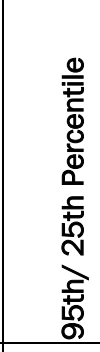 & 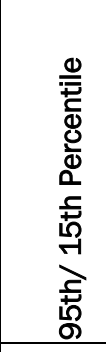 & 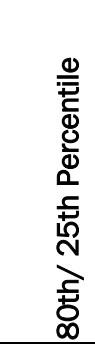 & 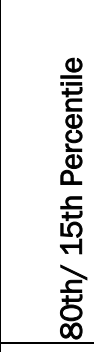 & $\begin{array}{c}\frac{\Sigma}{\mathbb{N}} \\
\sum\end{array}$ & $\begin{array}{l}\frac{c}{\sigma} \\
\frac{\mathbb{O}}{\mathbb{d}} \\
\Sigma\end{array}$ & 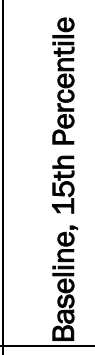 & 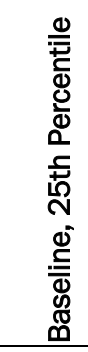 & 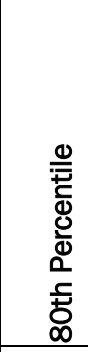 & 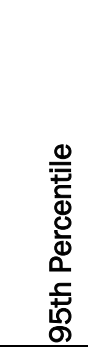 & \\
\hline \multirow{5}{*}{ CD-In } & Total & 1.05 & 1.06 & 1.06 & 1.08 & 1.22 & 1.24 & 1.13 & 1.14 & 5.6 & 5.6 & 5.3 & 5.3 & 6.0 & 6.5 & 139 \\
\hline & $\begin{array}{l}\text { Under } \\
500 \mathrm{ft}\end{array}$ & 1.05 & 1.06 & 1.05 & 1.07 & 1.17 & 1.19 & 1.13 & 1.15 & 5.7 & 5.7 & 5.3 & 5.4 & 6.1 & 6.3 & 23 \\
\hline & $500-699 \mathrm{ft}$ & 1.05 & 1.08 & 1.06 & 1.09 & 1.20 & 1.24 & 1.11 & 1.15 & 5.6 & 5.6 & 5.2 & 5.3 & 5.9 & 6.4 & 105 \\
\hline & $700-899 \mathrm{ft}$ & 1.06 & 1.10 & 1.07 & 1.10 & 1.20 & 1.24 & 1.15 & 1.18 & 5.8 & 5.8 & 5.3 & 5.4 & 6.2 & 6.5 & 10 \\
\hline & Over $900 \mathrm{ft}$ & 1.00 & 1.00 & 1.00 & 1.00 & 1.00 & 1.00 & 1.00 & 1.00 & 5.5 & 5.5 & 5.5 & 5.5 & 5.5 & 5.5 & 1 \\
\hline \multirow{5}{*}{ VB-In } & Total & 1.06 & 1.08 & 1.27 & 1.30 & 2.38 & 2.43 & 1.25 & 1.28 & 11.3 & 9.4 & 8.8 & 8.9 & 11.2 & 21.2 & 980 \\
\hline & $\begin{array}{l}\text { Under } \\
500 \mathrm{ft}\end{array}$ & 1.07 & 1.08 & 1.24 & 1.26 & 2.89 & 2.94 & 1.25 & 1.27 & 13.6 & 11.8 & 10.8 & 11.0 & 13.8 & 31.8 & 35 \\
\hline & $500-699 \mathrm{ft}$ & 1.05 & 1.07 & 1.19 & 1.21 & 1.56 & 1.59 & 1.19 & 1.21 & 10.7 & 9.4 & 8.8 & 9.0 & 10.7 & 14.1 & 619 \\
\hline & $700-899 \mathrm{ft}$ & 1.08 & 1.10 & 1.50 & 1.53 & 4.42 & 4.50 & 1.36 & 1.39 & 12.9 & 9.3 & 8.4 & 8.6 & 11.7 & 37.9 & 173 \\
\hline & Over $900 \mathrm{ft}$ & 1.06 & 1.09 & 1.33 & 1.36 & 3.10 & 3.18 & 1.28 & 1.31 & 11.6 & 9.3 & 8.5 & 8.7 & 11.2 & 27.0 & 153 \\
\hline
\end{tabular}

* CD: C\&D Canal Route; VB: Virginia Beach (Chesapeake Bay) Route. 
Table B-6. TTOB performance measures by route and vessel type, in hours.

\begin{tabular}{|c|c|c|c|c|c|c|c|c|c|c|c|c|c|c|c|c|}
\hline \multirow[b]{2}{*}{$\begin{array}{l}\text { OB } \\
\text { Path* }\end{array}$} & \multirow[b]{2}{*}{ Vessel Type } & \multicolumn{4}{|c|}{ Travel Time Index } & \multicolumn{4}{|c|}{ Planning Time Index } & \multicolumn{6}{|c|}{ Travel Time } & \multirow[b]{2}{*}{ 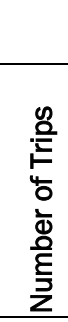 } \\
\hline & & 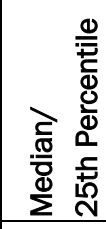 & 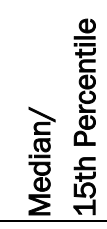 & 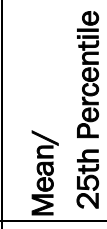 & 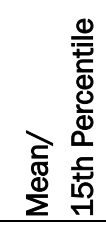 & 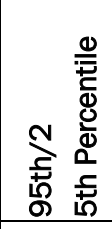 & 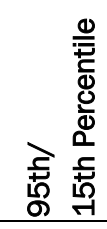 & 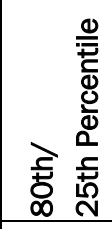 & 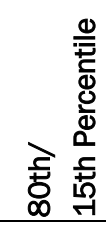 & 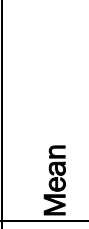 & $\frac{\frac{c}{\sigma 0}}{\frac{\mathbb{d}}{\mathrm{d}}}$ & 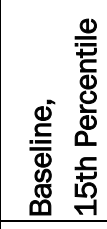 & 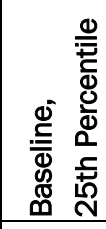 & 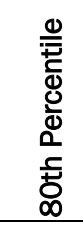 & 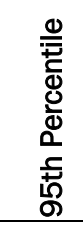 & \\
\hline \multirow{7}{*}{ CD-Out } & Total & 1.07 & 1.08 & 1.07 & 1.09 & 1.25 & 1.28 & 1.11 & 1.13 & 5.5 & 5.4 & 5.0 & 5.1 & 5.7 & 6.4 & 200 \\
\hline & Bulk & 1.10 & 1.13 & 1.08 & 1.12 & 1.27 & 1.31 & 1.17 & 1.21 & 5.7 & 5.8 & 5.1 & 5.3 & 6.2 & 6.7 & 19 \\
\hline & Chemical & 1.04 & 1.08 & 1.04 & 1.08 & 1.13 & 1.17 & 1.08 & 1.12 & 5.4 & 5.4 & 5.0 & 5.2 & 5.6 & 5.8 & 6 \\
\hline & $\begin{array}{l}\text { General } \\
\text { Cargo Ship }\end{array}$ & 1.07 & 1.10 & 1.09 & 1.13 & 1.30 & 1.34 & 1.25 & 1.29 & 5.4 & 5.3 & 4.8 & 5.0 & 6.3 & 6.5 & 19 \\
\hline & Other & 1.03 & 1.07 & 1.04 & 1.08 & 1.13 & 1.17 & 1.13 & 1.17 & 5.2 & 5.2 & 4.8 & 5.0 & 5.7 & 5.7 & 13 \\
\hline & Tanker & 1.07 & 1.10 & 1.08 & 1.11 & 1.25 & 1.29 & 1.12 & 1.15 & 6.1 & 6.0 & 5.5 & 5.7 & 6.3 & 7.1 & 6 \\
\hline & $\begin{array}{l}\text { Vehicle } \\
\text { Carrier }\end{array}$ & 1.05 & 1.07 & 1.07 & 1.08 & 1.18 & 1.20 & 1.11 & 1.13 & 5.4 & 5.3 & 5.0 & 5.1 & 5.7 & 6.0 & 137 \\
\hline \multirow{8}{*}{ VB-Out } & Total & 1.05 & 1.07 & 1.14 & 1.17 & 1.59 & 1.62 & 1.22 & 1.25 & 10.0 & 9.2 & 8.6 & 8.8 & 10.7 & 13.9 & 919 \\
\hline & Bulk & 1.14 & 1.17 & 1.16 & 1.20 & 1.38 & 1.42 & 1.30 & 1.34 & 12.9 & 12.6 & 10.8 & 11.1 & 14.4 & 15.3 & 125 \\
\hline & Chemical & 1.04 & 1.08 & 1.08 & 1.13 & 1.14 & 1.19 & 1.11 & 1.16 & 11.3 & 10.8 & 10.0 & 10.5 & 11.6 & 11.9 & 51 \\
\hline & $\begin{array}{l}\text { Container } \\
\text { Ship-Fully } \\
\text { Cellular }\end{array}$ & 1.03 & 1.05 & 1.08 & 1.10 & 1.21 & 1.23 & 1.10 & 1.12 & 9.2 & 8.8 & 8.3 & 8.5 & 9.4 & 10.3 & 195 \\
\hline & $\begin{array}{l}\text { General } \\
\text { Cargo Ship }\end{array}$ & 1.10 & 1.12 & 1.11 & 1.13 & 1.33 & 1.36 & 1.21 & 1.23 & 10.1 & 10.0 & 8.9 & 9.1 & 11.0 & 12.1 & 101 \\
\hline & Other & 1.03 & 1.04 & 1.17 & 1.18 & 1.54 & 1.55 & 1.13 & 1.15 & 10.1 & 8.9 & 8.6 & 8.7 & 9.8 & 13.3 & 51 \\
\hline & Tanker & 1.06 & 1.10 & 1.93 & 1.99 & 5.88 & 6.08 & 3.32 & 3.43 & 19.9 & 11.0 & 10.0 & 10.3 & 34.3 & 60.8 & 8 \\
\hline & $\begin{array}{l}\text { Vehicle } \\
\text { Carrier }\end{array}$ & 1.03 & 1.04 & 1.04 & 1.05 & 1.14 & 1.15 & 1.08 & 1.09 & 9.1 & 9.0 & 8.7 & 8.8 & 9.4 & 10.0 & 388 \\
\hline
\end{tabular}

\footnotetext{
* CD: C\&D Canal route; VB: Virginia Beach (Chesapeake Bay) route.
} 
Table B-7. TTOB performance measures by route and vessel size, in hours.

\begin{tabular}{|c|c|c|c|c|c|c|c|c|c|c|c|c|c|c|c|c|}
\hline \multirow[b]{2}{*}{ OB Path* } & \multirow[b]{2}{*}{ Vessel Type } & \multicolumn{4}{|c|}{ Travel Time Index } & \multicolumn{4}{|c|}{ Planning Time Index } & \multicolumn{6}{|c|}{ Travel Time } & \multirow[b]{2}{*}{$\begin{array}{l}\text { Number } \\
\text { of Trips }\end{array}$} \\
\hline & & 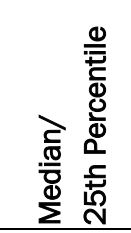 & 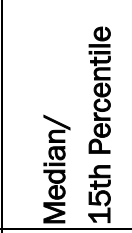 & 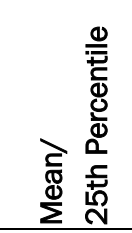 & 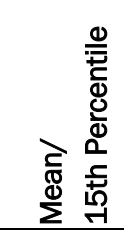 & 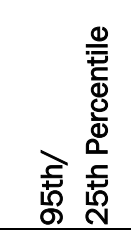 & 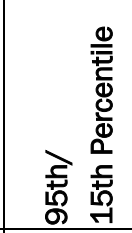 & 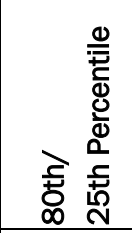 & 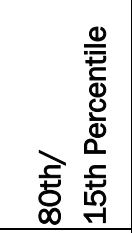 & 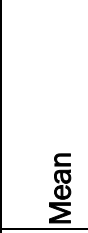 & 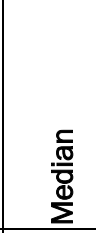 & 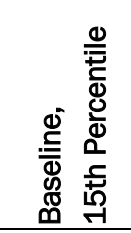 & 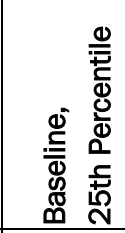 & 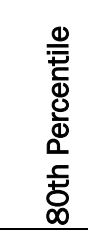 & 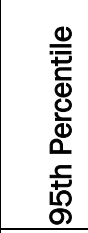 & \\
\hline \multirow{5}{*}{ CD-Out } & Total & 1.07 & 1.08 & 1.07 & 1.09 & 1.25 & 1.28 & 1.11 & 1.13 & 5.5 & 5.4 & 5.0 & 5.1 & 5.7 & 6.4 & 200 \\
\hline & Under $500 \mathrm{ft}$ & 1.03 & 1.13 & 1.03 & 1.12 & 1.13 & 1.24 & 1.10 & 1.20 & 5.1 & 5.2 & 4.6 & 5.0 & 5.5 & 5.7 & 11 \\
\hline & $500-699 \mathrm{ft}$ & 1.07 & 1.08 & 1.07 & 1.09 & 1.23 & 1.25 & 1.11 & 1.13 & 5.5 & 5.4 & 5.0 & 5.1 & 5.7 & 6.3 & 171 \\
\hline & $700-899 \mathrm{ft}$ & 1.09 & 1.09 & 1.10 & 1.10 & 1.37 & 1.37 & 1.18 & 1.18 & 5.7 & 5.6 & 5.2 & 5.2 & 6.1 & 7.1 & 18 \\
\hline & Over $900 \mathrm{ft}$ & NA & NA & NA & NA & NA & NA & NA & NA & NA & NA & NA & NA & NA & NA & 0 \\
\hline \multirow{5}{*}{ VB-Out } & Total & 1.05 & 1.07 & 1.14 & 1.17 & 1.59 & 1.62 & 1.22 & 1.25 & 10.0 & 9.2 & 8.6 & 8.8 & 10.7 & 13.9 & 919 \\
\hline & Under $500 \mathrm{ft}$ & 1.05 & 1.06 & 1.08 & 1.09 & 1.26 & 1.27 & 1.15 & 1.16 & 11.5 & 11.1 & 10.5 & 10.6 & 12.2 & 13.3 & 47 \\
\hline & $500-699 \mathrm{ft}$ & 1.04 & 1.05 & 1.09 & 1.10 & 1.32 & 1.33 & 1.17 & 1.18 & 9.6 & 9.2 & 8.8 & 8.8 & 10.3 & 11.7 & 553 \\
\hline & $700-899 \mathrm{ft}$ & 1.04 & 1.06 & 1.28 & 1.31 & 1.80 & 1.83 & 1.56 & 1.59 & 11.0 & 8.9 & 8.4 & 8.6 & 13.4 & 15.4 & 165 \\
\hline & Over $900 \mathrm{ft}$ & 1.05 & 1.06 & 1.15 & 1.16 & 1.68 & 1.70 & 1.25 & 1.26 & 9.9 & 9.0 & 8.5 & 8.6 & 10.8 & 14.4 & 154 \\
\hline
\end{tabular}

* CD: C\&D Canal route; VB: Virginia Beach (Chesapeake Bay) route. 
Table B-8. Harbor stay hours performance measures by vessel type, in hours.

\begin{tabular}{|c|c|c|c|c|c|c|c|c|c|c|c|c|c|c|c|}
\hline \multirow[b]{2}{*}{ Vessel Type } & \multicolumn{4}{|c|}{ Travel Time Index } & \multicolumn{4}{|c|}{ Planning Time Index } & \multicolumn{6}{|c|}{ Travel Time } & \multirow[b]{2}{*}{ 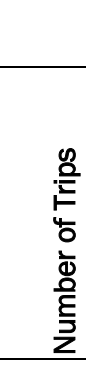 } \\
\hline & 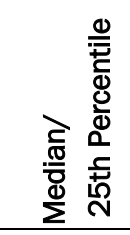 & 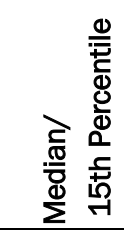 & 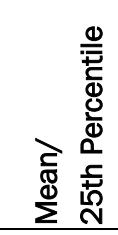 & 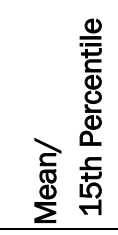 & 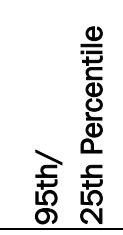 & 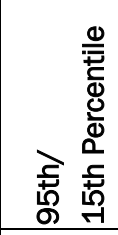 & 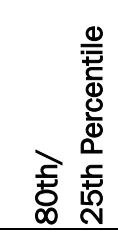 & 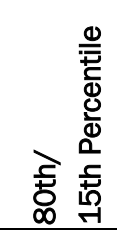 & $\begin{array}{l}\mathbb{\Phi} \\
\stackrel{\mathbb{\Xi}}{\Sigma}\end{array}$ & 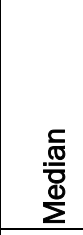 & 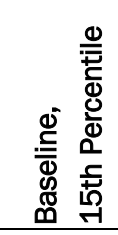 & 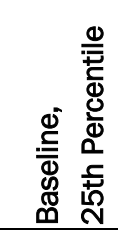 & 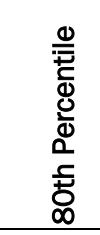 & 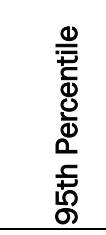 & \\
\hline Total & 1.48 & 1.83 & 2.17 & 2.68 & 6.17 & 7.61 & 2.79 & 3.45 & 37.3 & 25.4 & 13.9 & 17.2 & 48.0 & 105.9 & 1125 \\
\hline Bulk & 1.38 & 1.63 & 1.92 & 2.26 & 4.65 & 5.47 & 2.75 & 3.23 & 76.6 & 55.2 & 33.9 & 39.9 & 109.6 & 185.4 & 146 \\
\hline Chemical & 1.39 & 1.61 & 2.25 & 2.61 & 7.23 & 8.37 & 3.38 & 3.91 & 41.5 & 25.6 & 15.9 & 18.4 & 62.3 & 133.2 & 57 \\
\hline $\begin{array}{l}\text { Container } \\
\text { Ship-Fully } \\
\text { Cellular }\end{array}$ & 1.29 & 1.41 & 1.42 & 1.56 & 2.89 & 3.16 & 1.75 & 1.91 & 20.5 & 18.6 & 13.2 & 14.4 & 25.2 & 41.7 & 195 \\
\hline $\begin{array}{l}\text { General } \\
\text { Cargo Ship }\end{array}$ & 1.39 & 1.89 & 1.79 & 2.45 & 3.90 & 5.34 & 2.69 & 3.68 & 63.9 & 49.4 & 26.1 & 35.7 & 96.0 & 139.2 & 123 \\
\hline Other & 1.36 & 1.59 & 1.61 & 1.88 & 3.28 & 3.84 & 2.24 & 2.62 & 30.6 & 25.9 & 16.3 & 19.0 & 42.5 & 62.4 & 65 \\
\hline Tanker & 1.78 & 1.86 & 2.23 & 2.33 & 5.94 & 6.20 & 3.80 & 3.97 & 53.4 & 42.6 & 22.9 & 23.9 & 90.9 & 142.2 & 14 \\
\hline $\begin{array}{l}\text { Vehicle } \\
\text { Carrier }\end{array}$ & 1.57 & 1.84 & 1.78 & 2.08 & 3.50 & 4.10 & 2.36 & 2.77 & 26.2 & 23.2 & 12.6 & 14.8 & 34.9 & 51.6 & 525 \\
\hline
\end{tabular}


Table B-9. HSH performance measures by vessel size, in hours.

\begin{tabular}{|c|c|c|c|c|c|c|c|c|c|c|c|c|c|c|c|}
\hline \multirow[b]{2}{*}{ Vessel Type } & \multicolumn{4}{|c|}{ Travel Time Index } & \multicolumn{4}{|c|}{ Planning Time Index } & \multicolumn{6}{|c|}{ Travel Time } & \multirow[b]{2}{*}{ 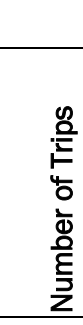 } \\
\hline & 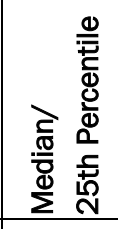 & 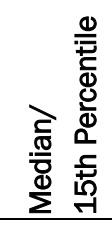 & 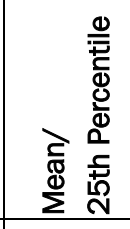 & 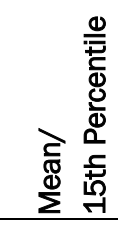 & 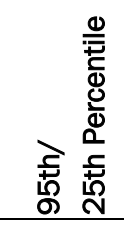 & 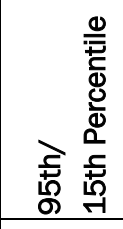 & 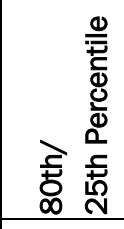 & 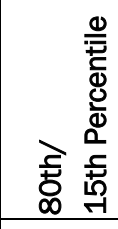 & 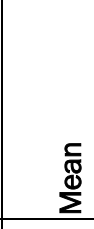 & 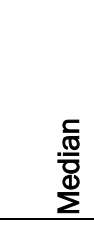 & 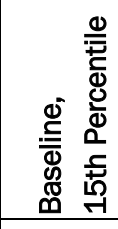 & 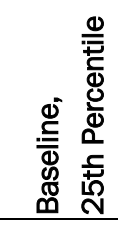 & 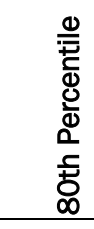 & 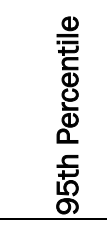 & \\
\hline Total & 1.48 & 1.83 & 2.17 & 2.68 & 6.17 & 7.61 & 2.79 & 3.45 & 37.3 & 25.4 & 13.9 & 17.2 & 48.0 & 105.9 & 1125 \\
\hline Under $500 \mathrm{ft}$ & 1.55 & 1.95 & 2.01 & 2.53 & 5.78 & 7.29 & 3.21 & 4.05 & 42.0 & 32.3 & 16.6 & 20.9 & 67.2 & 120.8 & 59 \\
\hline $500-699 \mathrm{ft}$ & 1.54 & 1.96 & 2.27 & 2.90 & 6.71 & 8.57 & 2.94 & 3.75 & 38.4 & 26.0 & 13.3 & 16.9 & 49.8 & 113.6 & 728 \\
\hline $700-899 \mathrm{ft}$ & 1.55 & 1.75 & 2.31 & 2.60 & 4.74 & 5.36 & 2.76 & 3.12 & 36.9 & 24.8 & 14.2 & 16.0 & 44.2 & 75.9 & 183 \\
\hline Over $900 \mathrm{ft}$ & 1.27 & 1.56 & 1.68 & 2.06 & 3.98 & 4.87 & 2.45 & 3.00 & 30.5 & 23.1 & 14.8 & 18.2 & 44.5 & 72.3 & 155 \\
\hline
\end{tabular}


Figure B-1. Monthly average HSH by ship-type group, 2016.

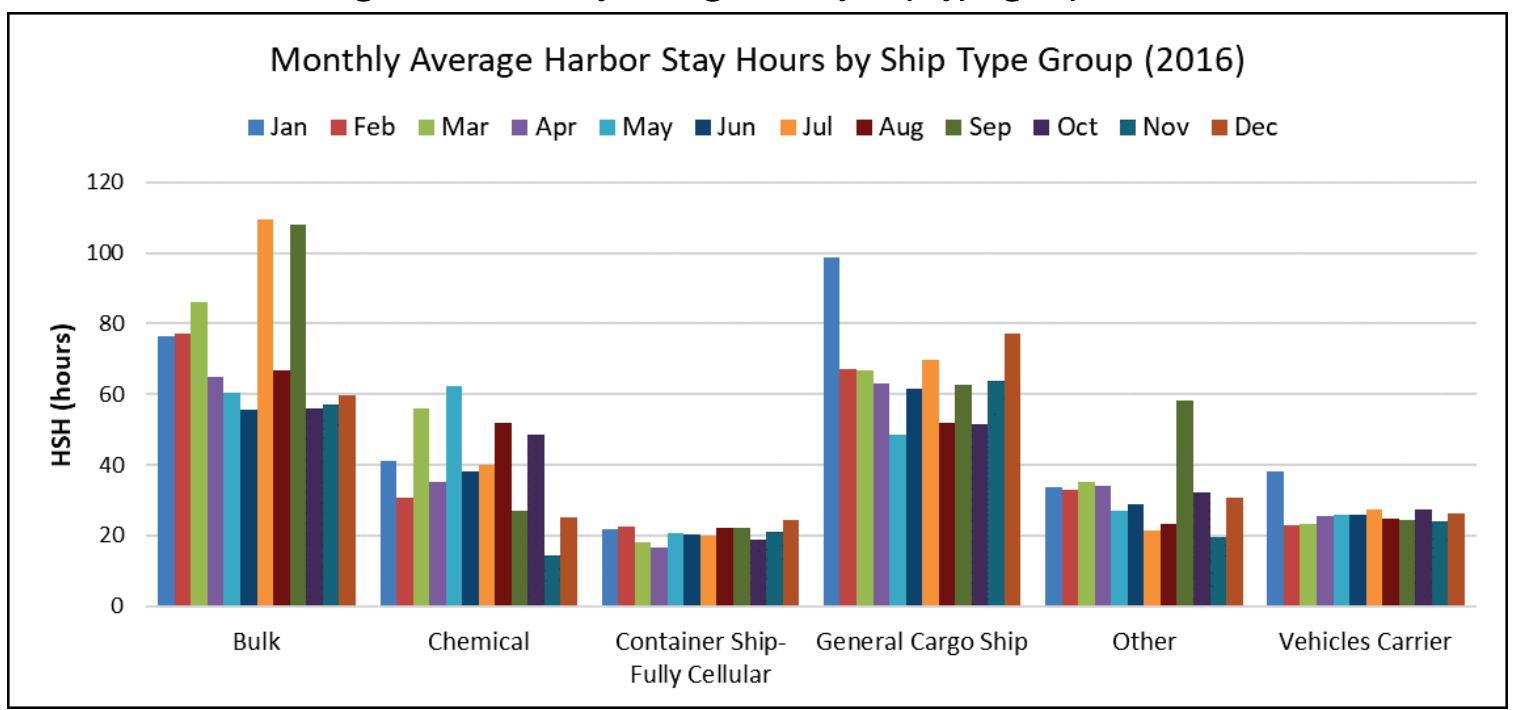

Figure B-2. Monthly arrival count by ship-type group, 2016.

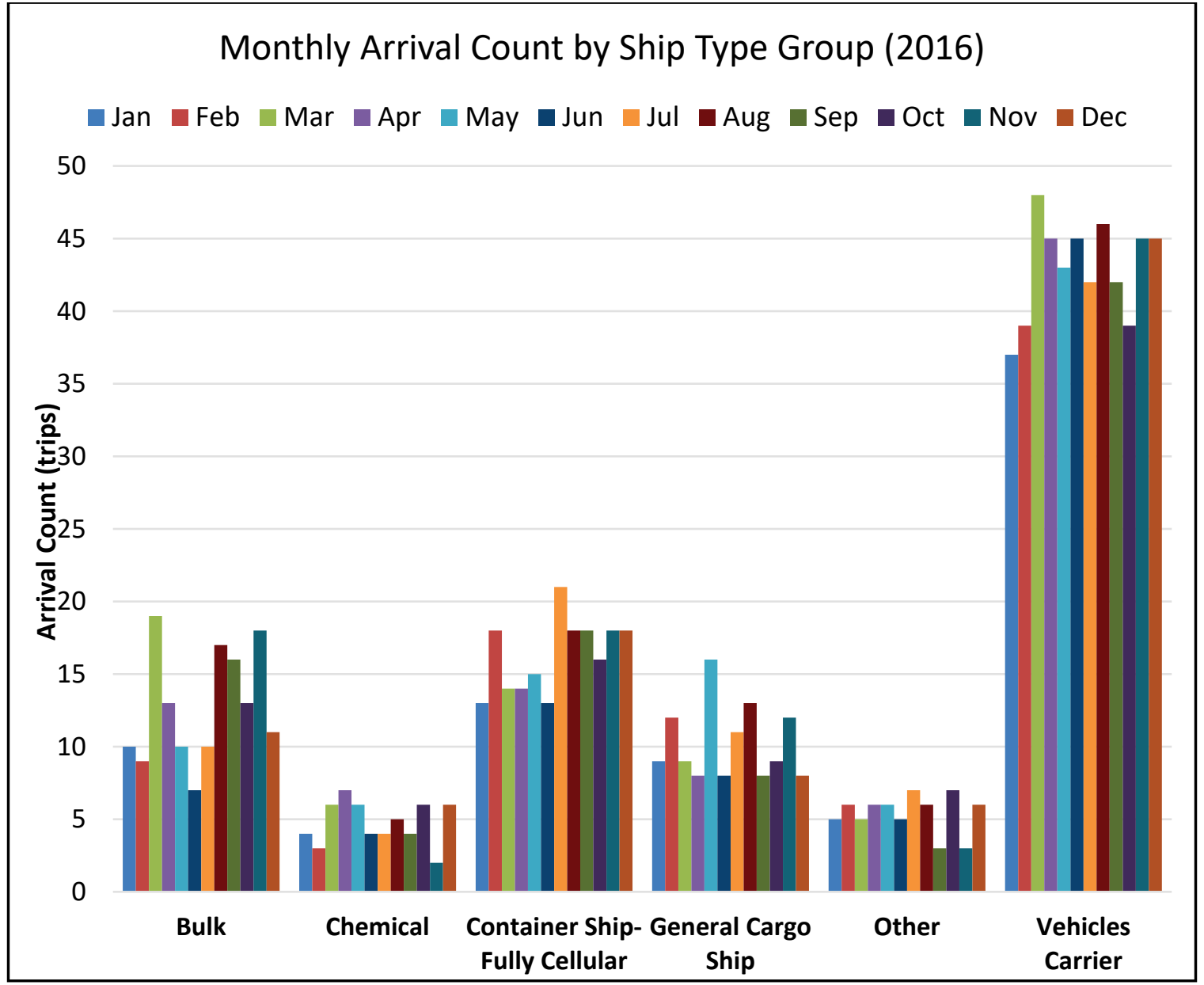




\section{Appendix C: Director's Letter}

The initial summary technical memorandum delivered from the Texas Transportation Institute included the following note from the Center Director, reproduced in Figure C-1 below.

Figure C-1. Director's letter included with technical memorandum delivery.

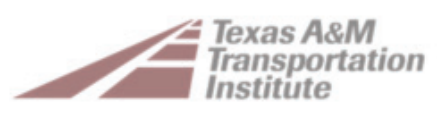

February 22, 2019

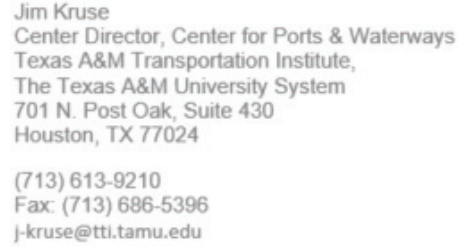

TECHNICAL MEMORANDUM

TO: K. Ned Mitchell, Ph.D.

U.S. Army Engineer Research and Development Center Coastal and Hydraulics Laboratory

FROM: Jim Kruse, Director, Center for Ports and Waterways, $\mathrm{TT}$

RE: Port of Baltimore Analysis

This technical memorandum provides a summary of the work performed on Port of Baltimore Automatic Identification System (AIS) data. The analytical approach is comparable to what was done at the Port of Mobile.

The Port of Baltimore is a slightly more complex situation than the Port of Mobile. It has two approaches-one through Chesapeake Bay and the other through the C\&D Canal. The transit through Chesapeake Bay is over 150 miles - the longest ship channel in the United States and maybe the world. The Maryland Pilots handle the transit through Chesapeake Bay. They also handle transits in the portion of the C\&D Canal west of the Chesapeake City Bridge. Delaware and Maryland pilots handle the transfer in a zone that extends one mile either side of the bridge.

For this analysis, the harbor entrance is defined as the Francis Scott Key Bridge. In most cases, the pilots that bring in the vessels from the ocean hand the vessel off to docking pilots, although this is not always the case (cruise ships being the most notable exception). Interestingly, regardless of where a pilot exchange takes place, the vessel rarely stops for the exchange-it merely slows down so the exchange can be accomplished. This explains the lack of anchored vessels at the entrance to the port.

The next step in the analysis will be to undertake a complete fluidity analysis that relates the vessel data to truck traffic data on key port corridors. The proposed scope of work for that effort has been submitted in a separate memorandum

Please contact me at j-kruse@tti.tamu.edu or (713) 613-9210 if you have any questions about this technical memorandum or the underlying methodology employed. 


\section{Unit Conversion Factors}

\begin{tabular}{|l|c|l|}
\hline Multiply & By & To Obtain \\
\hline feet & 0.3048 & meters \\
\hline inches & 0.0254 & meters \\
\hline knots & 0.5144444 & meters per second \\
\hline miles (nautical) & 1,852 & meters \\
\hline miles (US statute) & $1,609.347$ & meters \\
\hline miles per hour & 0.44704 & meters per second \\
\hline yards & 0.9144 & meters \\
\hline
\end{tabular}




\section{Acronyms and Abbreviations}

$\begin{array}{ll}\text { AIS } & \text { Automatic Identification System } \\ \text { AISAP } & \text { AIS Analysis Package } \\ \text { CD-In } & \text { C\&D Canal Inbound (Route) } \\ \text { CD-Out } & \text { C\&D Canal Outbound (Route) } \\ \text { HSH } & \text { Harbor Stay Hours } \\ \text { IB } & \text { inbound } \\ \text { IMO } & \text { International Maritime Organization } \\ \text { LR } & \text { Lloyd's Register } \\ \text { MMSI } & \text { Maritime Mobile Service Identity } \\ \text { NAIS } & \text { Nationwide Automatic Identification System } \\ \text { PCT } & \text { Port Cycle Time } \\ \text { PTI } & \text { Planning Time Index } \\ \text { TAMTI } & \text { Texas A\&M Transportation Institute } \\ \text { TP } & \text { trip point } \\ \text { TTI } & \text { travel time index } \\ \text { TTIB } & \text { travel time inbound } \\ \text { TTOB } & \text { travel time outbound } \\ \text { USACE } & \text { US Army Corps of Engineers } \\ \text { USCG } & \text { US Coast Guard } \\ \text { VB-In } & \text { Virginia Beach inbound (Route) } \\ \text { VB-Out } & \text { Virginia Beach outbound (Route) } \\ & \\ \text { TR } & \\ \text { TH } & \end{array}$




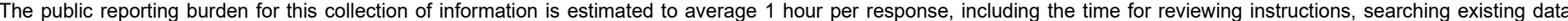

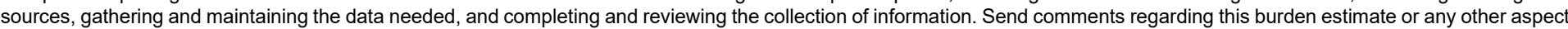

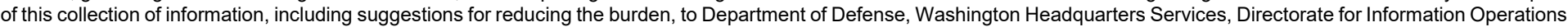

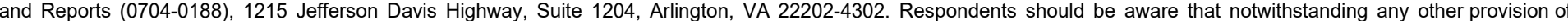
law, no person shall be subject to any penalty for failing to comply with a collection of information if it does not display a currently valid OMB control number. PLEASE DO NOT RETURN YOUR FORM TO THE ABOVE ADDRESS.

\begin{tabular}{l|l|l}
$\begin{array}{l}\text { 1. REPORT DATE } \\
\text { January } 2022\end{array}$ & $\begin{array}{l}\text { 2. REPORT TYPE } \\
\text { Final Report }\end{array}$ & 3. DATES COVERED (FrOm - To)
\end{tabular}

\section{TITLE AND SUBTITLE}

Freight Fluidity for the Port of Baltimore: Vessel Approach and Maritime Mobility Metrics 5a. CONTRACT NUMBER

5b. GRANT NUMBER

5c. PROGRAM ELEMENT NUMBER

5d. PROJECT NUMBER

5e. TASK NUMBER

5f. WORK UNIT NUMBER

8. PERFORMING ORGANIZATION REPORT NUMBER

\section{US Army Engineer Research and Development Center 3909 Halls Ferry Rd Vicksburg, MS 39180-6199 \\ 7. PERFORMING ORGANIZATION NAME(S) AND Texas A\&M Transportation Institute \\ 701 N. Post Oak, Suite 430 \\ Houston, TX 77024}

\section{SPONSORING/MONITORING AGENCY NAME(S) AND ADDRESS(ES)}

Headquarters, US Army Corps of Engineers

Washington, DC
ERDC/CHL TR-22-1

10. SPONSOR/MONITOR'S ACRONYM(S) HQUSACE

\section{SPONSOR/MONITOR'S} REPORT NUMBER(S)

\section{DISTRIBUTION/AVAILABILITY STATEMENT}

Approved for public release; distribution is unlimited.

\section{SUPPLEMENTARY NOTES}

Funding Account Code W912HZ-16-BAA-01: Broad Agency Announcement contract

\section{ABSTRACT}

The United States Army Corps of Engineers is tasked with maintaining waterborne transportation system elements. Understanding channel utilization by vessels informs decisions regarding operations, maintenance, and investments in those elements. Historically, investment decisions have been informed by safety, environmental considerations, and projected economic benefits of alleviating channe restrictions or shipping delays (usually derived from models). However, quantifying causes and impacts of shipping delays based on actual historical vessel location data and then identifying which causes could be ameliorated through investment has been out of reach until recently. In this study, Automatic Identification System vessel position reports were used to develop quantitative measures of transit and dwell-time reliabilities for commercial vessels calling at the Port of Baltimore, Maryland. This port has two deep-water approaches: Chesapeake Bay and the Chesapeake and Delaware Canal. Descriptive metrics were determined for each approach, including port cycle time, harbor stay hours, travel time inbound, and travel time outbound. Then, additional performance measures were calculated: baseline travel time, travel time index, and planning time index. The key finding of this study is that the majority of variability in port cycle time is due to the variability in harbor stay hours, not from channel conditions or channel restrictions.

\section{SUBJECT TERMS}

Baltimore (Md.) - Harbors_Evaluation, Inland navigation-Evaluation, Shipping, Ships_-Automatic identification systems, Waterways--Evaluation

\section{SECURITY CLASSIFICATION OF:}

\begin{tabular}{|l|l|l|}
\hline a. REPORT & b. ABSTRACT & c. THIS PAGE \\
Unclassified & Unclassified & Unclassified \\
\hline
\end{tabular}

17. LIMITATION OF ABSTRACT

SAR
18. NUMBER

OF PAGES

70 19a. NAME OF RESPONSIBLE PERSON Marin M. Kress

19b. TELEPHONE NUMBER (Include area code) 202-761-7422 